\title{
Spatial \& Temporal Patterns of Microplastic Pollution in Wellington, New Zealand, and the Southern Ocean
}

Caitlyn Shannon

A thesis submitted to Victoria University of Wellington in partial fulfilment of the requirements of the degree of Master of Science in Marine Biology.

Victoria University of Wellington

May 2020

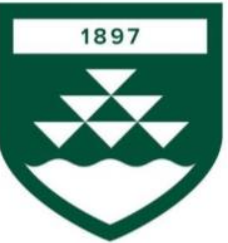

TE HERENGA WAKA 


\section{Acknowledgments}

This thesis could not have been achieved without the help and support of mentors, friends, and family, for which I am extremely grateful. I should specifically like to thank my supervisor, Nicole Phillips, for her continued support, advice, and willingness to take on a new research topic with me. I also thank Moira Decima (NIWA) and Karen Robinson (NIWA) for their willingness to cooperate with me on this project, as well as their guidance over the past two years. Thanks must also go to Mary Livingston (MPI) who had the idea to analyse the NIWA CPR samples - without your input this thesis would not have been the same.

Thanks also to my support team at VUCEL; to the technicians - John and Snout - I sincerely appreciate all the advice and assistance over the last couple of years. Also Mel Dohner and Kayla Griffin, who helped with the boating field work. A massive thank you to my field volunteers, Sophie and Conor, who both brought some light and laughter to getting smacked in the face by Wellington waves!

To my parents, thank you for being the team that constantly supports me throughout everything I do, and for always encouraging and championing my love for the marine world. To Conor, again, thank you for not only the help with field work, but the statistics advice and proof reading. You have listened to all my ideas, thoughts, and worries, and for that I am extremely grateful. To my eco pals, thank you for reminding me to have fun!

This work was carried out, in part, under the tenure of the Hunter Postgraduate Award by the VUW Scholarships Committee. 


\section{$\underline{\text { Abstract }}$}

The global marine environment is currently facing unprecedented anthropomorphic change and stress. One such stressor is plastic pollution, which has continually increased in magnitude since mass production began in the 1940's. An increase in plastic debris throughout the oceans not only results in an infiltration of the pollutants throughout the entirety of the marine environment, but also increases the risk that it impacts the physiological, structural, and behavioural traits of various organisms - including humans. These negative interactions are particularly likely with microplastic particles $(<5 \mathrm{~mm})$, as they can enter and be transferred throughout the food web with ease. However, research in the field of microplastic pollution is extremely one-sided, with most present studies focusing on the Northern Hemisphere. Additionally, comparatively little has been investigated regarding temporal and spatial patterns of microplastic occurrence. The aim of this research was to 1) examine the abundance and distribution of synthetic particles in sub-surface waters of the Southern Ocean, across broad temporal and spatial scales and 2) examine finer-scale spatial and temporal patterns of microplastic load within the urbanised Wellington Harbour, New Zealand, using a combination of environmental and biological indicators.

To assess the broad-scales of temporal and spatial variation in the Southern Ocean, annual Continuous Plankton Recorder (CPR) tows were undertaken between New Zealand waters and the Ross Sea, Antarctica, over a span of 9 years (the austral summers of 2009/10 2017/18) and a range of 5 oceanographic zones and two frontal systems, totalling a distance of approximately 22,000 km. Overall, patterns were inconsistent, with no constant increase or decrease in load throughout the years, while spatial variation was minimal and not associated with particular oceanographic fronts or proximity to an urban area. Despite no consistent spatial variation, temporal differences did occur between years. Again, there were no identifiably consistent trends across years (i.e. a gradual increase), but there was a substantial peak in $2009 / 10$ and a trough in 2012/13. Such changes are likely due to large-scale variations in ocean circulation systems, along with environmental drivers such as El Niño and La Niña events.

To investigate the microplastic load in a more urbanised environment, 3-monthly surveys were undertaken with surface waters, beach sediments, and M. gallloprovincialis mussels in Wellington Harbour, New Zealand, using samples from three sites for beach and mussel 
surveys, and two sites for the surface water tows. Weekly variation was also measured for beach sediments and mussel tissues. Again, no consistency was observed in temporal or spatial variation for any environmental or biological indicator, however the average pollutant loads were on par with reported results in other literature, particularly for $M$. galloprovincialis tissues. Temporally, the peak microplastic load in the tissues of the mussel, M. galloprovincialis, appeared to correlate with the peak load found within the surface waters of the harbour, indicating a possible relationship between plastic pollution in the environment and that which is found within organisms. Finally, the spatial variation observed within beach sediments was far larger than that seen throughout the mussel tissues, supporting the idea that beach sediments are microplastic sinks, but also susceptible to a range of environmental drivers including wind strength, wind direction, and sediment erosion.

Throughout the Southern Ocean and within Wellington Harbour, particle characteristics were similar, in that microfibres were the prevailing synthetic morphotype - accounting for upwards of $90 \%$ of all particles found. These results are similar to reports from other current literature, but not associated with public knowledge that is currently in the media and represented in the legislation. The results of this thesis illustrate the importance of monitoring and managing the occurrence and effect of microplastics on both fine- and broad-scales of temporal and spatial variation and helps address the knowledge gap surrounding microplastics in the Southern Hemisphere. 


\section{Table of Contents}

Spatial \& Temporal Patterns of Microplastic Pollution in New Zealand and the Southern

Ocean

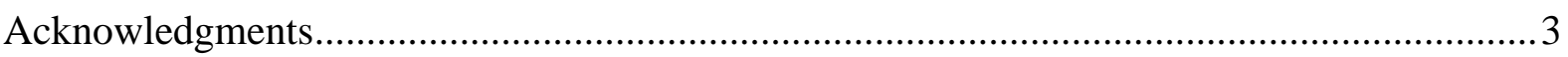

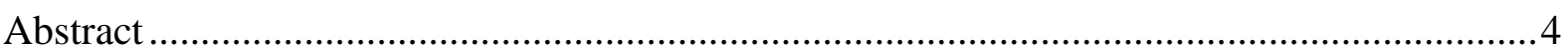

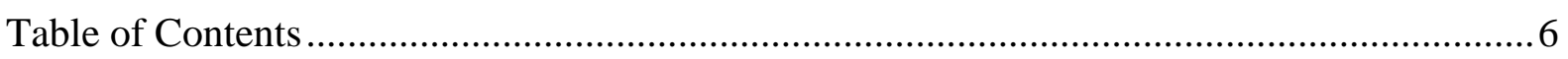

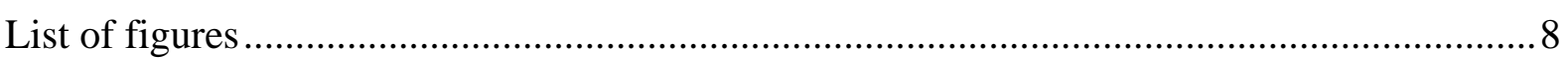

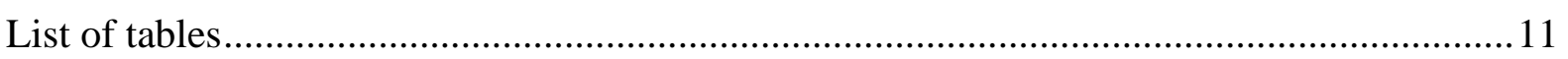

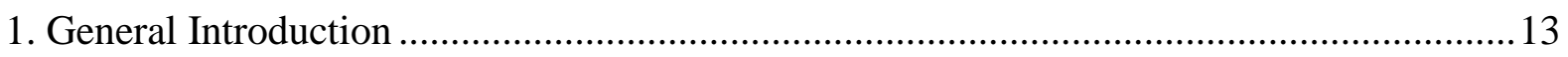

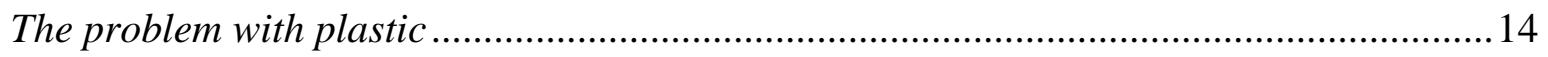

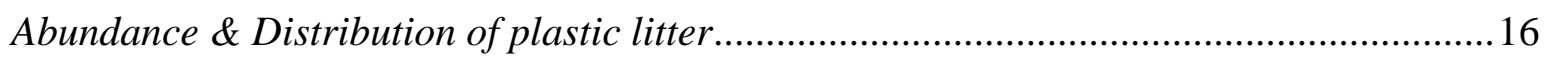

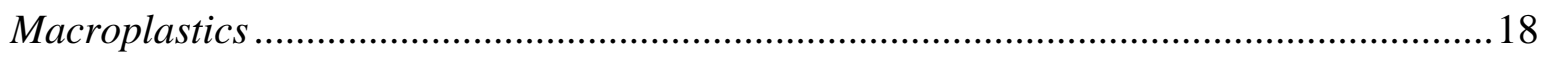

Research trends - Spatial \& temporal patterns .................................................. 18

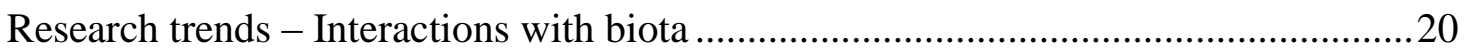

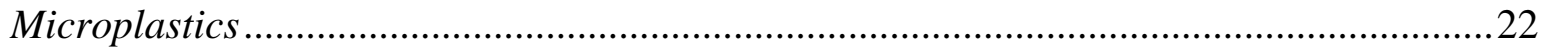

Origin \& history of microplastic research ..........................................................2 22

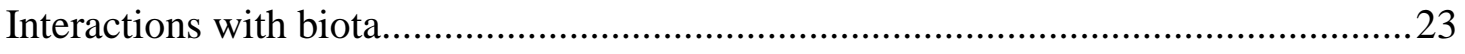

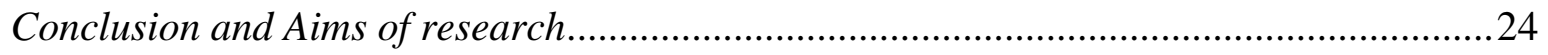

2. Large-scale temporal and spatial patterns of microplastic pollution between New Zealand

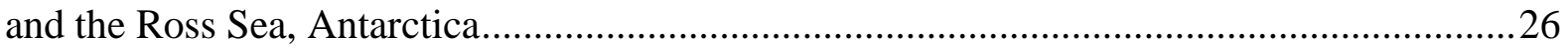

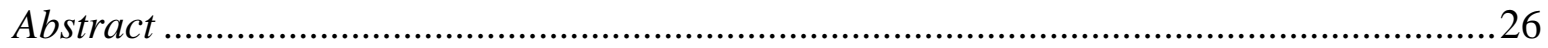

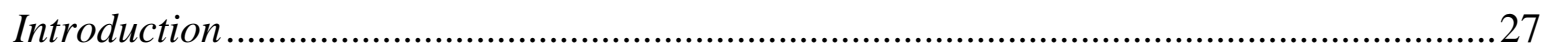

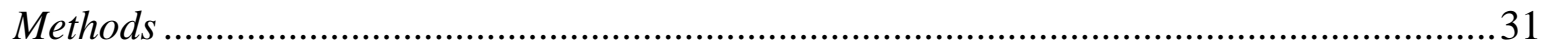

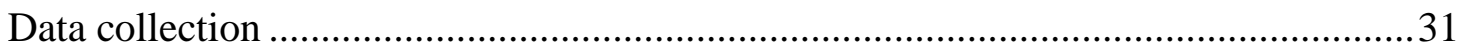

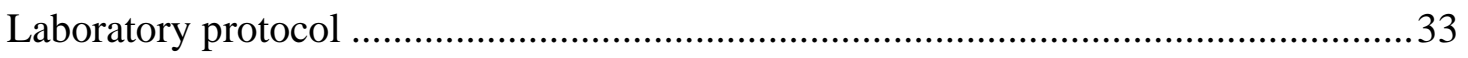

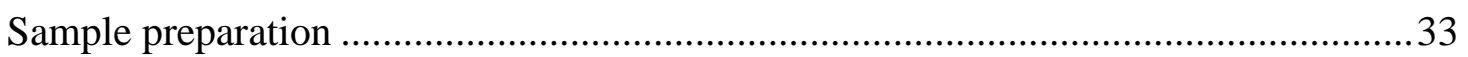

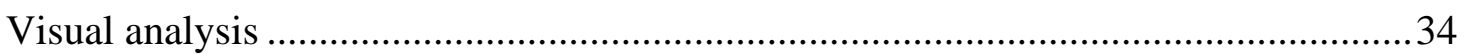

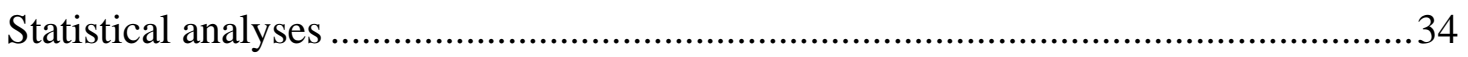

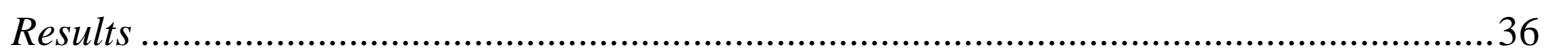

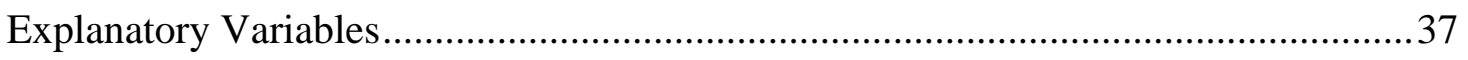

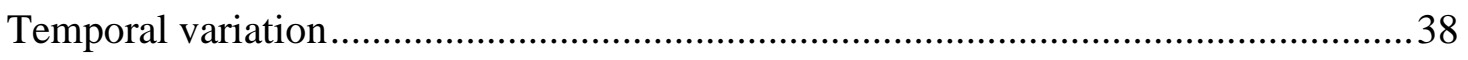

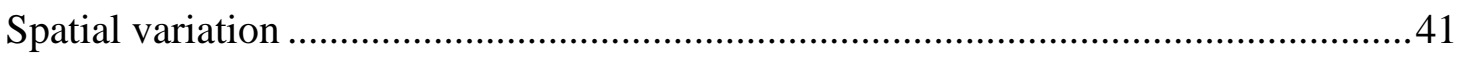

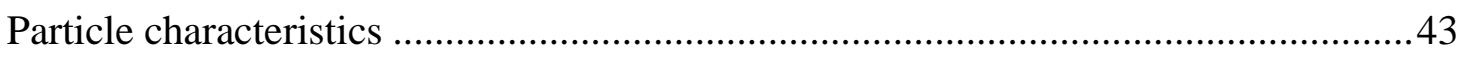


3. Temporal surveys of microplastic load in sediment, surface water, and mussel (Mytilus

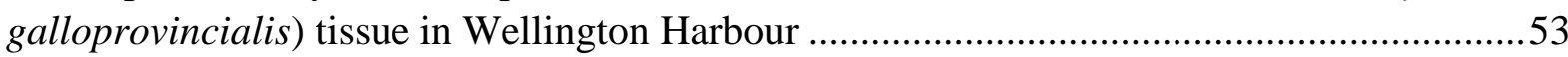

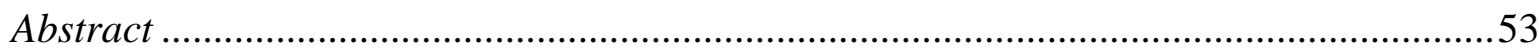

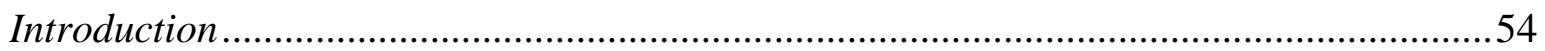

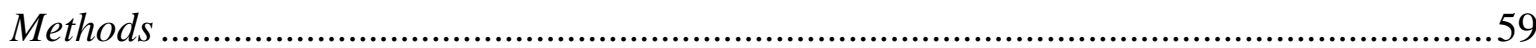

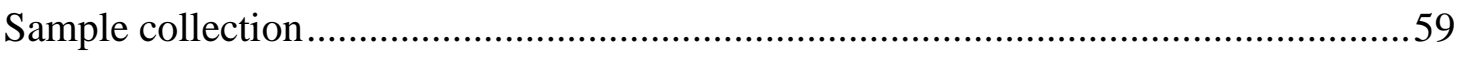

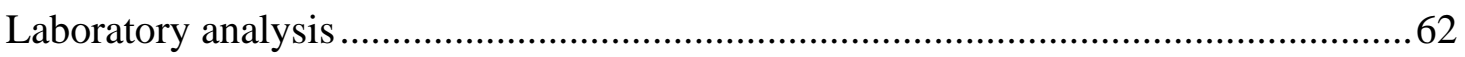

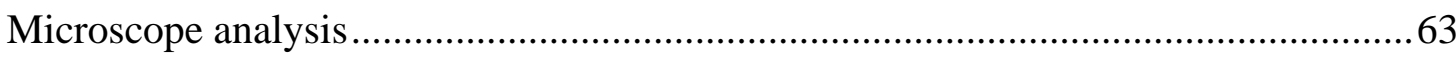

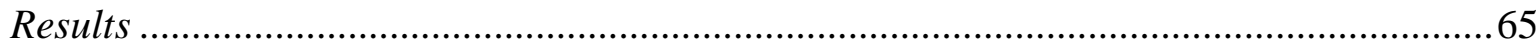

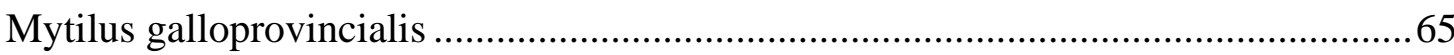

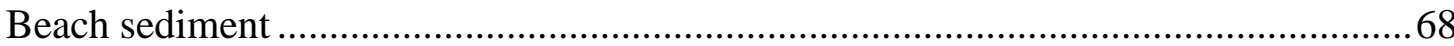

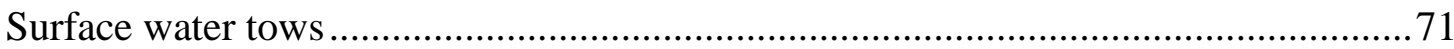

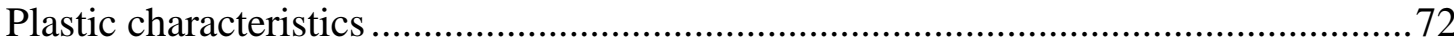

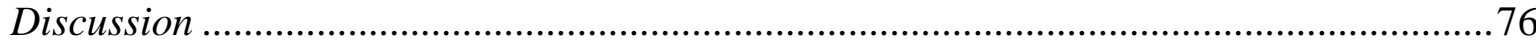

Microplastic abundance \& distribution in Mytilus galloprovincialis ............................77

Microplastic abundance \& distribution in beach sediments ........................................79

Microplastic abundance \& distribution in surface water tows..................................... 81

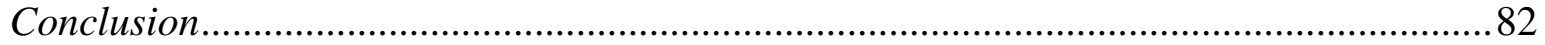

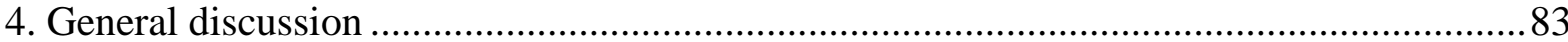

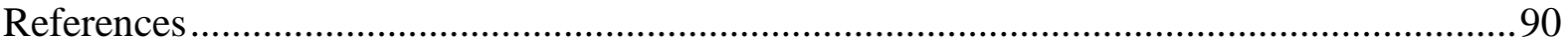

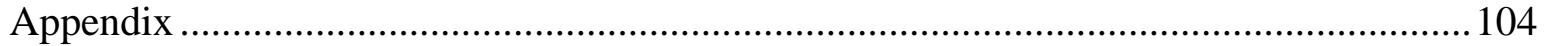




\section{$\underline{\text { List of figures }}$}

Figure 1.1: PlasticsEurope (2019) market data, illustrating global growth in plastic production (per million tonnes) between $2005-2018$

Figure 1.2: Distribution and results of studies investigating A) macroplastic abundance, and B) microplastic abundance across the globe .20

Figure 1.3: Images of A) a dead shearwater seabird and B) a sea turtle, both entangled in discarded fishing nets

Figure 1.4: Images of A) a deceased Laysan Albatross with ingested plastic debris in its internal tissues and B) a sea turtle in the process of eating a discarded plastic bag

Figure 2.1: Schematic depiction of major currents of the Southern Ocean, with particular reference to the Antarctic Circumpolar Current (ACC) and its associated fronts

Figure 2.2: A map of CPR tows undertaken by FV San Aotea II during the first five annual sampling voyages (2008/09 - 2012/13), through five latitudinal zones and three frontal systems

Figure 2.3: SCAR Southern Ocean CPR survey tows between 1991-2013, with particular focus upon the light grey transects conducted by the FV San Aotea II

Figure 2.4: A depiction of the internal workings of a Continuous Plankton Recorder (CPR), as used in this study

Figure 2.5: An image of the $270 \mu \mathrm{m}$ collecting mesh, which was used in CPR tows throughout this study .34

Figure 2.6: Preparation of mesh silks and formaldehyde solution, for stereomicroscope analysis .35

Figure 2.7: Proportion of total samples containing at least one synthetic particle, for each collection year .38

Figure 2.8: Distribution of synthetic particle abundances in surface waters between New Zealand and the Ross Sea, over a 9-year period (2009/10 - 2017/18) 
Figure 2.9: Distribution of synthetic particle abundances across the 5 different collection months in the austral summer (November - March)

Figure 2.10: Mean surface water microplastic abundance from the 2009/10 - 2017/18, between five oceanographic zones and two frontal systems 42

Figure 2.11: Distribution of synthetic particle abundances between five oceanographic zones and a frontal system

Figure 2.12: Examples of different synthetic particles found during this study, where A) is a large yellow fibre, B) is a large blue fibre, and C) is a medium-size paint chip .44

Figure 2.13: Percentages of the total count data between 2009/10 - 2017/18, for all different plastic types collected during CPR tows

Figure 2.14: Percentage of different microplastic size distributions between 2009/10 $2017 / 18$ .46

Figure 2.15: Percentage of different microplastic colour distributions between 2009/10 $2017 / 18$

Figure 3.1: Microplastics found on Evan's Bay Beach, Wellington, where A) depicts the difficulty of extracting synthetic particles from organic matter and B) demonstrates the occurrence of microplastics in situ .56

Figure 3.2: Map of sites sampled within Wellington Harbour .62

Figure 3.3: Mussel digestion process, including A) at the commencement of digestion, and B) after a week of digestion .64

Figure 3.4: Average abundance of microplastics observed within M. galloprovincialis samples collected 3-monthly

Figure 3.5: Average abundance of microplastic particles within $M$. galloprovincialis samples collected weekly .67

Figure 3.6: Average microplastic abundances per mussel between sites and within each collection month

Figure 3.7: Average abundance of microplastics observed within beach sediment samples of approximately $400 \mathrm{~cm}^{3}$, collected 3-monthly .70 
Figure 3.8: Average abundance of microplastic particles within beach sediment samples of approximately $400 \mathrm{~cm}^{3}$, collected weekly

Figure 3.9: Average microplastic abundances between sites within each sediment collection month

Figure 3.10: Total microplastic abundance per $200 \mathrm{~m}$ neuston net transect, collected 3monthly

Figure 3.11: Two examples of synthetic particles collected within this study, A) a blue fragment in mussel tissue, and B) shows two fibres (black and blue) of small and medium sizes, from sea surface samples

Figure 3.12: Percentage of different morphotypes of synthetic particles found within $M$. galloprovincialis individuals, beach sediments, and surface water tows

Figure 3.13: Percentage of different microplastic size distributions within $M$.

galloprovincialis individuals, sediment, and surface water tows .75

Figure 3.14: Percentage of different microplastic colour distributions within $M$. galloprovincialis individuals, sediment, and surface water tows

Figure 4.1: Examples of the various sea surface sampling methods that are commonly used for assessing microplastic load. A) is a 'grab' system, B) a neuston net, C) a Continuous Plankton Recorder (CPR), and D) is a manta trawl 


\section{$\underline{\text { List of tables }}$}

Table 2.1: Total number of samples collected from surface waters between New Zealand and the Ross Sea that contained at least one synthetic particle, and those without

Table 2.2: Effects of collection month, collection transit, year, and oceanographic zone on microplastic abundance between New Zealand and the Ross Sea Region

Table 2.3: Effects of sampling year (2009/10 - 2017/18), on microplastic abundance within surface waters between New Zealand and the Ross Sea Region

Table 2.4: Effect of month (November, December, January, February, March), on microplastic abundance within surface waters between New Zealand and the Ross Sea Region

Table 2.5: Effect of oceanographic zone (PFZ, POOZ, SAZ, SIZ, STF, and STZ), on microplastic abundance within surface waters between New Zealand and the Ross Sea Region

Table 2.6: Count data investigating the number of synthetic particles collected between New Zealand and the Ross Sea Region

Table 2.7: Count data investigating size distributions of synthetic particles in surface waters between New Zealand and the Ross Sea Region. Not inclusive of macroplastic particles $>5$ $\mathrm{mm}$ in length/diameter

Table 2.8: Count data investigating colour distributions of synthetic particles in surface waters between New Zealand and the Ross Sea Region

Table 3.1: Between-month variation of microplastic abundance within pooled $M$. galloprovincialis samples

Table 3.2: Between-week variation of microplastic abundance within M. galloprovincialis samples

Table 3.3: Between-site variation (Kau Point, Oriental Bay, and Scorching Bay) of microplastic abundance within $M$. galloprovincialis samples 
Table 3.4: Between-month variation of microplastic abundance within pooled beach sediment samples

Table 3.5: Between-week variation of microplastic abundance within beach sediment samples of approximately $400 \mathrm{~cm}^{3}$

Table 3.6: Between-site variation (Balaena Bay, Oriental Bay, and Scorching Bay) of microplastic abundance within beach sediment samples of approximately $400 \mathrm{~cm}^{3}$

Table 3.7: : Count data investigating total number of synthetic particles within $M$. galloprovincialis tissues, sediment, and surface water tows

Table 3.8: Count data investigating size distributions of synthetic particles within $M$. galloprovincialis tissues, sediment, and surface water tows, not inclusive of macroplastic particles $>5 \mathrm{~mm}$ in length or diameter

Table 3.9: Count data investigating colour distributions of synthetic particles found within $M$. galloprovincialis tissues, sediment, and surface water tows .76

Table A2.1: Collective number of tows undertaken, samples collected, and distance towed (nmi) throughout each annual CPR survey from the FV San Aotea II 


\section{$\underline{1 . \text { General Introduction }}$}

Ensuring the health and productivity of the world's oceans is integral to maintaining global biodiversity and the earth's continued ability to thrive. However, numerous stresses are impacting the marine environment and its ability to support biodiversity on a global scale, including climate change, ocean acidification, and pollution. One key source of pollution is plastic debris, which has recently been described as any object that contains a synthetic or semi-synthetic polymer as the essential component, solid in natural environments and insoluble at $20^{\circ} \mathrm{C}$ (Hartmann et al., 2019). However, in general, plastic as a material can be defined as any synthetic organic polymer which is derived from oil and gas monomer polymerisation (Derraik, 2002; Rios et al., 2007; Thompson et al., 2009; Cole et al., 2011). As a result, plastics are extremely diverse in size, colour, chemical composition, and origin; they exist throughout the world as a key material that is used daily.

The commercial manufacture of plastic took off in the 1940's, around the time of the Second World War (Cole et al., 2011). Since this first instance of mass production, the development and use of plastic items has continued to grow, with the material's seemingly inexhaustible purposes cementing its place in modern society. This rise in popularity can be attributed to its key characteristics, strength, durability, and flexibility. The latest data shows that 359 million tonnes of plastic were produced globally in 2018 alone (Figure 1.1), the highest amount produced in a single year since commercial manufacture began (PlasticsEurope, 2019). However, this figure is likely to be highly conservative, as it does not account for synthetic fibre production or direct microplastic production (Hermabessiere et al., 2017). 


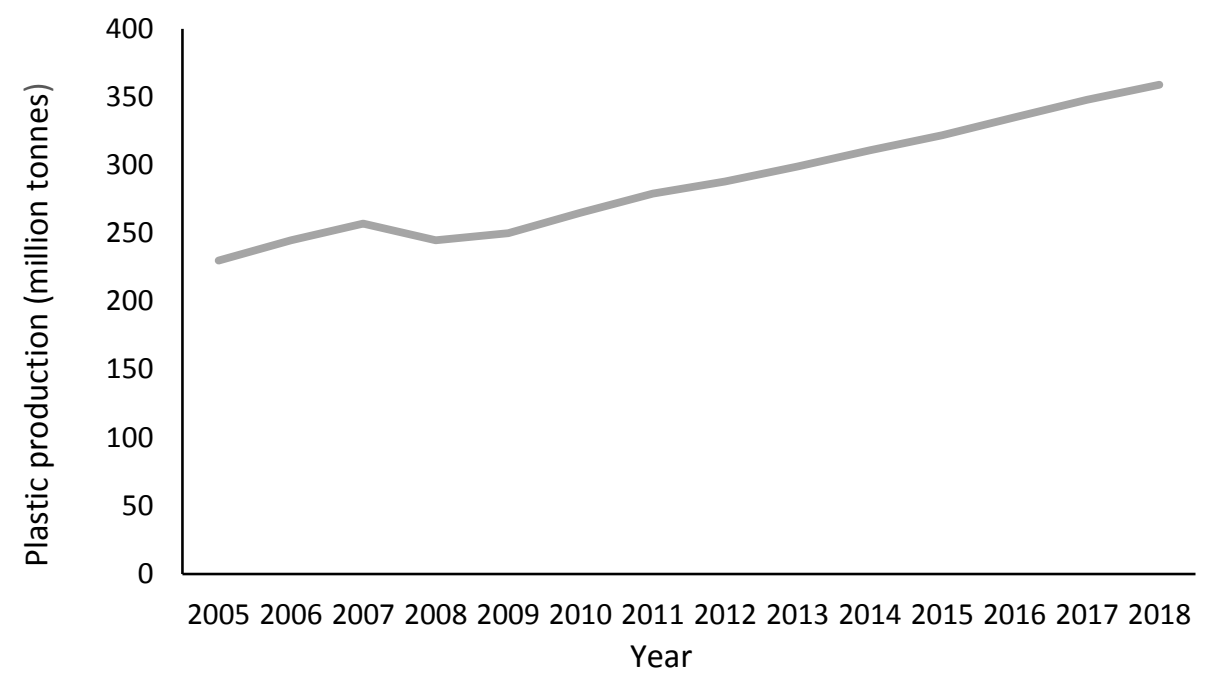

Figure 1.1: Data from PlasticsEurope (2019) market data, demonstrating the global growth in plastic production from 2005 - 2018, measured in million tonnes.

\section{The problem with plastic}

Considering the sheer amount of annual plastic production that has been occurring for decades, and the diverse range of uses the material has throughout human society, it is unsurprising that plastic debris also exists in many forms. In fact, the characteristics of plastics that make them invaluable materials within human society are precisely the features that enable them to persist in the natural environment as long-lasting pollutants (Derraik, 2002). Such debris can be found along an extensive size array, ranging from large commercial fishing nets that have been discarded, through to microscopic beads from beauty products (Fendall \& Sewell, 2009; Napper et al., 2015). Consequently, plastic is ubiquitous around the globe and spread across terrestrial, freshwater, and marine biomes. Plastics are associated with numerous interactions and negative impacts on a wide range of ecosystems. For example, microplastics ( $<5 \mathrm{~mm})$ within terrestrial environments are thought to leach chemicals into the surrounding soil and environment, leading to negative effects upon organisms such as plants and earthworms (Chae \& An, 2018). However, despite plastic being manufactured by humans on land, a vast majority ends up in the marine ecosystem (Derraik, 2002; Thompson et al., 2004; Eriksen et al., 2014; Galgani et al., 2015). Plastic litter makes its way into the ocean via several different pathways, including direct inputs such as littering, and run-off of manufactured consumer products (Reisser et al., 2013). Conversely, indirect inputs such as chemical and physical weathering of larger plastic debris inevitably results in fragmentation of the synthetic polymers into smaller particles that are continuously decreasing in size (Andrady, 2011; Jambeck et al., 2015). This inability to successfully 
biodegrade causes a high abundance of plastic debris to infiltrate the world's oceans - from the sea surface to the benthos of the deep sea, and polar regions to the tropics (for example: Goldberg, 1997; Obbard et al., 2014; Woodall et al., 2014; Van Sebille et al., 2015). The numerous pathways to the marine environment are exacerbated by contributing factors such as low regional and national plastic recycling rates. The recycling of these materials is often limited, due to the wide variety of plastic polymers available for use, which complicates the ability of governments to develop adequate methods for recycling, in ways that will not be detrimental to the environment (Dauvergne, 2018).

To compound this issue, once in the marine environment, many plastic polymers are initially less dense than the surrounding seawater, so can be transported over long distances via surface currents (Maes et al., 2017). However, as factors like weathering and biofouling alter the appearance and structure of plastics, the buoyancy of the material decreases, thus promoting mixing of the pollutants throughout other parts of the water column (Ye \& Andrady, 1991; Morishige et al., 2007; Maes et al., 2017). As a result, these synthetic materials interfere with many different marine species and taxa through direct contact such as entanglement and ingestion. Given that plastic comes in many different sizes and shapes, it is bioavailable to many different marine organisms. Size ranges of plastic includes

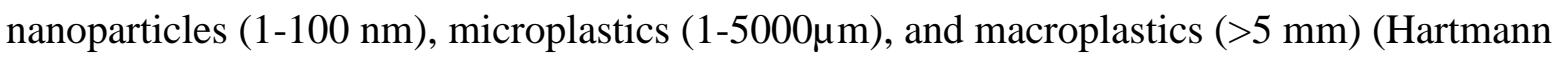
et al., 2019). It can therefore enter the food web at various levels, from primary consumers to apex predators (Derraik, 2002; Van Freneker et al., 2011).

However, it is not only the direct interactions that organisms have with marine debris that presents a problem. In contrast to the initial school of thought - that plastic litter is a longlasting yet inert pollutant - the production of plastic materials involves the addition of chemicals such as plasticizers and flame retardants which enhance the durability and functionality of the material (Andrady, 2017). Consequently, as fragmentation occurs in the ocean, these chemicals leach into the surrounding environment where they become available for ingestion by marine biota (Oehlmann et al., 2009). Leaching is not the only toxicity issue that arises from plastic pollutants, as Persistent, Bioaccumulative, and Toxic substances (PBT's) known as Persistent Organic Pollutants (POPs) are efficiently bound to synthetic polymers (Andrady, 2011; Engler, 2012). Although POPs are naturally found in seawater at low concentrations, they can accumulate at a faster rate on the surface of plastic debris due to both compounds being hydrophobic (Engler, 2012). Consequently, the ingestion of plastic debris not only establishes the presence of synthetic particles within the food web, but also 
introduces POPs to marine biota at unnatural levels (Bakir et al., 2012; Andrady, 2017). Chemical interactions such as these can impact the health and mortality of organisms (Rochman et al., 2016; Andrady, 2017), but are also deleterious at non-lethal levels, through the alteration of behaviours like predation efficiency (De Sá et al., 2015).

\section{Abundance \& Distribution of plastic litter}

Plastic pollution is rightly considered a global environmental issue, as there is a high abundance of both macro- and microplastic pollution along a wide spatial gradient. Plastic has been observed and documented in most marine environments from the poles to the equator, in urbanised and remote oceanographic regions. The local, national, and international extent of this pollutant impacts the effect that it may have on marine biota. For this reason, a comprehensive portrayal of the global plastic pollutant load and distribution within the oceans, along with how its physical, chemical, and structural characteristics are integral to understanding the risks for various ecosystems. Additionally, the continued increase of global plastic production rates (Figure 1.1), along with its long-lasting nature, complex recycling governance, and the unsatisfactory waste management indicates that plastic is likely to persist, if not increase in prevalence, throughout the marine environment for the foreseeable future (Barnes et al., 2009; Tetu et al., 2019). Consequently, data provided on plastic abundance and distribution may be valuable in focussing minimisation and management efforts.

Estimates vary on how much plastic debris can be found in the world's oceans, as the load can be highly variable due to factors such as widely ranging oceanographic conditions, seasonal effects, and spatial differences in plastic inputs. Despite this complexity, Cole et al. (2011) suggests that marine plastic debris likely accounts for $10 \%$ of all plastic produced. Conversely, Hermabessiere et al. (2017) stated that a low estimate for global, floating plastic litter may be between 70,000 - 270,000 tonnes. Combinations of intensive sea-surface sampling and statistical modelling indicates that microplastics comprise $1 \%$ of the plastic debris that enters the oceans each year from land-based sources (Van Sebille et al., 2015). However, one type of microplastic, microfibers, are thought to account for up to $95 \%$ of the sea surface, benthic, and coastline litter (Cesa et al., 2017; Galgani et al., 2015). Three comprehensive studies have been undertaken with the aim of determining microplastic occurrence, utilising various methodologies and oceanographic models. Cózar et al. (2014) estimated between $7000-35,000$ tons of plastic (size range $0.20-100 \mathrm{~mm}$ ), while Eriksen et al. (2014) suggested 35,500 metric tonnes (size range 0.33-200 mm). Van Sebille et al. 
(2015) produced a considerably higher estimate than previous studies of 93,000 - 236,000 metric tonnes (size range $<200 \mathrm{~mm}$ ). Despite these estimates being highly variable and including meso-particles larger than $5 \mathrm{~mm}$, cumulatively they highlight the sheer magnitude of the issue.

Abundance estimates are likely conservative and do not show the full extent of the problem. Currently, sea surface tows and oceanographic models are the primary measures available to monitor microplastic. Eriksen et al. (2014) recognises this limitation, particularly after considering how macroplastic fragmentation impacts the prevalence of microplastics. Theoretically, since large debris degrades into smaller particles, the volume of microplastics in the marine environment should be comparable to the volume of macroplastic. In addition, these global estimates only account for microplastics on the sea surface, and does not include those suspended in the water column, on the benthos, within sediment and sea ice, or ingested by organisms, which together likely comprise a large fraction of what is in the oceans (Eriksen et al., 2014). Sampling efforts may also impact the abundance of particles, with a wide range of collection methods and weather events disrupting sampling. Strong winds, for example, decrease surface microplastic concentrations by as much as five times (Collignon et al., 2012; Kukulka et al., 2012; Ivar de Sul \& Costa, 2014). Additionally, other removal processes impact the abundance and distribution of surface microplastics, including decreased particle buoyancy (Barnes et al., 2009) and biodegradation of some synthetic polymers by microbes (Shah et al., 2008).

Along with aiding fragmentation, physical processes help to determine where plastic litter is distributed. Although plastic debris has been documented in all major oceans, factors such as ocean circulation and wind-driven vertical mixing increase the likelihood of its concentration in certain oceanographic regions (Van Sebille et al., 2015). Consequently, plastics at the sea surface are of highest densities in the convergence zones of sub-tropical gyres (Cózar et al., 2014; Kanhai et al., 2017). Cózar et al. (2014) describes this convergence as a large conveyor belt that collects floating plastic debris from the continents and brings it together using largescale vortices. Van Sebille et al. (2015) identifies the North Pacific Gyre as containing the largest global reservoir of plastic litter. This is the result of its proximity to plastic inputs by the populous United States and Asia, along with the convergence of Ekman transports (Jambeck et al., 2015; Van Sebille et al., 2015). Eriksen et al. (2014) estimates that $55.6 \%$ of the total floating plastics are in the Northern Hemisphere, $37.9 \%$ of which are confined within the North Pacific. 
Despite occurring in high concentrations at convergence zones, plastic debris also infiltrates many other habitats and ecosystems, including both the deep sea and polar regions - For example within sea ice. Although often far-removed from urbanisation and human society, habitats such as the deep sea and its associated benthos have been reported to contain a microplastic load of up to one particle per $25 \mathrm{~cm}^{2}$ in the Mediterranean and Atlantic Ocean (Van Cauwenberghe et al., 2013). Synthetic fibres were also documented in similar regions, with concentrations reaching up to four orders of magnitude higher than microplastics surveyed at the sea surface (Woodall et al., 2014). Larger plastic debris has also been documented within the deep-sea benthos of the Arctic (Bergmann \& Klages, 2012). As the deep-sea is considered a sink for plastic litter (Goldberg, 1997), it can be inferred that both micro- and macroplastics are likely to be a typical part of the sediment layer throughout all major ocean basins.

Sea ice, on the other hand, typically incorporates microplastics as opposed to larger plastic debris. Formation of ice concentrates whatever particles are encompassed within it, trapping it until the ice melts (Obbard et al., 2014). This was the first publication that illustrated direct evidence for substantial microplastic pollution in the Arctic (Lusher, 2015). Obbard et al. (2014) sampled ice cores from remote locations around the North Pole, with the subsequent results showing concentrations two-times higher than the surface waters throughout the Atlantic or the North Pacific gyre at the same time $\left(38-234\right.$ particles per $\left.\mathrm{m}^{3}\right)$. As sea ice is a temporary sink for microplastics, it is highly likely that amplified annual sea-ice melt due to ever-increasing effects of climate change, will result in the release of a large amount of microplastics into the surrounding water column where they are able to negatively interact with organisms (Obbard et al., 2014; Peeken et al., 2018).

\section{Macroplastics}

\section{Research trends - Spatial \& temporal patterns}

Throughout the second half of the $20^{\text {th }}$ century, the rise in global plastic production coincided with the understanding that plastic did, in fact, pose a problem to the oceanic environment. Consequently, scientific studies began to investigate the impacts of the pollutant, primarily focussing upon macroplastic debris as it can be detected within the environment more easily, as well as detecting deleterious effects upon organisms from interactions such as entanglement and ingestion. Moreover, publications that demonstrated the direct impact of plastic on marine biota played a meaningful role in altering society's view of the pollutant, 
aiding a perspective shift from plastic debris being an inert and insignificant pollutant, to one that can interfere with physiology, behaviour, and mortality of organisms.

The quantification of macroplastic abundance and distribution has long been a secondary focus to the direct effects that these materials have upon organisms. In fact, a recent paper by Ostle et al. (2019) was one of the first that investigated long-term trends in surface water macroplastic abundance. This study demonstrated a clear increase in plastic litter over the 60year time series (1957-2016), across the North Atlantic. Although this is the most extensive study on how marine plastic debris has changed over time, previous studies have also indicated similar trends. For example, a report by Ryan \& Moloney (1993) demonstrates an exponential increase in litter on an uninhabited island in the Tristan da Cunha group of the South Atlantic Ocean, between 1984-1990. Interestingly, both studies also note how, despite the clear increase in debris within the marine environment, research and monitoring surrounding the issue dropped off after 1987 (Ryan \& Moloney, 1993; Ostle et al., 2019). A visual database of more than 1,000 marine litter studies - LITTERBASE (Tekman et al., 2019) - illustrates that the number of macroplastic and microplastic abundance and distribution studies are similar (Bergmann et al., 2017; Ostle et al., 2019), but also most widely distributed around heavily populated regions (Figure 1.2). Considering that microplastic pollution is an emerging field, it is surprising that there are also significant gaps in the temporal and spatial trends regarding macroplastic pollution. In general, there appears to be a consensus that more work needs to be undertaken to understand patterns surrounding plastic pollution for all size classes, although visual databases such as LITTERBASE are a useful first step to recognise areas that require further attention (Bergmann et al., 2017; Ostle et al., 2019).

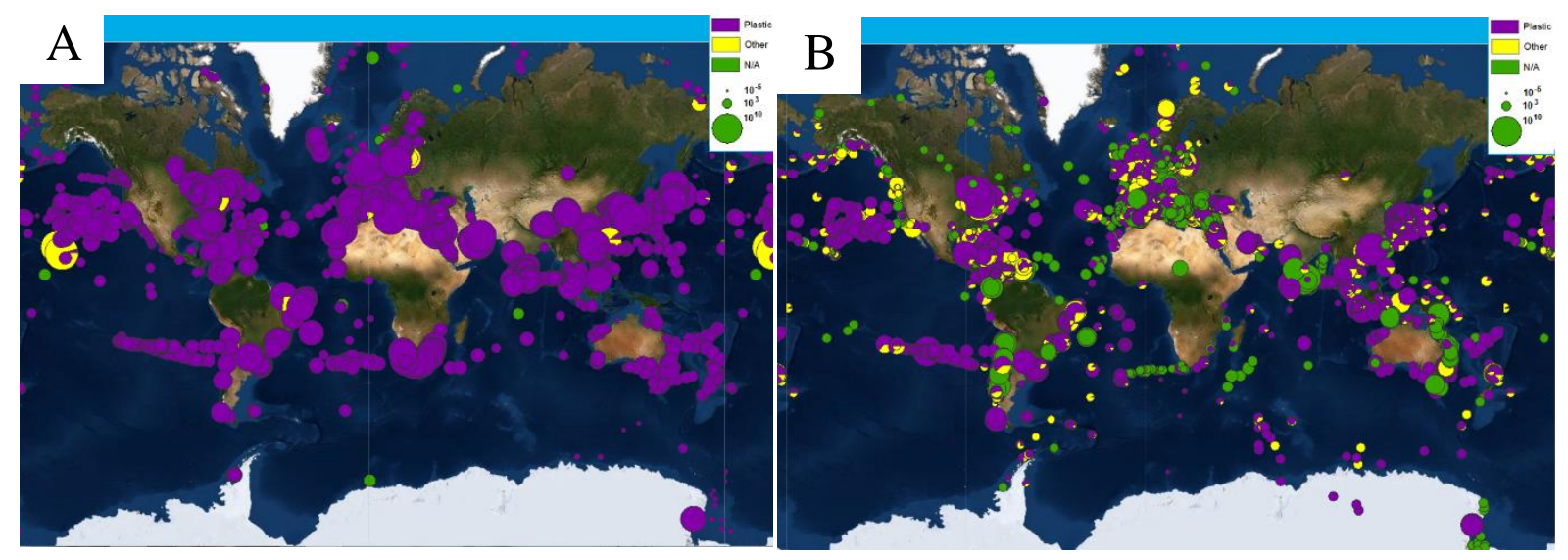

Figure 1.2: Distribution and results of studies investigating A) macroplastic abundance, and B) microplastic abundance across the globe (Tekman et al., 2019), where size of circle indicates relative reported pollutant concentrations. 


\section{Research trends - Interactions with biota}

Although there are distinct research gaps regarding long term distribution modelling and monitoring of macroplastic, the impacts that this pollutant has had upon marine organisms has been well described in the literature. Most of this literature centres around ingestion and entanglement, including many of the early studies and reports. In 1947, for example, a herring gull was reported to be entangled in a string (Jacobson, 1947; Ostle et al., 2019). Ten years later, a piece of twine - assumedly from fishing trawls - and a plastic bag were found tangled in a Continuous Plankton Recorder (CPR) (Ostle et al., 2019). At this stage, only a decade or so had passed from the beginning of commercial plastic production, yet there was already evidence of this pollutant being found in the open ocean.

Entanglement in plastic debris became a persistent problem for marine organisms almost from the time that this synthetic material entered the ocean. The issue has been wellunderstood for decades (Law, 2017), but the threats has only become more prevalent as the amount of plastic litter in the oceans increases. Evidence now suggests that approximately $46 \%$ of seabird species, $100 \%$ of sea turtle species, and $26 \%$ of marine mammal species are negatively impacted by plastic entanglement, often resulting in serious injury or death (Koelmans et al., 2014; Worm et al., 2017). Although entanglement directly impacts individuals, this threat has been linked to the population decline of different species, including seals and sea lions (Fowler, 1987; Henderson, 2001; Derraik, 2002). One common cause of entanglement is discarded fishing nets (Figure 1.3), often referred to ghost fishing nets (Worm et al., 2017). For marine air-breathing taxa such as turtles, seabirds, and mammals, the inability to breathe due to entrapment in a net will likely have severe consequences. There is a myriad of other plastic items that are able to wrap around, choke, and encase organisms, with the immense variety of plastic shapes and sizes exacerbating the number of species and taxa that are vulnerable to plastic entanglement (Worm et al., 2017). In addition to impaired breathing, the other key consequences for individuals affected by entanglement include suffering abrasions and deep cuts into tissue from a tightly-wound item, as well as a negative effect upon mobility; thus, becoming vulnerable to predation (Derraik, 2002). Additionally, problems may arise when juveniles become tangled in plastic pollution. As the individuals grow, they are likely to become constricted and impaired by the material. Entanglement is an issue typically constrained to macroplastic pollution, as microplastics are generally not large enough to entrap an organism. Consequently, past research has heavily focussed upon the effects of entanglement, as the results are both easily noticeable and 
severe. Entanglement presents a significant problem to countless marine species, particularly as it is not only thought to impact individuals, but rather the fitness and success of populations.

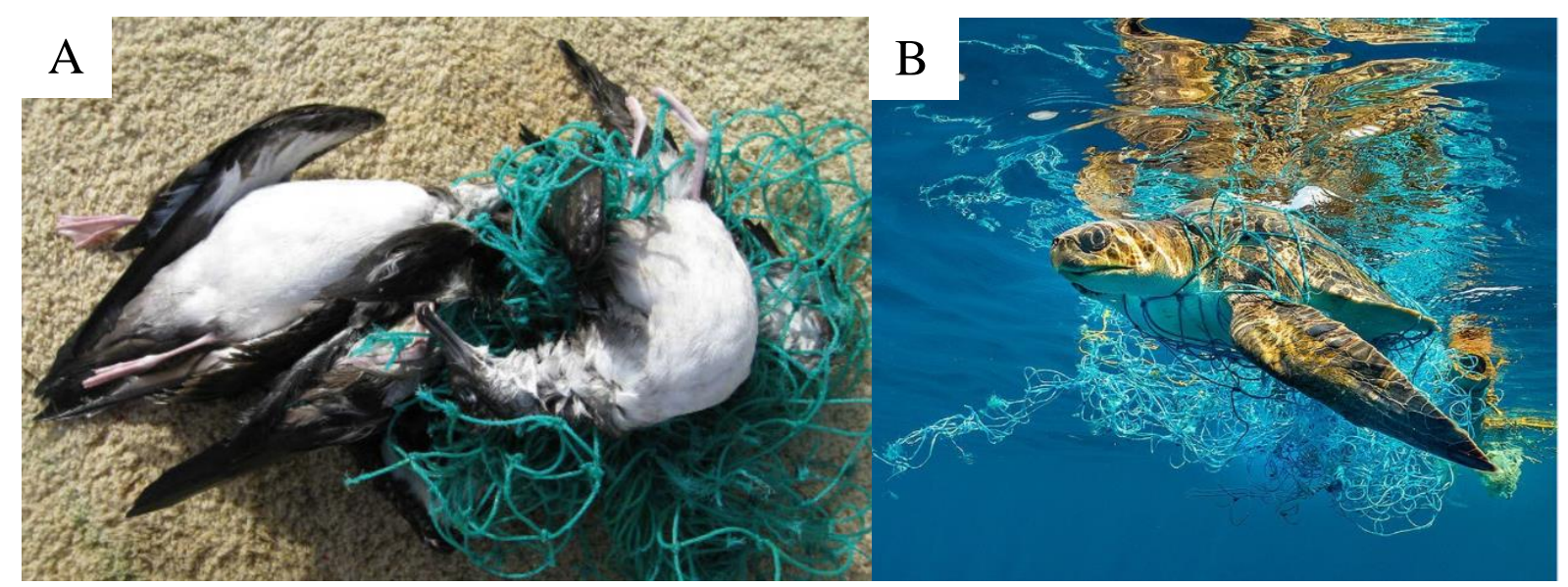

Figure 1.3: Images of A) a dead shearwater seabird and B) a sea turtle, both entangled in a common form of marine plastic pollution; discarded fishing nets. Image credit: A) NOAA Fisheries Pacific Islands Regional Office, B) Brian Skerry, National Geographic photographer.

Within addition to entanglement, ingestion of macroplastic is also extremely common, with countless anecdotal and scientific reports of marine animals being found with some form of plastic in their digestive system (Derraik, 2002). This was first illustrated in the 1960's with seabirds (Figure 1.4) and marine turtles (Harper \& Fowler, 1987; Gregory, 2009; Law, 2017), however, like the issue of entanglement, research is still being undertaken to demonstrate the exact impacts of macroplastic ingestion and how widespread the problem is across taxa and oceanographic location. Ingestion may either be passive, such as the act of filter-feeding, or active, which may involve mistaking the item for prey (Derraik, 2002). Active ingestion is a mechanism that is common amongst marine biota such as sea turtles, who regularly mistake items such as plastic bags for a primary prey source, jellyfish (Figure 1.4) (Mattlin \& Cawthorn, 1986; Derraik, 2002; Worm et al., 2017). This interaction is not only cited often in scientific literature, but also widespread in the general media and often credited as the inspiration behind plastic bag bans in numerous nations (Xanthos \& Walker, 2017; AveryGomm et al., 2018). Compared to microplastic ingestion, the larger and easier-to-observe size of macroplastic often results in its direct interactions with biota being more commonly reported in the media and in peer-reviewed publications, especially since this type of marine debris has extensive consequences for charismatic megafauna like sea turtles, seabirds, and cetaceans. The size of the debris also means that fewer items are required to cause gastrointestinal blockages, with gradual starvation a readily cited negative impact of plastic ingestion, in conjunction with chemical leaching (Derraik, 2002). 


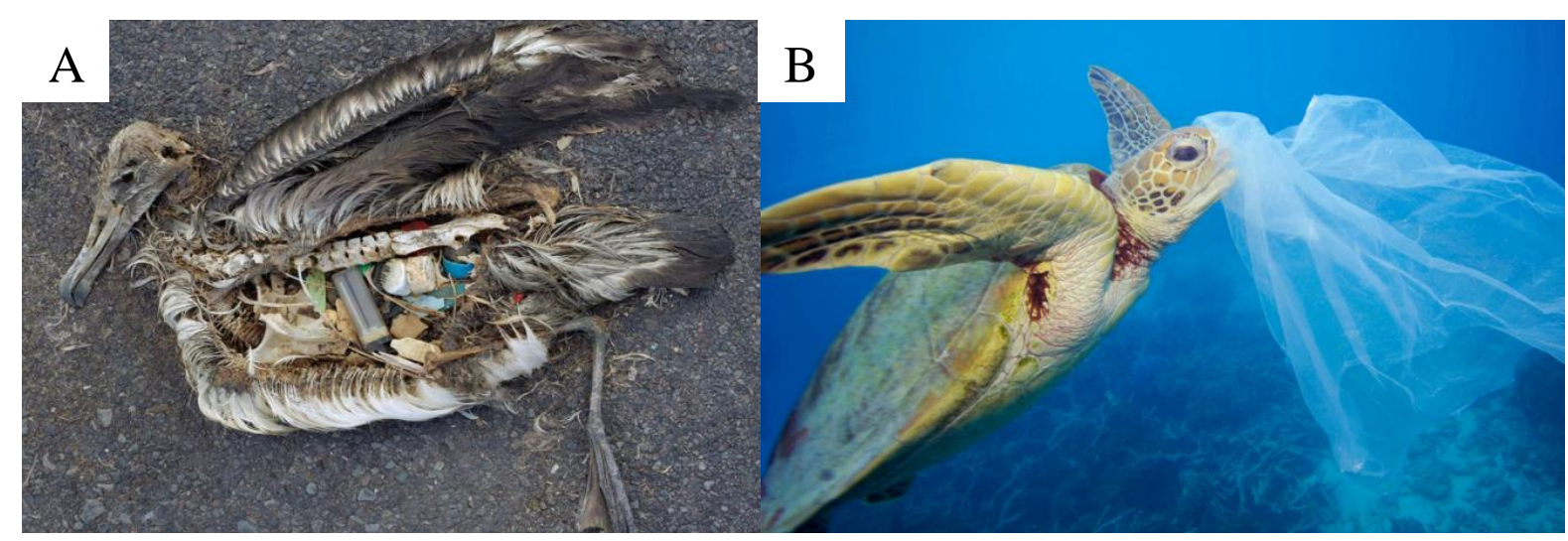

Figure 1.4: Images of A) a deceased Laysan Albatross with ingested plastic debris in its internal tissues and B) a sea turtle in the process of eating a discarded plastic bag. Image credit: A) Chris Jordon, Smithsonian Museum, B) Troy Mayne, WWF.

\section{Microplastics}

\section{Origin \& history of microplastic research}

In contrast to the substantial research of macroplastics and their effects on marine biota, microplastics are a relatively new and emerging research topic within the field of marine pollution. Although there has been an increasing focus on these particles within the scientific community since the early 2000's (Ivar do Sul \& Costa, 2014), much is still unknown regarding their abundance, distribution, and impacts on organisms in the marine environment.

The first publication solely focused on plastic $<5 \mathrm{~mm}$ in length/diameter was released in 1971 and was the only report or paper to discuss the issue of synthetic fibres in the marine environment before the rise of the $21^{\text {st }}$ century (Ivar do Sul \& Costa, 2014). Even though this was the first paper of its kind in the scientific literature, Buchanan (1971) recognised that the particles appeared to be steadily increasing in abundance. Furthermore, despite the field of microplastic research having only recently emerged, with fewer than 20 papers published pre2000 , the research commonly recognised the potential consequences that these synthetic particles could have on the marine environment and the function of its ecosystems. Carpenter and Smith (1972) discussed how increasing concentrations of such particles may lead to a high accumulation on the sea surface. Similarly, Colton et al. (1974) emphasised the inability of plastic debris to biodegrade, which is an issue then confounded by the particles' ability to provide an ideal surface for PCB's to grow. However, most of the early papers generally observed and documented the abundance and distribution of microplastics in Northern Hemisphere regions such as the Sargasso Sea (Carpenter \& Smith, 1972), the North-western Atlantic (Colton et al., 1974), coastal New England (Carpenter et al., 1972), and the Bristol Channel (Morris \& Hamilton, 1974). 
Although early papers had a primary focus on determining where microplastics were found, as well as how abundant they were, interactions with and effects on marine biota were also often recognised. This included the ingestion of particles by seabirds (Hays \& Cormons, 1974; Fry et al., 1987; Ryan., 1988; Van Franeker \& Bell, 1988) and fish (Carpenter et al., 1972; Kartar et al., 1973), although the effects on these organisms remained unclear, due to the biological implications being more difficult to show or test for (Colton et al., 1974). However, it was assumed by early researchers that microplastics were unlikely to be beneficial to any animal (Gregory, 1996; Zitko \& Hanlon, 1991). Early publications also began to speculate on the sources of such pollution, and how efforts could be made to minimise the introduction of further litter. Zitko \& Hanlon (1991) demonstrated, for example, that plastic scrubbers from facial cleansers could be attributed to some of the direct microplastic inputs into the marine environment in the forms of polyethylene, polypropylene, or polystyrene. In addition, they proposed that from a 'common sense basis', use of such products - as well as unnecessary discharge - should be minimised, otherwise accumulation will likely occur in the marine environment.

\section{Interactions with biota}

Due to their small size, microplastics are often biologically available for marine organisms. Consequently, both direct and indirect interactions such as ingestion and subsequent trophic transfer are a widespread issue in many different ecosystems. A plethora of studies have examined ingestion of these synthetic particles, along with the issues microplastics may cause for various individuals, populations, and species. Unlike the ingestion of macro debris, microplastics often enters the food web at the lower trophic levels, for example marine invertebrates (Lusher, 2015). However, it has also been shown that marine alga can absorb microplastic debris by incorporating the particles into their cellulose, resulting in measurable oxidative stress and decreased photosynthetic output (Battacharya et al., 2010). However, whether ingestion occurs as the result of accidental consumption or selective choice often depends on the relative concentration of plastic associated with normal prey items, as well as the organism's ability to discriminate between prey and plastic litter (Moore et al., 2001; Moore, 2008).

Although many macroplastic ingestion studies focus on larger marine organisms, most microplastic ingestion studies are carried out at lower trophic levels, particularly with smaller benthic and planktonic invertebrates. These organisms are commonly filter-, suspension-, or deposit-feeders, and are therefore highly susceptible to microplastic ingestion from the water 
column and sediments. However, whilst it is straightforward to demonstrate that an animal has ingested or absorbed plastic debris, it is more difficult to determine how long plastic debris remains in an organism's digestive tract and tissues, as well as any physiological, structural, or behavioural effects. A few such studies have reported evidence of decreased feeding rates in zooplankton (Cole et al., 2013) and lugworms (Besseling et al., 2013), while increased mortality was observed in copepods after generational exposure to the toxicity of microplastics (Lee et al., 2013). In addition to feeding and survival, fitness of marine invertebrates is also thought to be adversely affected. Oysters experience reduced fecundity and decreased offspring quality, both of which are attributed to the ingestion of microplastic particles (Galloway \& Lewis, 2016; Sussarellu et al., 2016).

\section{Conclusion and Aims of research}

Plastics are an important pollutant in the oceanic environment, regardless of size, shape, or type. They are now recognised as being long-lasting and ubiquitous in abundance and distribution worldwide. Furthermore, both microplastics and macroplastics have significant and adverse effects upon marine organisms; ranging from primary producers through to apex predators. These effects may be direct, such as entanglement or ingestion of plastic debris. Alternatively, indirect effects are also experienced, including the ingestion of leached chemicals from the surface of plastic, or the trophic transfer of synthetic materials that may lead to bioaccumulation of both physical debris and/or chemical toxicity.

Efforts are continuously being made to expand the understanding of how plastic pollution impacts marine organisms, but it is also vital to understand where the debris is found and in what quantities. Such information enables research on biological effects to focus upon organisms particularly susceptible to direct impacts, as well as oceanographic regions with high pollutant loads. Most of the studies within this review have been carried out in the Northern Hemisphere, leaving parts of the Southern Hemisphere greatly under-researched and lacking reliable plastic pollution metrics (Avio et al., 2017). In particular, studies undertaken to assess plastic load within the remote oceanographic region of the Southern Ocean have only recently started to be carried out, and New Zealand's microplastic research has only recently had a resurgence (e.g. Clunies-Ross et al., 2016; Webb et al., 2019; Bridson et al., 2020) after a strong beginning in the 1970's (Gregory, 1977; Gregory, 1978). Increasing awareness surrounding microplastic patterns throughout the world's oceans is also integral, as the fragmentation of larger plastics already in the marine environment will likely result in an increasing amount of smaller synthetic particles in the coming decades. 
Consequently, this thesis explores the abundance and distribution of microplastics over temporal and spatial scales, to identify patterns in both a remote area of the ocean, as well as a heavily urbanised setting. The first chapter examines surface water microplastic load over a 10-year time series in the Ross Sea Region of the Southern Ocean. The second chapter surveys the inner harbour of Wellington, New Zealand, encompassing surface water, sediment, and biological samples. to gain a broad perspective of microplastic pollution across multiple surfaces. Up-to-date assessments and information on microplastic load and its distribution should aid in developing plans and legislation to manage and mitigate the spread of global oceanic plastic pollution. 


\section{Large-scale temporal and spatial patterns of microplastic pollution between New Zealand and the Ross Sea, Antarctica}

\section{Abstract}

This study aimed to characterize the pollutant load of synthetic particles in a multi-year, large scale study between New Zealand waters and the Ross Sea Region of Antarctica.

Field collections were made during each austral summer (November - March), between the years $2009 / 10-2017 / 18$. Sub-surface tows collected plankton and inorganic material such as microplastic with a $270 \mu \mathrm{m}$ mesh silk, using a Continuous Plankton Recorder (CPR). Microplastic abundance, colours, sizes, and morphotypes were counted and subsequently quantified over temporal and spatial scales.

There was no evidence for consistent patterns of change across the sampled months, years, or latitudinal zones, however pollutant loads were often dynamic in their occurrence. Yearly abundances varied substantially, with a large peak in the 2009/10 sampling year, and a deep trough in 2012/13. These responses suggest that floating microplastic debris is likely at the mercy of ocean circulation systems and large-scale environmental drivers such as El Niño and La Niña effects. Regarding particle characteristics throughout the sub-surface waters of the Southern Ocean, a broad range of both colours and sizes were found. In total, 9 different colours were identified across the samples, and these ranged in size from $<1-5 \mathrm{~mm}$. Overwhelmingly, however, the most significant result regarding particle characteristics came from the morphotypes that were observed. Microfibres accounted for $90.6 \%-99.5 \%$ of all particles collected each year, which supports the figures reported in other literature. 


\section{Introduction}

Antarctica and the surrounding Southern Ocean is considered, on a whole, to be the most remote geographical region in the world, with the relatively recent increase of scientists and tourism operations becoming the only regular visitors to the icy continent (Hughes, K.A., 2010; Shah, R.M., 2013). However, the ubiquity of plastic pollution would suggest that debris is likely to have also permeated these waters. This is especially probable when considering the oceanography of the Southern Ocean and the current system that drives it. In comparison to the remote nature of the Antarctic land mass, the Southern Ocean is integrally connected to the rest of the world. The Antarctic Circumpolar Current (ACC) wraps around the Antarctic continent and thus is connected to the Atlantic, Indian, and Pacific oceans (Figure 2.1) (Rintoul, et al., 2001; Rintoul, 2018). This oceanic circulation system, the ACC, both thermally isolates the Southern Ocean to prevent excessive melting of ice, and transports nutrient-rich, warmer water that has originated from low latitudes around the continent (Tynan, 1998; Martinson, 2012). This large-scale, circumpolar circulation provides a pathway for pollutants such as microplastics to be introduced to and established within the waters of the Southern Ocean.

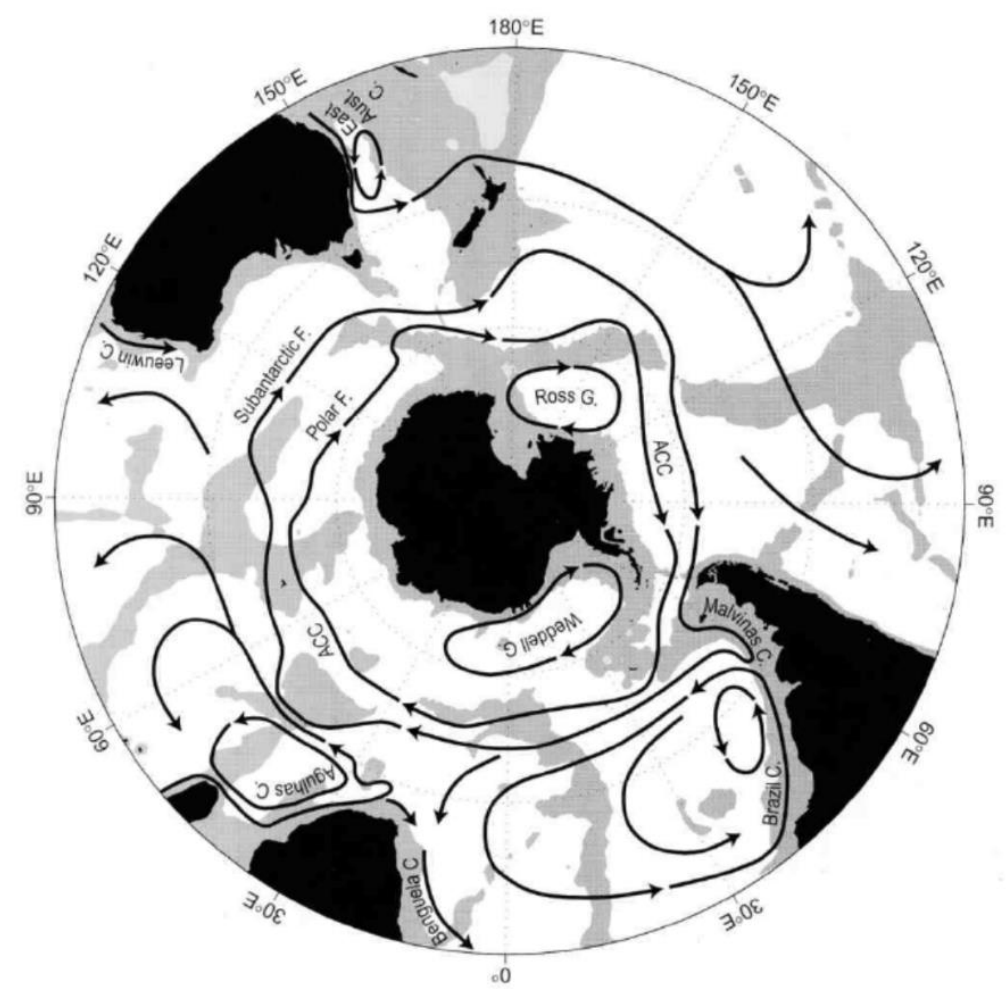

Figure 2.1: Schematic depiction of major currents of the Southern Ocean, with particular reference to the Antarctic Circumpolar Current (ACC) and its associated fronts, which encircles the Antarctic continent. Image credit: Rintoul et al., 2001. 
Research into plastic pollution throughout the polar regions has been a recent development, with many studies focussing on the more accessible and urbanised parts of the ocean. Before 2014, no studies had shown any direct evidence for a substantial microplastic pollutant load in the Arctic (Lusher, 2015), and it wasn't until 2017 that researchers began sampling sediments and surface waters around the coast of Antarctica (Cincinelli et al., 2017; Isobe et al., 2017; Munari et al., 2017; Waller et al., 2017). Prior to this, only two scientific papers had been published on plastic debris in the Southern Ocean, one on macroplastic occurrence (Barnes et al., 2010) and the other on ingestion by petrels (Van Franeker \& Bell, 1988). More recently, abundance and distribution estimates around the Antarctic continent have been carried out by multiple research teams from numerous nationalities, with an emphasis on using data from the surface waters of the Southern Ocean to explain how macro and microplastic pollution loads are impacted by oceanic currents and their rate of dispersal around the globe (e.g. Isobe et al., 2019). Plastic pollution in polar regions is still an emerging research topic, and recent papers examining the abundance of microplastics in Antarctic waters are highly variable. In general, publications accept that microplastics are found within multiple environments in the Southern Ocean, including sediments and surface waters. In Admiralty Bay, microfibers had an average abundance of $2.40( \pm 4.57)$ particles per $100 \mathrm{~m}^{-3}$ across 60 samples in the 2010-11 austral summer (Absher et al., 2019). Similarly, a study carried out around the Antarctic Peninsula found an average abundance of meso- and microplastics of 0.008 particles per $\mathrm{m}^{-3}$ (Lacerda et al., 2019). Altogether, Southern Ocean microplastic abundances have been poorly classified, with most publications focused on a localised area such as the Antarctic Peninsula or a specific bay (Absher et al., 2019; Lacerda et al., 2019). Such a lack of broad spatial and temporal studies is largely due to the logistical difficulties of carrying out research in this isolated region of the world.

The Southern Ocean, covering the region south of $60^{\circ} \mathrm{C}$ (Stössel et al., 2015), covers a vast expanse of ocean, so to limit microplastic studies to a narrow temporal or spatial range is to limit the knowledge that can be obtained on how extensive this pollutant is. Between New Zealand and the Ross Sea Region lies five major oceanographic zones and three main frontal systems (Figure 2.2), where each frontal system and its associated latitudinal zones have distinct characteristics and biological associations (Robinson et al., 2014; Rintoul, 2018). For example, satellite observations have recorded distinct differences in sea surface temperature and sea surface height across the different zones (Moore et al., 1999; Solokov \& Rintoul, 2009; Graham et al., 2012) The Sub-Tropical Front (STF) and its associated Sub-Tropical 
Zone (STZ) have been suggested to be more susceptible to wind shifts, as this region is surface intensified (Graham et al., 2012). However, the other frontal systems, located at higher latitudes and within the ACC, are reported to be more sensitive to the associated topography, as opposed to wind shifts (Graham et al., 2012). Differences between the frontal systems are also observed when regarding biological communities. For example, Tynan (1998) and Rodhouse \& White (1995) reported that the ecological community found within the Polar Frontal Zone (PFZ) includes cephalopods, but krill and fishes were absent. The spatial variability between frontal systems not only helps to control the global climate (Graham et al., 2012), but is also possibly a factor that contributes to the distribution of microplastics throughout the Southern Ocean, along with the interactions that these synthetic particles may have with the ecological communities which inhabit these waters.

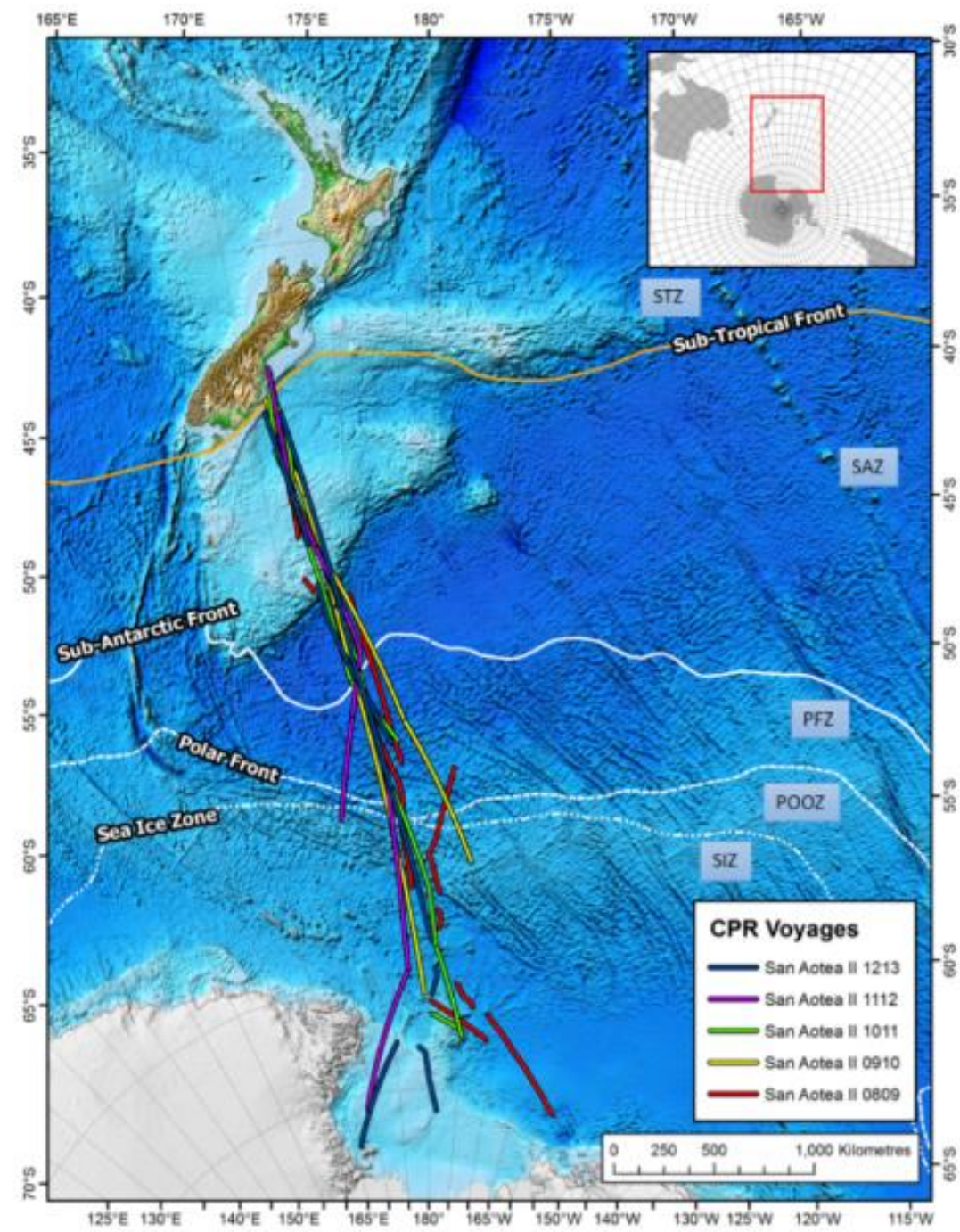

Figure 2.2: CPR tows undertaken by FV San Aotea II during the first five annual sampling voyages (2008/09 2012/13), where transects can be seen traversing the five latitudinal zones and three frontal systems. 
Another contributing factor to the abundance and distribution of floating marine microplastic pollution is time. With the ever-increasing amount of plastic that is produced - and consequently discarded into the environment each year - temporal variation is an integral aspect of microplastic research. Currently, the only multi-year, long-term temporal study investigating floating debris has been carried in the Northern Hemisphere (Ostle et al., 2019). This study took place over a period of 60 years (1957-2016) and recorded a clear increase in macro- and microplastic pollution throughout sub-surface waters in the North Atlantic. On the other hand, Isobe et al. (2019) conducted a survey in the Southern Hemisphere, between Japan and Antarctica, in the Austral summer of 2016-2017. This study, while not a long-term temporal field study, utilised a numerical model to predict likely microplastic abundances in the future - up to 2066. This study by Isobe et al. (2019) also predicted that there will be an unmistakable increase in microplastic loads throughout these southern waters in the next $\sim 40$ years. This limited understanding of long-term temporal patterns surrounding microplastic research severely limits the future advancement of this field, as mitigation efforts depend largely upon a well-defined knowledge of its distribution and abundance. Without a solid grasp of these long-term patterns, models will not be able to effectively predict the dispersal or occurrence patterns of this pollutant throughout the world's oceans.

The aim of this chapter is to characterise the trends in abundance as well as size and colour of microplastics in sub-surface tows over a 9-year sample period. I examine the abundance of synthetic particles and their spatial distribution over a $\sim 22,000 \mathrm{~km}(11,900$ nautical mile) transect between New Zealand and the Ross Sea, within and between years. I hypothesized that the prevalence of microplastics will increase with the proximity to urbanised, New Zealand waters, but that there will be significant variation in microplastic abundance between years, due to random dispersal effects and environmental variables. In the same way that other scientific literature has found fibres to be the most predominant type of microplastic within surface waters, I also hypothesized that these types of particles will have the highest abundance within the study area and time period. 


\section{Methods}

\section{Data collection}

Field sampling occurred every austral summer from 2008, between New Zealand and the Ross Sea Region (defined here as $160^{\circ} \mathrm{E}-150^{\circ} \mathrm{W}$ and South of $40^{\circ} \mathrm{S}$ ), as seen in Figure 2.3. The collection of sub-surface water samples was directed by NIWA (National Institute of Water and Atmospheric research), in collaboration with the Antarctic toothfish fishing vessel, FV San Aotea II. Detailed descriptions of field methodology, along with the initial postvoyage sampling, can be found within the Robinson et al. (2014) Ministry for Primary Industries (MPI) report. Briefly, samples were collected by the FV San Aotea II as it followed a similar route to and from its Southern fishing grounds each year and also had long periods of continued cruising/steaming, both factors allowing for adequate sampling durations and annual repetitions (Figure 2.3). Water samples were collected while in transit between New Zealand and the Ross Sea Region, using a Continuous Plankton Recorder (CPR).
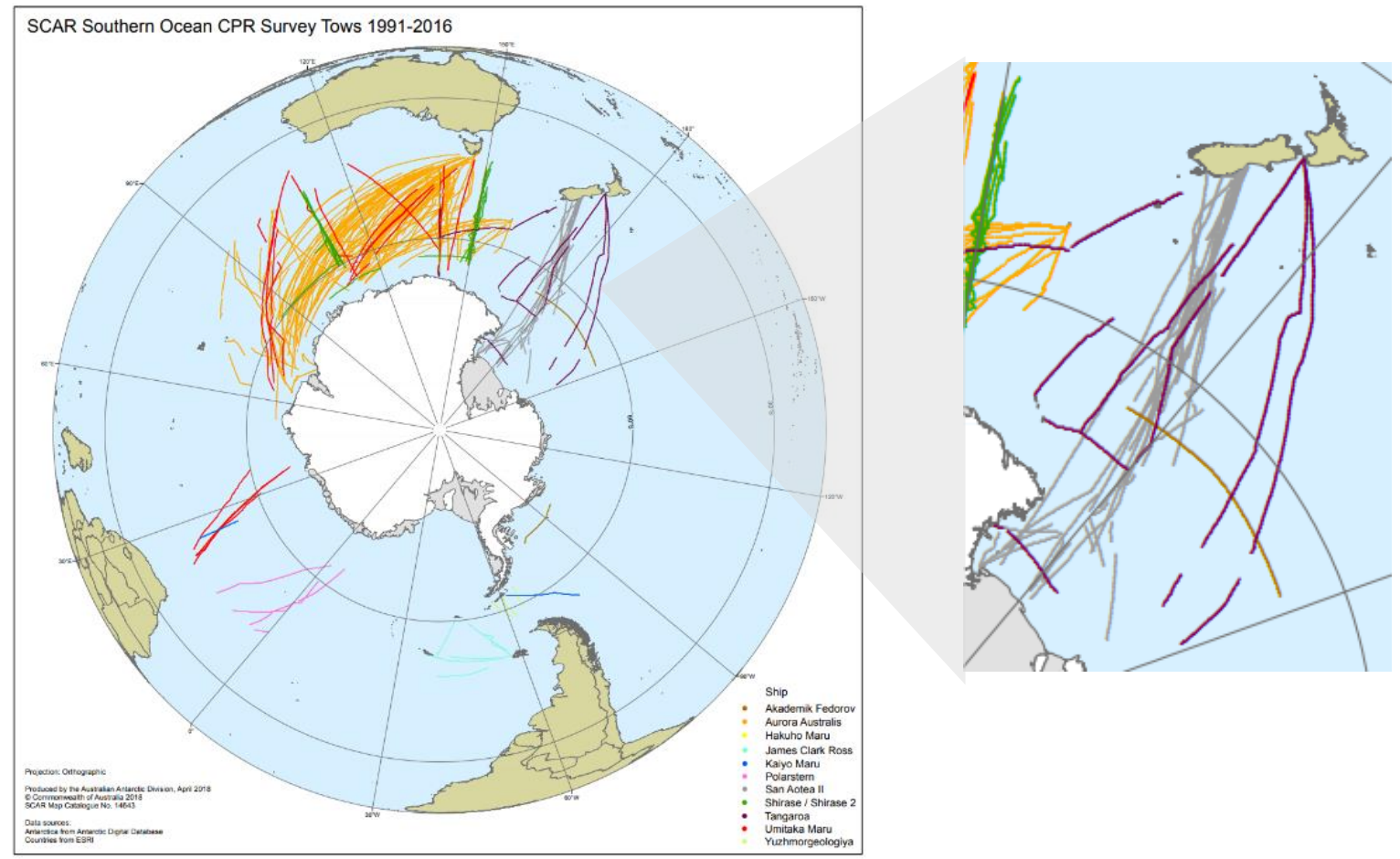

Figure 2.3: A depiction of SCAR Southern Ocean CPR survey tows between 1991-2013, with particular focus upon the light grey transects conducted by the FV San Aotea II for this study, in conjunction with NIWA. Image credit: Australian Antarctic Data Centre (C) Commonwealth of Australia.

Continuous Plankton Recorders (CPR) were initially created to aid plankton surveys in subsurface oceanic waters. However, because of their ability to capture small organisms like plankton, they could also be used for the purpose of assessing microplastic load. During this 
study, the CPR was towed roughly $100 \mathrm{~m}$ astern of the FV San Aotea II, at an approximate depth of $10 \mathrm{~m}$ below the sea surface. According to the methods described in Robinson et al. (2014), the CPR conducted tows whilst the vessel travelled at cruising speed. Throughout each deployment, water, organisms, and inorganic material entered the body of the CPR via a small opening $(12.7 \times 12.7 \mathrm{~mm})$, before they were passed through a $270 \mu \mathrm{m}$ collecting silk (Figure 2.4). This silk layer was then coated with a covering silk, which consequentially captured animals and inorganic materials between the two layers. During this process, an external propeller moved the silk through the internal workings of the CPR at an approximate rate of $1 \mathrm{~cm}$ per 1 nautical mile $(\mathrm{nm})$, regardless of the cruising speed at which the FV San Aotea II was travelling. Both silks were finally rolled into a preservation tank that contained a solution of buffered $40 \%$ formaldehyde at the rear of the CPR body (Figure 2.4), where they remained until the completion of the tow. Each CPR deployment was able to run for up to a maximum 450 nautical miles (nmi), however the actual tow length was heavily dependent upon environmental factors at play such as wave height and wind strength.

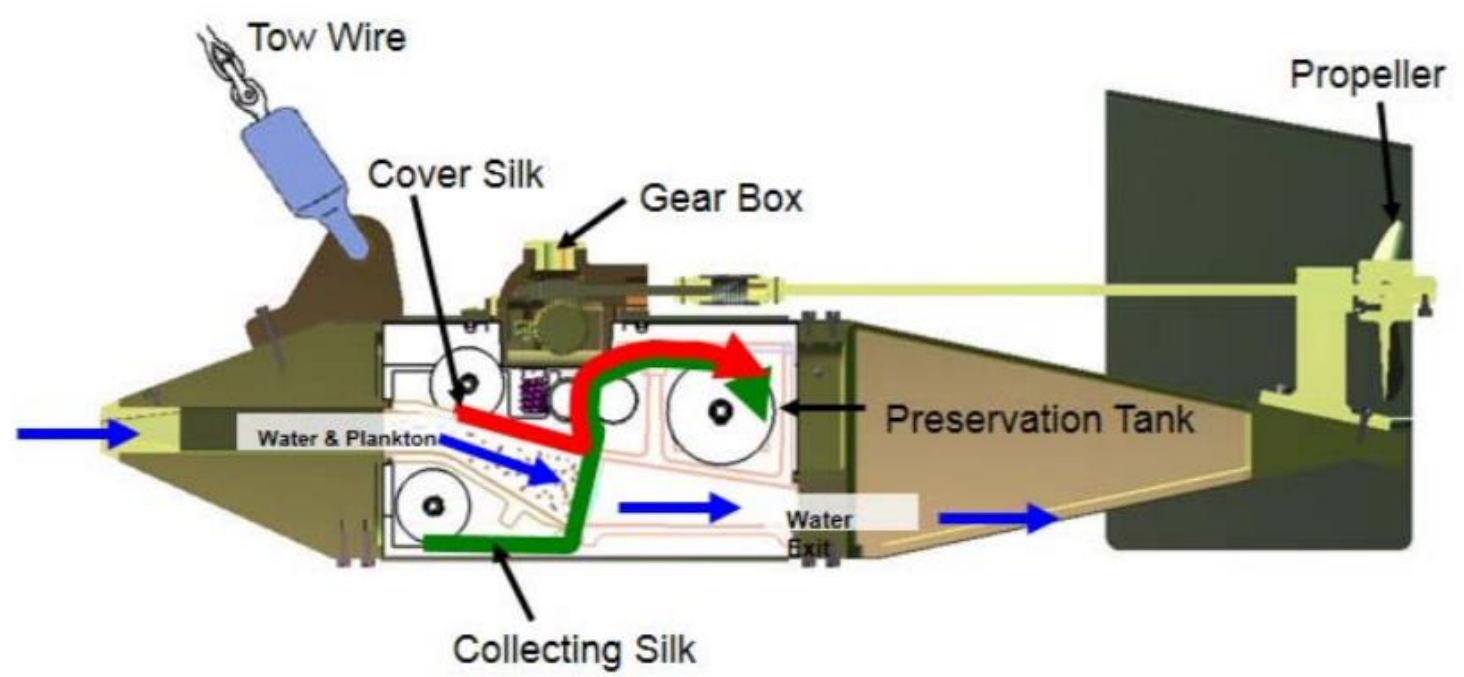

Figure 2.4: A depiction of the internal workings of a Continuous Plankton Recorder (CPR), as used in this study. Image credit: Robinson et al., 2014.

Over the 20 separate transits that were conducted over the 10-year sample period (2008/092017/18), the CPR was deployed 71 times over a collective distance of 23,286 $\mathrm{nmi}(43,140.5$ $\mathrm{km}$ ), with an average of 7 tows per transit (Table A2.1). FV San Aotea II crew members were trained by NIWA technicians to operate the CPR machinery and the associated chemicals, 
tools, and safety equipment effectively. They were also trained in correct preservation methodologies for all samples, so to minimise contamination (Robinson et al., 2014).

\section{Laboratory protocol}

Post voyage sampling

At the completion of each voyage, samples were transported to the NIWA laboratories, where they were cut into $5 \mathrm{~cm}$ segments that each represented 5 nautical miles of towed distance (Figure 2.5). These segments were individually analysed to determine Phytoplankton Colour Index (PCI), zooplankton abundance, and taxonomic identification to the highest possible level. Whilst examining samples for the presence and identification of biota, presence and absence of inorganic materials was recorded. All $5 \mathrm{~cm}$ segments were preserved in $10 \%$ formaldehyde. For tows between $2009 / 10$ - 2017/18, all samples that contained any inorganic material were set aside, and later sent to me to further characterize the microplastics at the Victoria University Coastal Ecology Laboratory (VUCEL). The samples from 2008/09 were not analysed as a part of this study, due to time constraints.

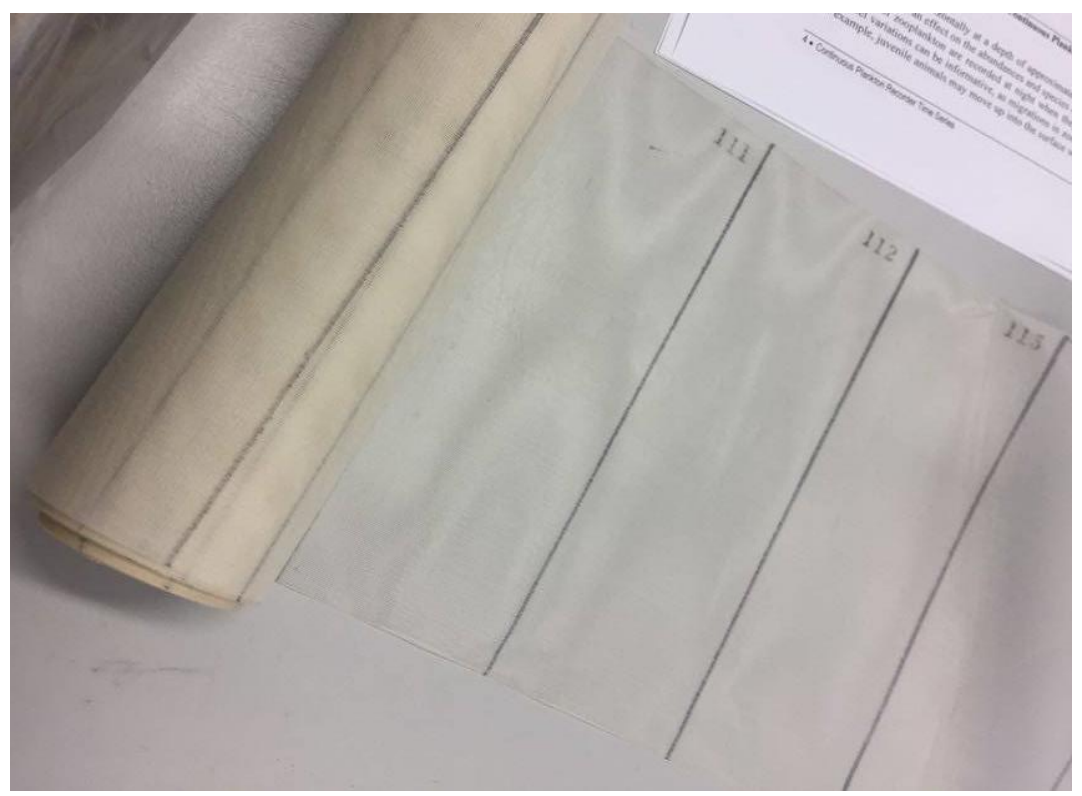

Figure 2.5: A roll of $270 \mu \mathrm{m}$ collecting mesh, which is used in CPR tows throughout this study. Once in the NIWA laboratory, these rolls are cut into the $5 \mathrm{~cm}$ samples along the marked lines, at which point they are ready for microscopic analysis.

\section{Sample preparation}

All 1558 samples with at least one piece of inorganic material (37\% of the total samples collected between 2009/10 - 2017/18) were individually washed with distilled water, visually analysed, then preserved using an adapted NIWA protocol. To prepare the individual samples for analysis, the two layers of silk were removed, then the $40 \%$ formaldehyde preserving 
solution was poured through a $75 \mu \mathrm{m}$ filter. The collecting and covering silks were also rinsed with distilled water and washed through a $75 \mu \mathrm{m}$ filter, to recover any residual trapped biological or inorganic material.

\section{Visual analysis}

Washed samples were transferred to a petri dish (Figure 2.6) and analysed under a stereo microscope at $15 x$ magnification. Synthetic materials were recorded by colour, size, and type. Particles were categorized into three size classes; small ( $<1 \mathrm{~mm})$, medium $(>1-2 \mathrm{~mm})$, or large (>2 - $5 \mathrm{~mm}$ ), determined by measuring each inorganic particle at its longest or widest point. The type of synthetic particle was either recorded as a fibre, fragment, foil, paint chip, or macroplastic (> $5 \mathrm{~mm}$ ). Finally, the colour of each synthetic particle was also recorded. To verify that the visual identification of a microplastic was correct, forceps were used to attempt to break apart the particle. If it could not be broken, it was determined to be a form of microplastic debris, whilst if it could be broken but was an irregular shape and/or colour, it was classed as a paint chip.

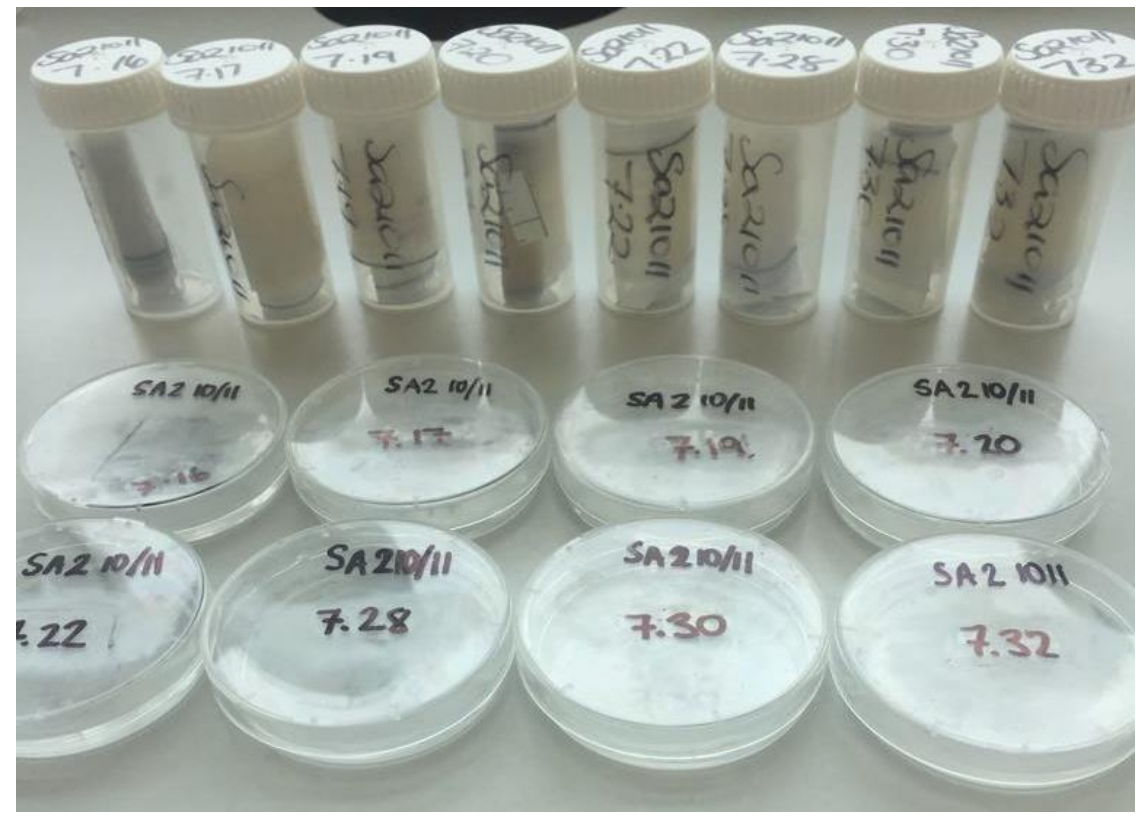

Figure 2.6: Samples arrived at Victoria University Coastal Ecology Laboratory (VUCEL) in tubes. To prepare each sample for microscopic analysis, silks were removed, and the formaldehyde solution was washed through a $75 \mu \mathrm{m}$ filter, along with both mesh layers. Samples were then transferred to the pictured petri dishes and labelled appropriately.

\section{Statistical analyses}

All analyses were conducted in R V3.6.3 (R Core Team 2020) using RStudio v1.2.5033

(RStudio Team, 2020). Firstly, a Chi-square Likelihood Ratio Test (LRT) was used to 
determine whether there was a significant effect of month, transit (North- or South-bound), year, or oceanographic zone. Further analyses were conducted if results were significant. For significant variables, a Poisson mixed effects model was used, with an adjustment made for autocorrelation using the AR1 structure. Pairwise comparisons using the EMMEANS package conducted tests for years that had significantly different counts from each other. Similar tests were conducted for the effects of month and oceanographic zone. Results were given on a log scale.

Pearson's Chi-square tests were conducted for the three aspects of particle characteristics: morphotype, size, and colour. The results of these determined if there was a significant difference between variables. 


\section{Results}

Throughout the 9-year sampling period, 4211 individual surface water samples were collected during CPR tows between New Zealand's waters and the Ross Sea Region of Antarctica. Of these, Figure 2.7 demonstrates that there was a high yearly variation in the proportion of individual $5 \mathrm{~cm}$ silk samples that contained at least one microplastic particle. The most recent survey, in the austral summer of 2017/18, had a total of 487 samples with $88.3 \%$ of these containing at least one synthetic particle (Table 2.1). In contrast, the austral summer of 2011/12 had a total of 404 samples, but only $26.8 \%$ of these contained any microplastics (Table 2.1). Overall, the percentage of samples containing microplastic was less than $50 \%$ in most years.

Table 2.1: Total number of samples collected from surface waters between New Zealand and the Ross Sea, broken down into the total number of samples containing at least one microplastic particle and those without any microplastics.

\begin{tabular}{|l|c|c|c|}
\hline Year & Total & $\begin{array}{c}\text { Number of samples } \\
\text { with } \geq 1 \text { microplastic }\end{array}$ & $\begin{array}{c}\text { Number of samples with } \\
\text { no microplastic particles }\end{array}$ \\
\hline $2009 / 10$ & 468 & 149 & 319 \\
\hline $2010 / 11$ & 541 & 192 & 349 \\
\hline $2011 / 12$ & 404 & 31 & 373 \\
\hline $2012 / 13$ & 504 & 135 & 369 \\
\hline $2013 / 14$ & 449 & 187 & 262 \\
\hline $2014 / 15$ & 454 & 103 & 351 \\
\hline $2015 / 16$ & 465 & 70 & 395 \\
\hline $2016 / 17$ & 439 & 260 & 179 \\
\hline $2017 / 18$ & 487 & 430 & 57 \\
\hline
\end{tabular}




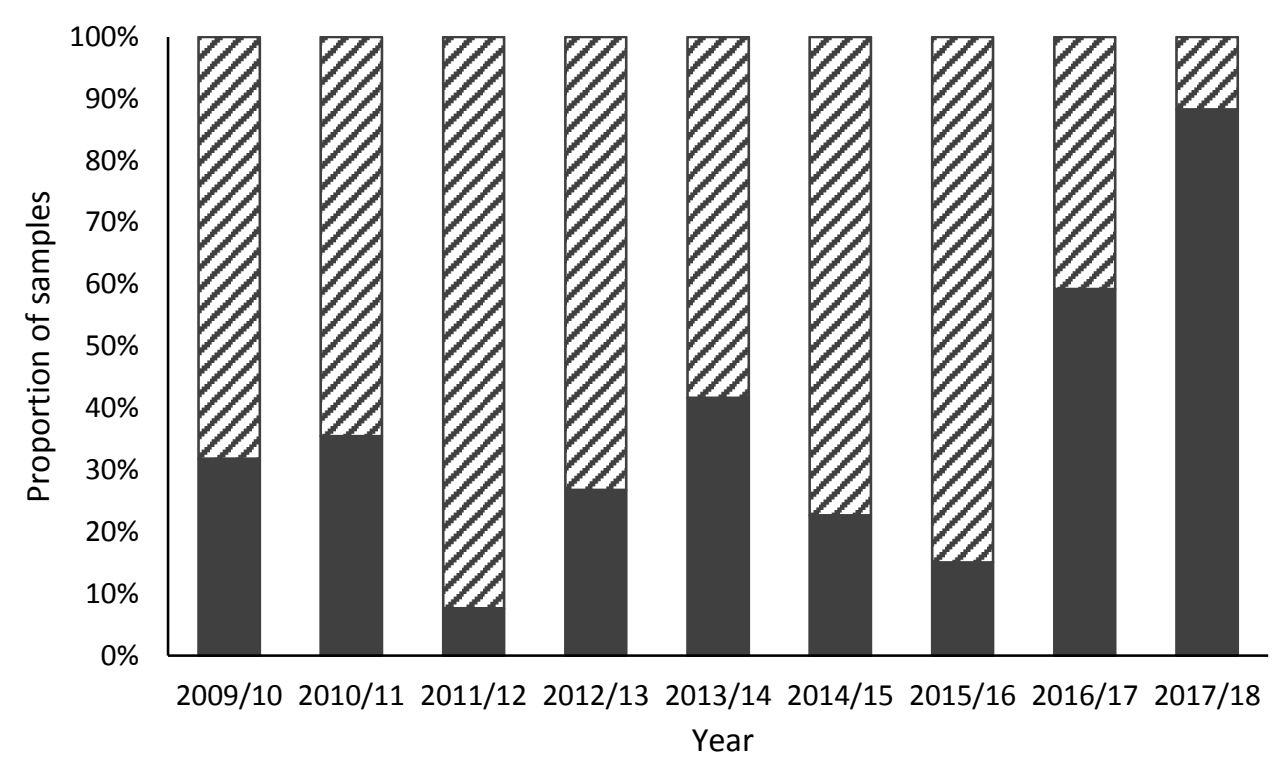

Figure 2.7: Proportion of total samples collected per year, where black bars represent the percentage of samples that contain at least 1 microplastic particle and striped bars represent the percentage of samples that do not contain any microplastics.

\section{Explanatory Variables}

For all explanatory variables of microplastic abundance in surface waters between New Zealand and the Ross Sea Region, three were not independent. Both temporal variables (month of collection and year) were significant predictors (Table 2.2) and so was the spatial variable; oceanographic zone. There was no effect of direction of travel, North- or Southbound along the transect, on microplastic abundance (Table 2.2). Since month, year, and oceanographic zone of surface water sampling all have a relationship with mean microplastic abundance, these were able to be investigated further.

Table 2.2: Results of Chi-squared Likelihood Ratio Test examining effects of collection month, collection transit, year, and oceanographic zone on microplastic abundance between New Zealand and the Ross Sea Region. * indicates significance at $\mathrm{p}=0.05$.

\begin{tabular}{|l|c|c|c|c|}
\hline & AIC & LRT & P. value & \\
\hline Month & 13126 & 23.107 & $<0.0001$ & $*$ \\
\hline Transit & 13109 & 0.05 & 0.8233 & \\
\hline Year & 13134 & 39.253 & $<0.0001$ & $*$ \\
\hline Zone & 13186 & 84.332 & $<0.0001$ & $*$ \\
\hline
\end{tabular}




\section{Temporal variation}

Between-year

Average microplastic abundance in surface waters between New Zealand and the Ross Sea Region was variable across years. There was no consistent increase or decrease in average load throughout the 9-year study (Figure 2.8), however the average amount of microplastics found in the 2009/10 survey was significantly higher than 2011/12, 2012/13, and 2013/14 (Table 2.3). In contrast, as shown in Figure 2.8, the 2012/13 samples only contained up to half the amount of microplastics on average compared with 2009/10, 2014/15, and 2015/16 (Table 2.3).

Table 2.3: Results of a pairwise comparison (adjusted for the effect of autocorrelation) examining the effect of sampling year (2009/10 - 2017/18), on microplastic abundance within surface waters between New Zealand and the Ross Sea Region. Results are averaged over the levels of Month, Transit, and Zone, and are significantly different at $\mathrm{p}=0.05$

\begin{tabular}{|c|c|c|c|c|c|c|}
\hline Contrast & Estimate & SE & df & t.ratio & P.value & \\
\hline $2009 / 10-2011 / 12$ & 0.7369 & 0.182 & 49 & 4.042 & 0.0054 & $*$ \\
\hline $2009 / 10-2012 / 13$ & 0.8728 & 0.137 & 49 & 6.392 & $<0.0001$ & $*$ \\
\hline $2009 / 10-2013 / 14$ & 0.5008 & 0.120 & 49 & 4.191 & 0.0034 & $*$ \\
\hline $2012 / 13-2014 / 15$ & -0.4932 & 0.148 & 49 & -3.327 & 0.0405 & $*$ \\
\hline $2012 / 13-2015 / 16$ & -0.7428 & 0.174 & 49 & -4.269 & 0.0027 & $*$ \\
\hline
\end{tabular}




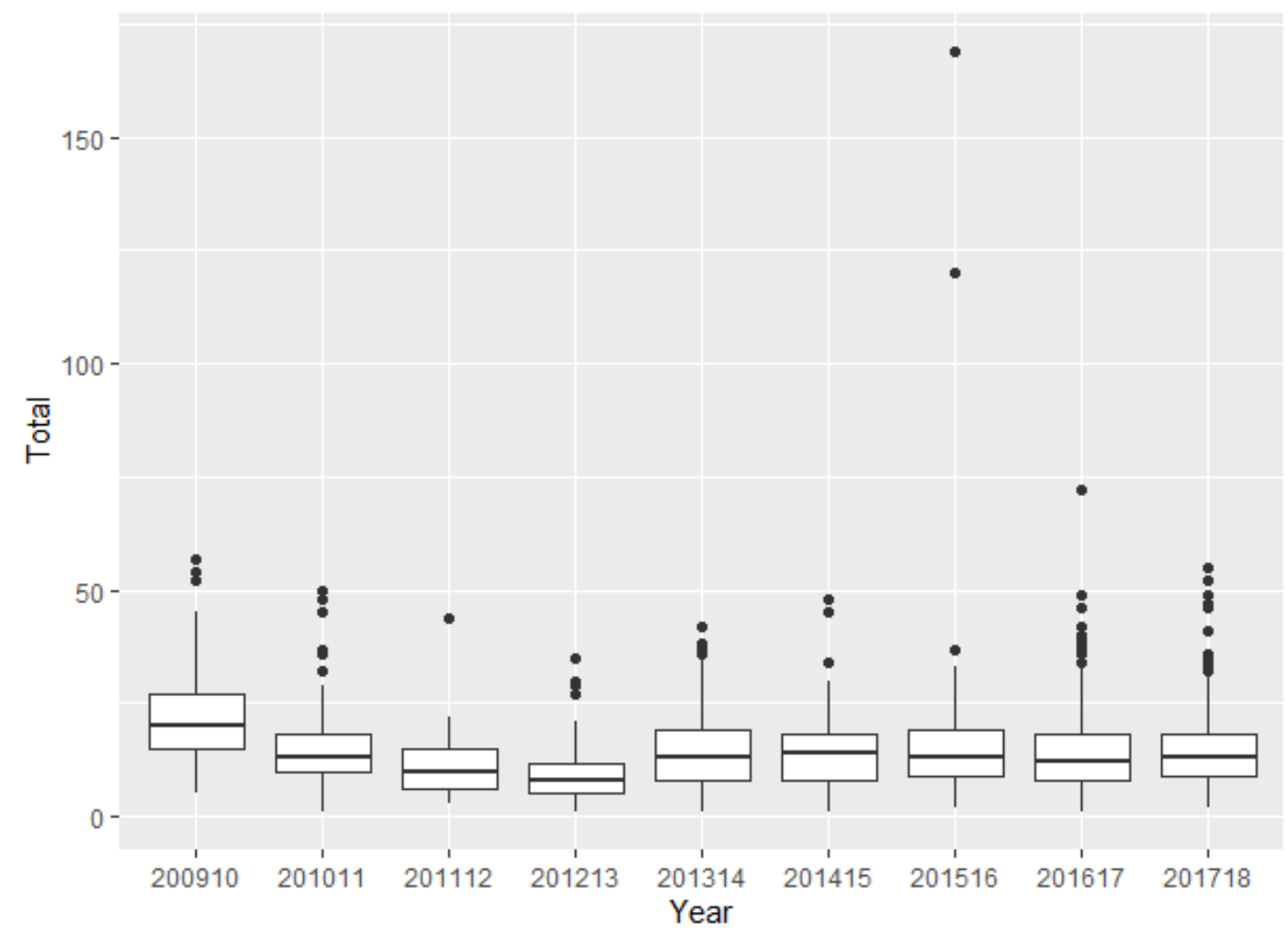

Figure 2.8: Distribution of synthetic particle abundances in surface waters between New Zealand and the Ross Sea, over a 9-year period $(2009 / 10-2017 / 18)$. Data is pooled across months, transit, and zones.

\section{Between-month}

Throughout the 9-year annual sampling period, tows were carried out between November and March (austral summer). Similar to the yearly variation, microplastic abundance was also dynamic between months, with no consistent increase or decrease in load throughout the summer (Figure 2.9). The largest difference occurred between the month of December and the following two months, with December having the highest average number of microplastics. However, there was no significant difference between the microplastic abundance in any month where sampling took place (Table 2.4). 
Table 2.4: Results of a pairwise comparison (adjusted for the effect of autocorrelation) examining the effect of month (November, December, January, February, March), on microplastic abundance within surface waters between New Zealand and the Ross Sea Region.

\begin{tabular}{|l|c|c|c|c|c|}
\hline Contrast & Estimate & SE & df & t. ratio & P.value \\
\hline Nov - Dec & -0.0026 & 0.162 & 1490 & -0.016 & 1.0000 \\
\hline Nov - Jan & 0.3867 & 0.221 & 1490 & 1.750 & 0.4039 \\
\hline Nov - Feb & 0.3195 & 0.254 & 1490 & 1.257 & 0.7178 \\
\hline Nov - Mar & 0.0276 & 0.399 & 1490 & 0.069 & 1.0000 \\
\hline Dec - Jan & 0.3893 & 0.221 & 1490 & 1.766 & 0.3942 \\
\hline Dec - Feb & 0.3221 & 0.215 & 1490 & 1.502 & 0.5616 \\
\hline Dec - Mar & 0.0302 & 0.374 & 1490 & 0.081 & 1.0000 \\
\hline Jan - Feb & -0.0672 & 0.129 & 1490 & -0.522 & 0.9852 \\
\hline Jan - Mar & -0.3592 & 0.339 & 1490 & -1.060 & 0.8269 \\
\hline Feb - Mar & -0.2920 & 0.310 & 1490 & -0.943 & 0.8800 \\
\hline
\end{tabular}

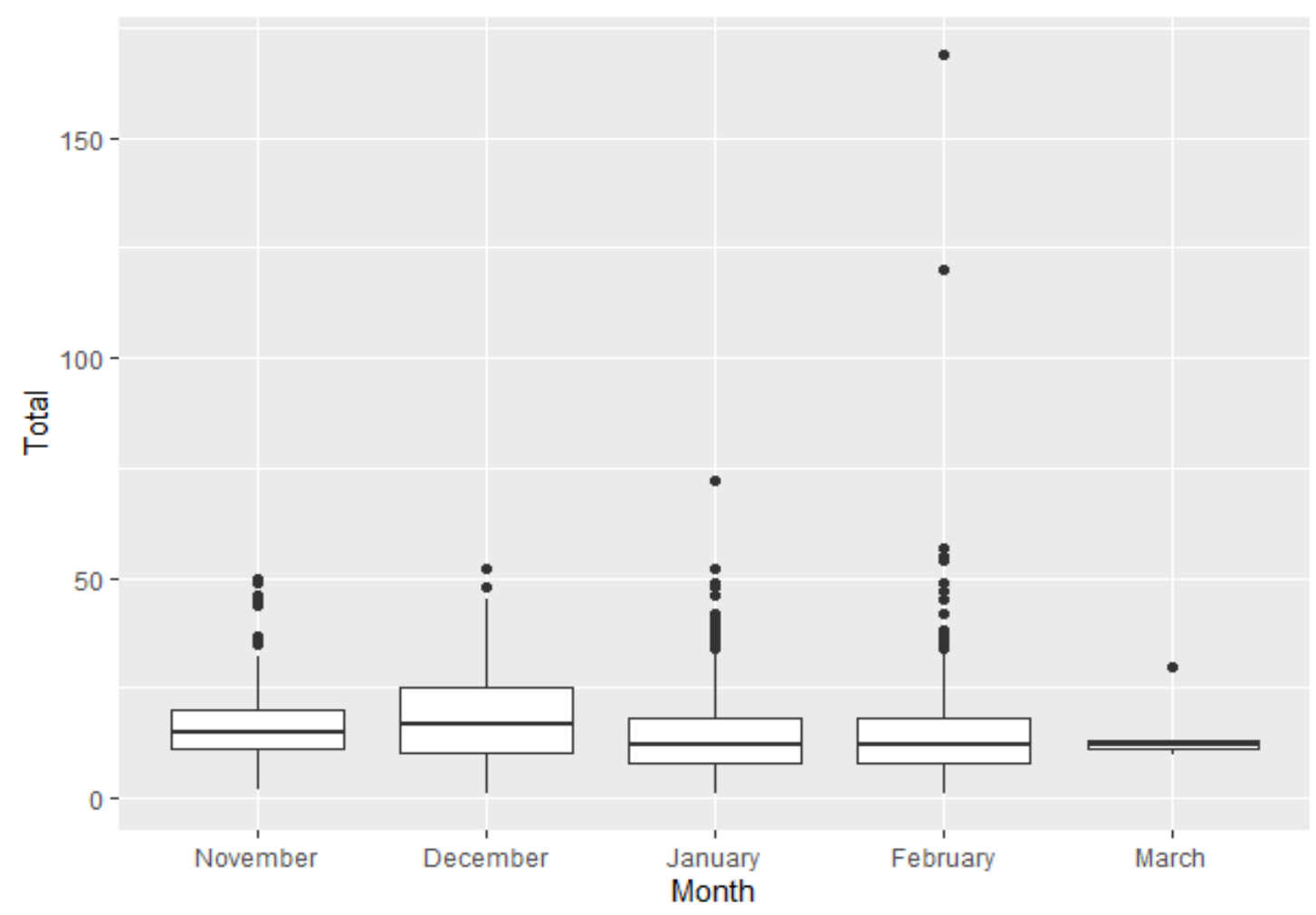

Figure 2.9: Distribution of synthetic particle abundances across the 5 different collection months in the austral summer (November - March), with data pooled across years, zones, and transits. 


\section{Spatial variation}

Overall variation

Figure 2.10 demonstrates the variability that was observed between microplastics throughout all zones and years. There was no discernible pattern or trend observed throughout the 9-year period, or the five oceanographic zones and frontal system where microplastics were collected.

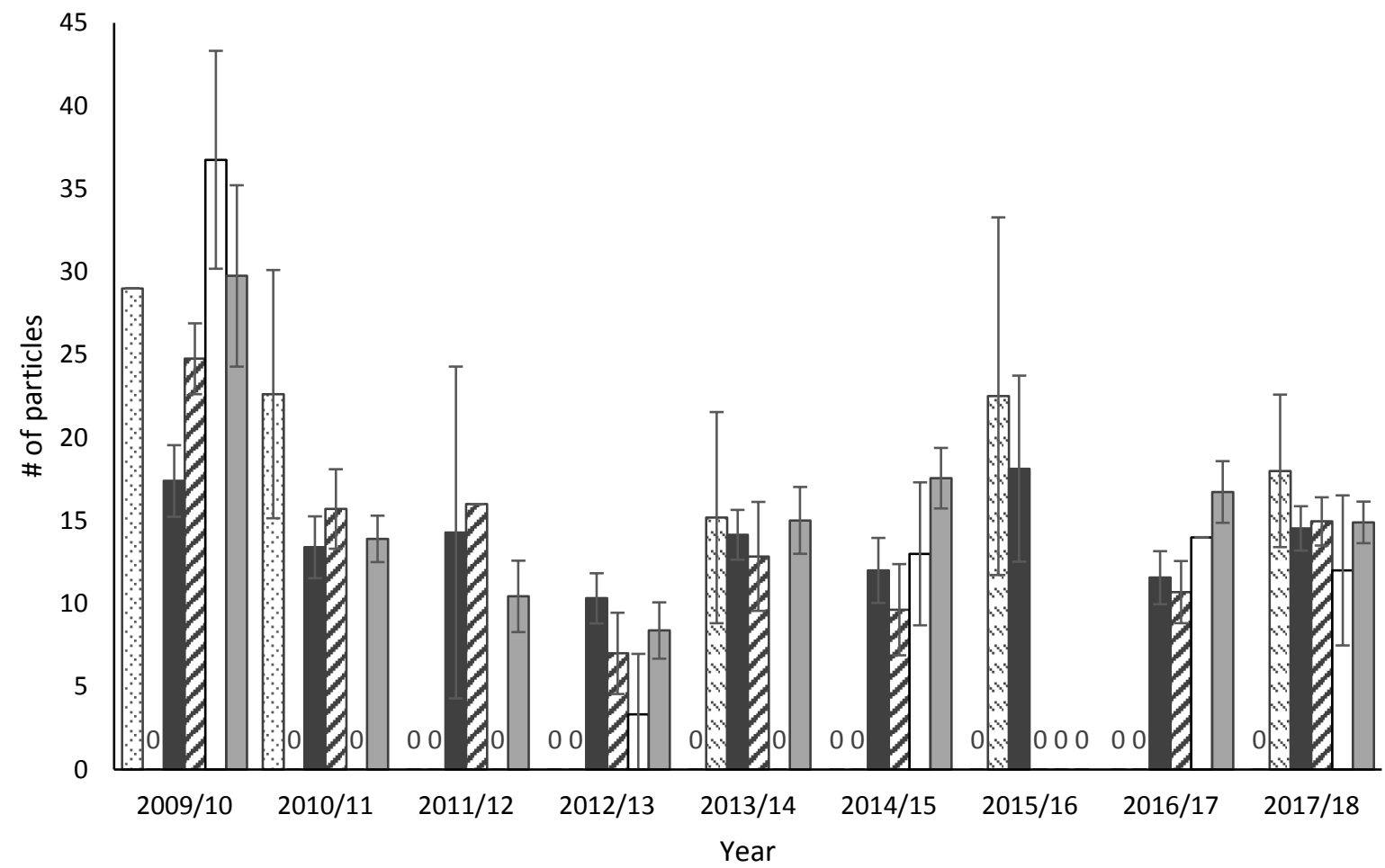

Figure 2.10: Mean (+/- 95\% confidence interval) surface water microplastic abundance from the 2009/10 sampling period to 2017/18, between five oceanographic zones and two frontal systems. In order from closest proximity to New Zealand, dotted bars represent the Sub-Tropical Zone (STZ), dashed bars represent the SubTropical Front (STF), black bars represent the Sub-Antarctic Zone (SAZ), striped bars show the Polar Frontal Zone (PFZ), open bars represent the Permanent Open Ocean Zone (POOZ), and grey bars represent the Sea Ice Zone (SIZ). On the graph, 0 demonstrates zones that collections did not occur in.

Between oceanographic zones

Between New Zealand and the Ross Sea Region of Antarctica, a variety of oceanographic zones and frontal systems were sampled during the annual CPR collections between 2009 2019. With data pooled across years, Figure 2.11 demonstrates that there was no noticeable difference in the amount of microplastics collected in most of the different oceanographic zones and frontal systems sampled during this study. However, Table 2.5 indicates that significant differences were observed between the Sea Ice Zone and both the Polar-Frontal (PFZ) and Sub-Antarctic Zone (SAZ). 
Table 2.5: Results of a pairwise comparison (adjusted for the effect of autocorrelation) examining the effect of oceanographic zone (PFZ, POOZ, SAZ, SIZ, STF, and STZ), on microplastic abundance within surface waters between New Zealand and the Ross Sea Region. * indicates significance at $\mathrm{p}=0.05$.

\begin{tabular}{|l|r|r|r|r|r|r|r|}
\hline Contrast & Estimate & SE & df & t.ratio & p.value & \\
\hline PFZ - POOZ & -0.14866 & 0.147 & 1490 & -1.027 & 0.9090 & \\
\hline PFZ - SAZ & -0.03257 & 0.0737 & 1490 & -0.442 & 0.9979 & \\
\hline PFZ - SIZ & -0.24607 & 0.0759 & 1490 & -3.241 & 0.0154 & $*$ \\
\hline PFZ - STF & -0.24798 & 0.1870 & 1490 & -1.326 & 0.7707 & \\
\hline PFZ - STZ & -0.54669 & 0.2131 & 1490 & -2.565 & 0.1065 & \\
\hline POOZ - SAZ & 0.11608 & 0.1512 & 1490 & 0.768 & 0.9728 & \\
\hline POOZ - SIZ & -0.09742 & 0.1489 & 1490 & -0.654 & 0.9867 & \\
\hline POOZ - STF & -0.09933 & 0.2288 & 1490 & -0.434 & 0.9981 & \\
\hline POOZ - STZ & -0.39804 & 0.2508 & 1490 & -1.587 & 0.6071 & \\
\hline SAZ - SIZ & -0.21350 & 0.0739 & 1490 & -2.888 & 0.0453 & $*$ \\
\hline SAZ - STF & -0.21541 & 0.1756 & 1490 & -1.227 & 0.8238 & \\
\hline SAZ - STZ & -0.51412 & 0.2056 & 1490 & -2.500 & 0.1245 & \\
\hline SIZ - STF & -0.00191 & 0.1858 & 1490 & -0.010 & 1.0000 & \\
\hline SIZ - STZ & -0.30062 & 0.2120 & 1490 & -1.418 & 0.7160 & \\
\hline STF - STZ & -0.29871 & 0.2693 & 1490 & -1.109 & 0.8777 & \\
\hline
\end{tabular}

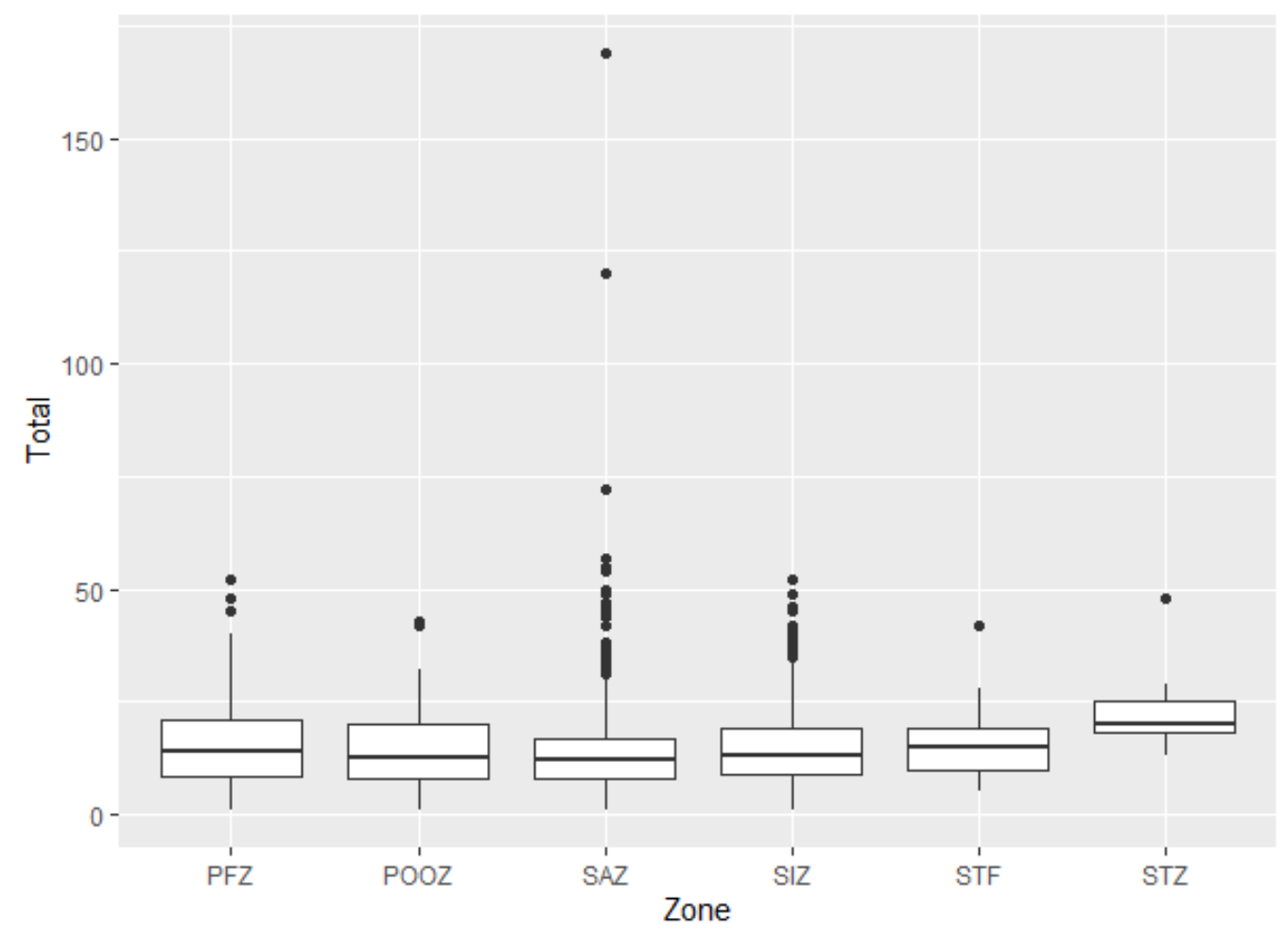

Figure 2.11: Distribution of synthetic particle abundances between five oceanographic zones (Polar Frontal Zone - PFZ, Permanent Open Ocean Zone - POOZ, Sub-Antarctic Zone - SAZ, Sea Ice Zone - SIZ, \& SubTropical Zone - STZ) and a frontal system (Sub-Tropical Front - STF), with data pooled across years, months, and transit. 


\section{Particle characteristics}

Type of particle

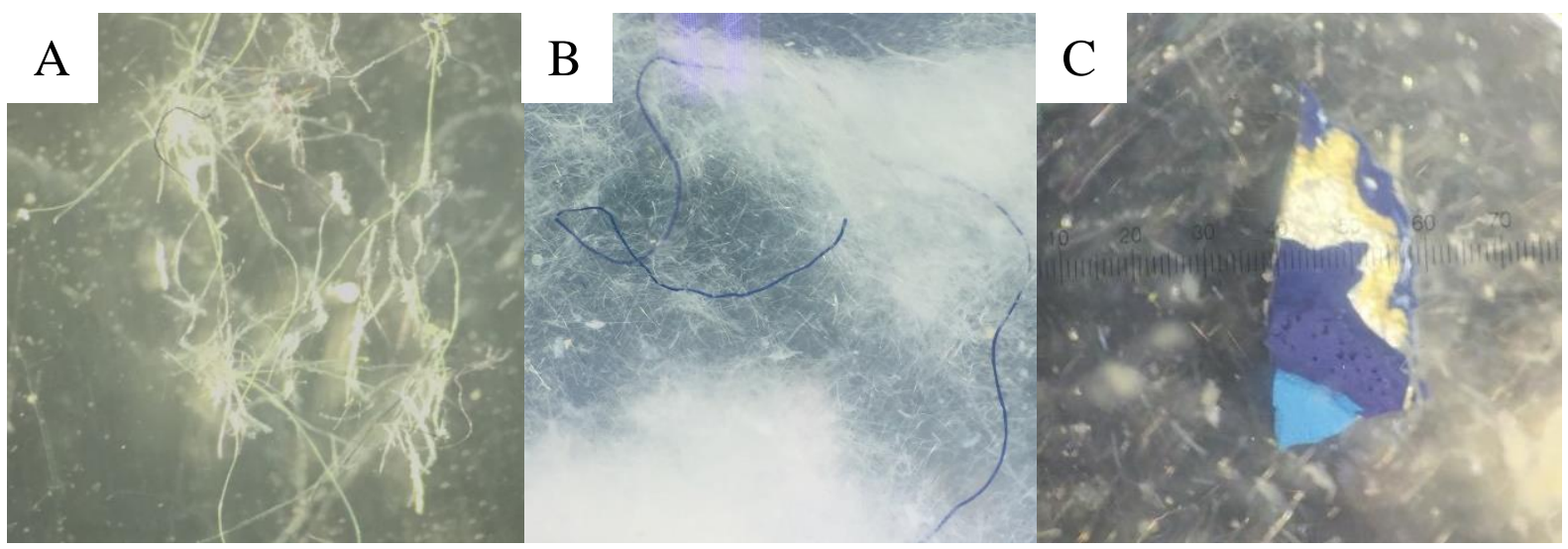

Figure 2.12: Examples of different synthetic particles found during the sample analysis conducted within this study, where A) is a large (> 2-5 mm) yellow fibre, B) is a large (>2 $-5 \mathrm{~mm})$ blue fibre, and C) is a mediumsize $(>1-2 \mathrm{~mm})$ multi-layered paint chip.

Five different types of synthetic particles were observed within the CPR surface water samples collected between 2009 - 2018, including those seen in Figure 2.12. Microfibers were the most prolific type across all years, accounting for between $90.6-99.5 \%$ of all observed microplastics (Figure 2.13). Fragments were also found throughout the span of the study, however these only accounted for between $0.8-8 \%$ of all microplastics. Synthetic particles such as foils, paint chips, and captured macroplastics (> $5 \mathrm{~mm}$ ) comprised a negligible amount of the total particles found throughout the entire study. In support of this, the percentage of each particle type (fibres, fragments, and 'other') was shown to differ significantly $\left(\mathrm{x}^{2}(16)=627.46, \mathrm{p}=<0.0001\right)$.

Table 2.6: Count data investigating the number of synthetic particles collected between New Zealand and the Ross Sea Region, using CPR tows.

\begin{tabular}{|c|c|c|c|c|c|}
\hline Year & Fibres & Fragments & Foils & $\begin{array}{c}\text { Macro } \\
(>5 \mathrm{~mm})\end{array}$ & Paint \\
\hline $2009 / 10$ & 3194 & 42 & 1 & 0 & 1 \\
\hline $2010 / 11$ & 2695 & 39 & 1 & 4 & 1 \\
\hline $2011 / 12$ & 344 & 12 & 0 & 0 & 0 \\
\hline $2012 / 13$ & 1108 & 107 & 6 & 0 & 2 \\
\hline $2013 / 14$ & 2565 & 129 & 3 & 0 & 0 \\
\hline $2014 / 15$ & 1449 & 29 & 1 & 0 & 1 \\
\hline $2015 / 16$ & 1268 & 11 & 3 & 5 & 1 \\
\hline $2016 / 17$ & 3537 & 17 & 0 & 0 & 0 \\
\hline $2017 / 18$ & 6328 & 30 & 0 & 13 & 0 \\
\hline
\end{tabular}




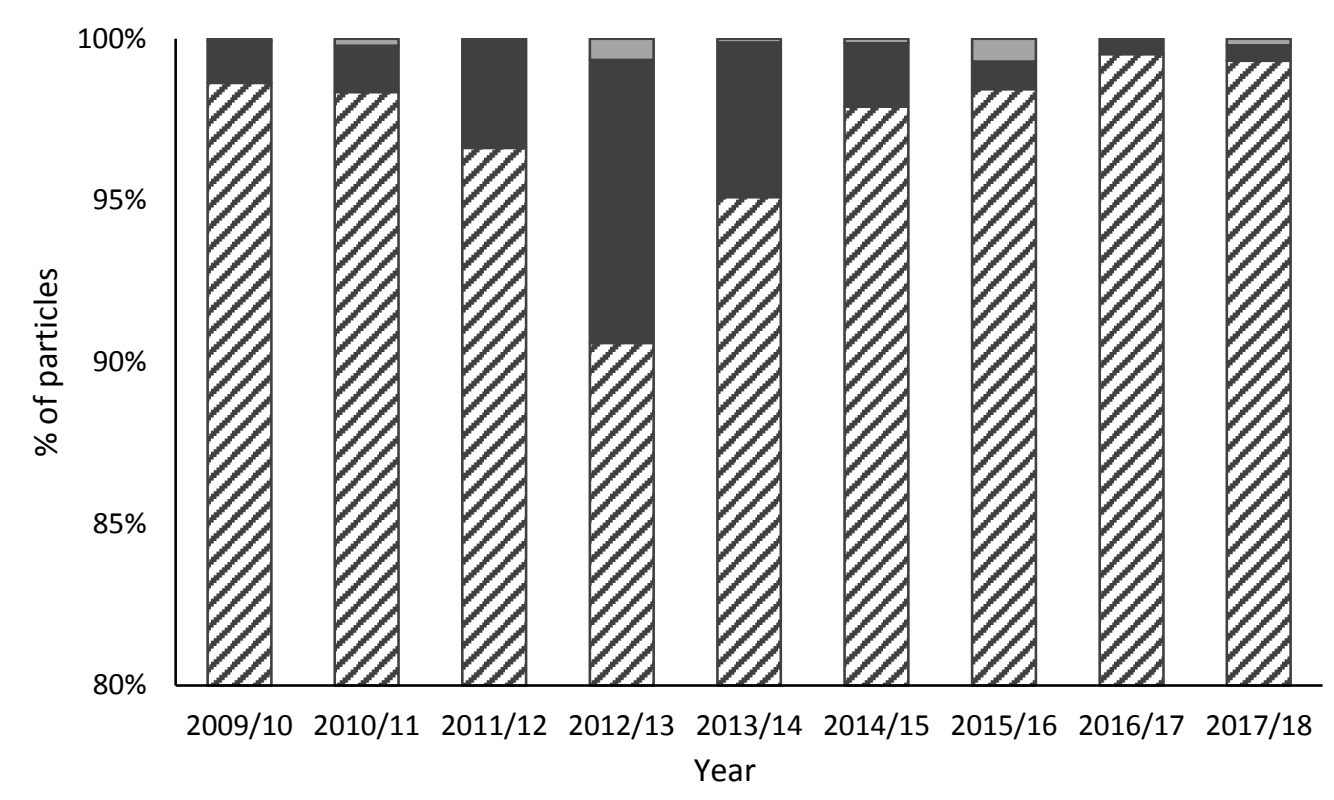

Figure 2.13: Percentages of the total count data between 2009 - 2018, for all different plastic types collected during CPR tows. Data is pooled across oceanographic zones. Striped bars represent the percentage of microfibres, black bars represent the percentage of fragments, and open bars represent the percentage of all other plastic types - foil, macroplastic, and paint chips.

Size of particles

Throughout this study, 22,913 microplastic particles were found in the surface waters between New Zealand and the Ross Sea Region (small = 6062; medium = 8697; large = 8154), excluding any macroplastic particles (Table 2.7). In the first three years of sampling, large particles were the most predominant, accounting for up to $56.7 \%$ of all microplastics. However, the CPR tows between 2013/14 - 2017/18 , the proportion of these dropped off and medium-sized particles became the most predominant size category (Figure 2.14). However, particle size categories were still found to be significantly different from one another $\left(\mathrm{x}^{2}(16)\right.$ $=1871, \mathrm{p}=<0.0001)$. 
Table 2.7: Count data investigating size distributions of synthetic particles in surface waters between New Zealand and the Ross Sea Region. Count data not inclusive of macroplastic particles $>5 \mathrm{~mm}$ in length or diameter.

\begin{tabular}{|c|c|c|c|}
\hline & $\begin{array}{c}\text { Small } \\
(<1 \mathrm{~mm})\end{array}$ & $\begin{array}{c}\text { Medium } \\
(>1-2 \mathrm{~mm})\end{array}$ & $\begin{array}{c}\text { Large } \\
(>2-5 \mathrm{~mm})\end{array}$ \\
\hline $2009-10$ & 591 & 811 & 1834 \\
\hline $2010-11$ & 566 & 645 & 1532 \\
\hline $2011-12$ & 121 & 96 & 139 \\
\hline $2012-13$ & 489 & 372 & 354 \\
\hline $2013-14$ & 860 & 973 & 861 \\
\hline $2014-15$ & 373 & 691 & 414 \\
\hline $2015-16$ & 282 & 627 & 370 \\
\hline $2016-17$ & 877 & 1545 & 1132 \\
\hline $2017-18$ & 1903 & 2937 & 1518 \\
\hline
\end{tabular}

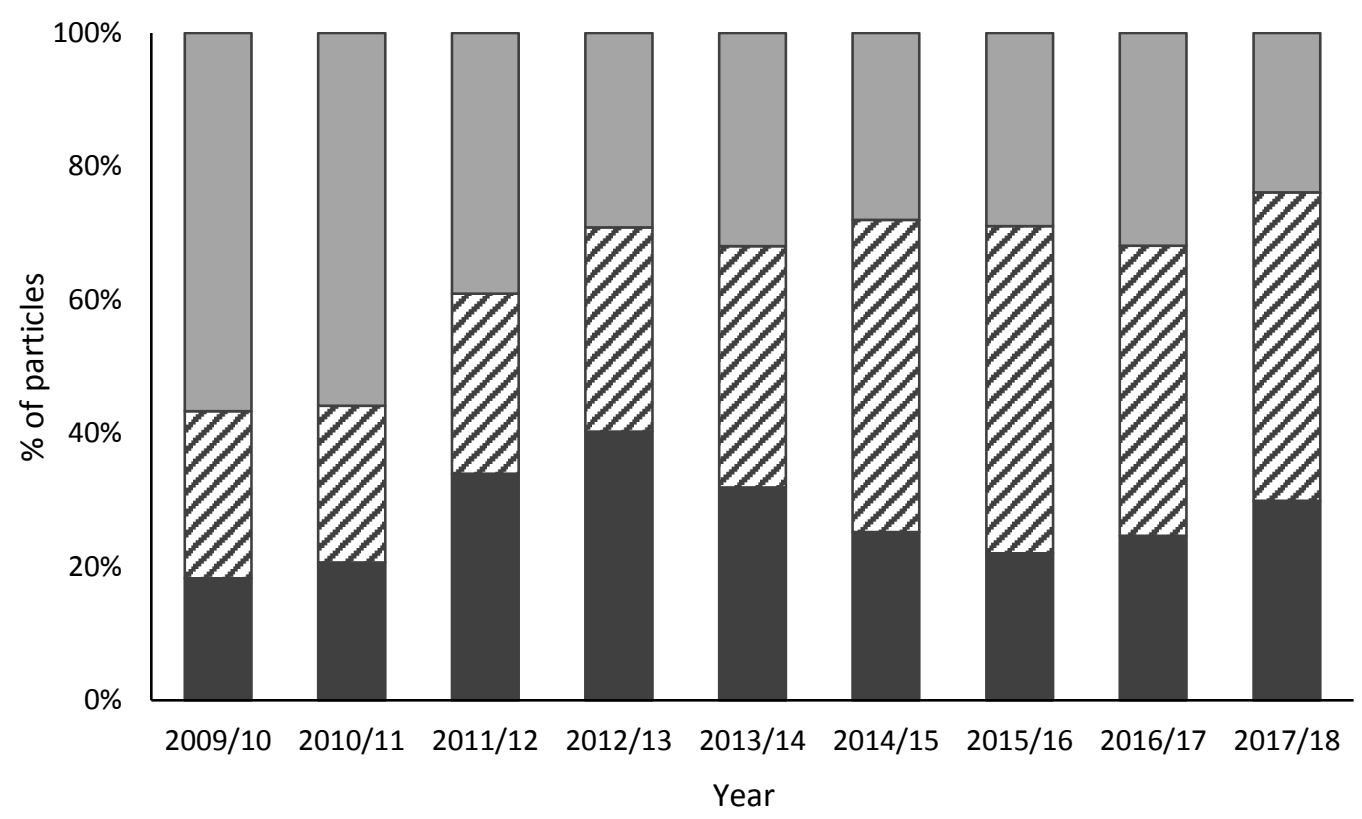

Figure 2.14 : Microplastic size distributions between $2009-2018$, expressed as a stacked percentage. Black bars represent the percentage of small particles $(<1 \mathrm{~mm})$, striped bars represent medium $(>1-2 \mathrm{~mm})$, and grey bars represent large particles ( $>2-5 \mathrm{~mm}$ ).

Colour of particles

Microplastics ranged in colour significantly throughout the surface water CPR samples, with nine different colours detected overall. Black and blue particles were the predominant colours found throughout the study (Figure 2.15), however other primary colours (red and yellow) were also highly abundant (Table 2.8). In support of this, the percentage of various colours analysed (black, blue, red, yellow, and 'other') was found to be significantly different ( $\mathrm{x}^{2}$ (32) $=1298.5, \mathrm{p}=<0.0001)$. 
Table 2.8: Count data investigating colour distributions of synthetic particles in surface waters between New Zealand and the Ross Sea Region, between 2009 - 2018.

\begin{tabular}{|c|c|c|c|c|c|c|c|c|c|}
\hline & Black & Blue & Colourless & Green & Orange & Purple & Red & White & Yellow \\
\hline $2009 / 10$ & 1272 & 907 & 0 & 42 & 116 & 112 & 351 & 26 & 408 \\
\hline $2010 / 11$ & 1081 & 764 & 75 & 28 & 46 & 108 & 356 & 14 & 260 \\
\hline $2011 / 12$ & 149 & 131 & 0 & 10 & 9 & 3 & 42 & 5 & 7 \\
\hline $2012 / 13$ & 502 & 450 & 4 & 24 & 26 & 46 & 146 & 11 & 7 \\
\hline $2013 / 14$ & 1101 & 626 & 8 & 36 & 72 & 80 & 474 & 29 & 268 \\
\hline $2014 / 15$ & 632 & 366 & 2 & 9 & 25 & 76 & 262 & 9 & 98 \\
\hline $2015 / 16$ & 511 & 341 & 3 & 24 & 16 & 13 & 139 & 2 & 236 \\
\hline $2016 / 17$ & 1007 & 866 & 0 & 40 & 40 & 45 & 632 & 16 & 908 \\
\hline $2017 / 18$ & 2460 & 1701 & 0 & 58 & 43 & 67 & 1111 & 42 & 880 \\
\hline
\end{tabular}

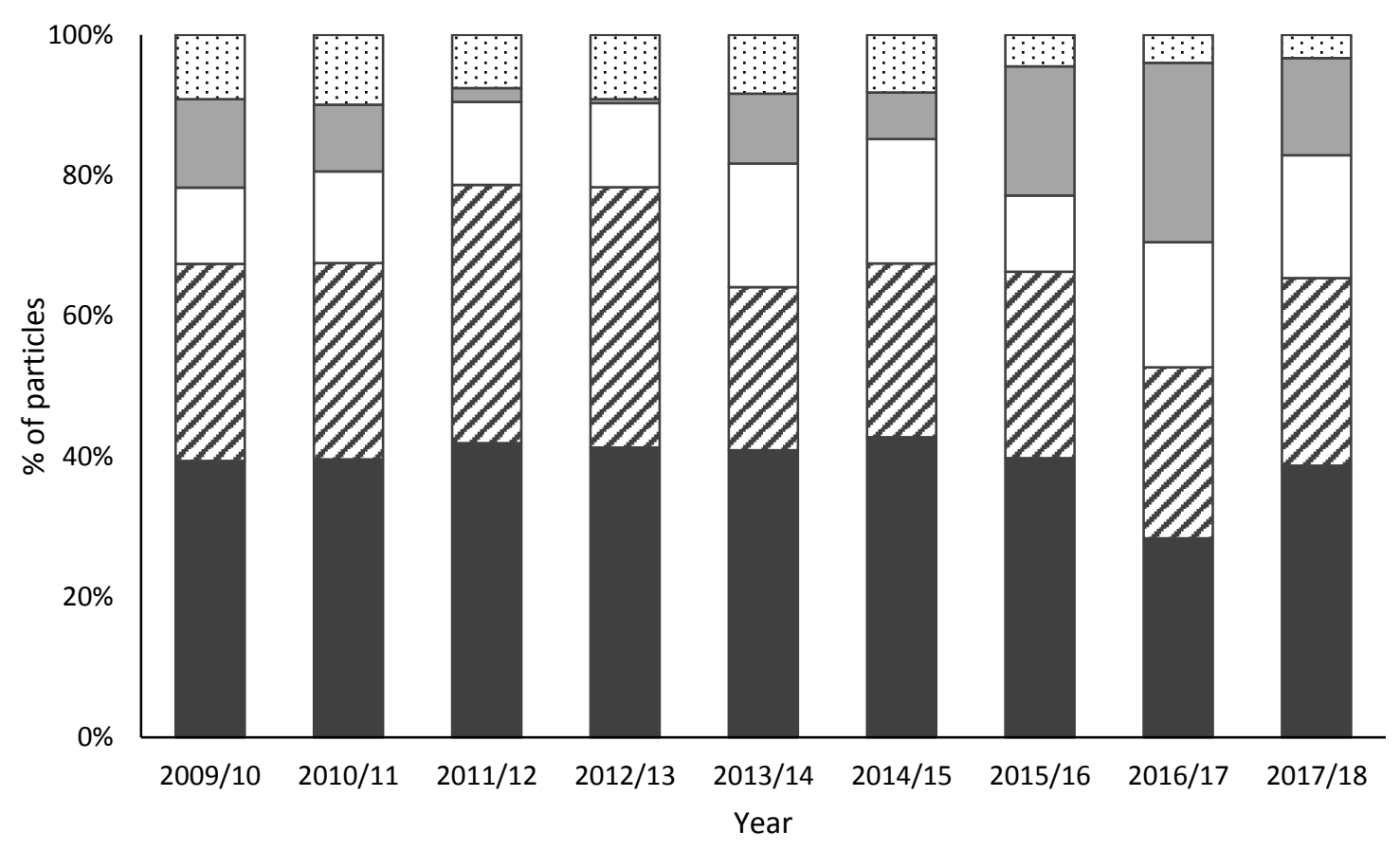

Figure 2.15: Microplastic colour distributions between 2009 - 2018, expressed as stacked percentages of the total count data for each year. Black bars represent the percentage of black particles, striped bars represent blue particles, open bars represent red particles, grey bars represent yellow particles, and dotted bars represent the total percentage of all other colours (colourless, green, orange, pink, purple, and white). 


\section{Discussion}

This study provided no evidence for consistent temporal or spatial patterns of microplastic occurrence between New Zealand and the Ross Sea Region of Antarctica, across the 9-year dataset. There was, however, a large amount of variation between years and zones, indicating that microplastic abundance and distribution is highly dynamic in these surface waters. In contrast to the initial hypothesis, the microplastic load within the sub-surface waters did not appear to increase with proximity to New Zealand, nor did the distribution change significantly across this $22,000 \mathrm{~km}$ stretch of the Southern Ocean. Despite microplastic levels not showing a clear increasing or decreasing temporal trend across the entire 9-year sample period, the mean abundance was highly dynamic and particularly for the tows collected during 2009/10 and 2012/13. The austral summer of 2009/10 contained up to double the average amount of microplastics compared to some other years, while those collected during the 2012/13 period had the smallest microplastic pollutant load overall. However, the morphotype most commonly found over the entire study was microfibres, which supports the original hypothesis. The variation in both spatial and temporal components of this study are likely due to a combination of factors, particularly environmental drivers, as well as sampling error.

Despite a lack of consistency in spatial or temporal distributions of microplastic between 2009/10 - 2017/18, the morphotypes, size distributions, and colours of particles found throughout the sub-surface waters of the Southern Ocean was quite consistent. Black and blue coloured particles were of highest abundance throughout the study, whilst size of particles favoured the medium size distribution $(>1-2 \mathrm{~mm}$ ) in earlier surveys, then large microplastics (>2-5 mm) in later years. This could be due to sampling methodology, namely the aperture of the CPR mesh size, or alternatively, particles $>1-5 \mathrm{~mm}$ in length/diameter may simply be more prevalent in these waters. However, throughout this entire study, microfibres were by far the most prevalent morphotype of synthetic particle present, occupying between $90.6 \%-99.5 \%$ of all synthetic particles collected each year. These results are relatively similar to the particle characteristics reported in other sea surface studies, particularly as microfibres are thought to comprise up to $90 \%$ of the global marine microplastic floating debris (Barrows et al., 2018; Woods et al., 2018).

From 2017 onwards, there has been a considerable rise in the number of studies looking at marine plastic pollution in the Southern Hemisphere, particularly around the Antarctic continent. This surge in publications is likely due to the realisation that knowledge of the 
abundance and distribution of marine plastic debris - particularly microplastics - had previously been limited to the Northern Hemisphere, thus creating a divide in the global knowledge of this pollutant. The recent research largely encompasses studies that have been confined to certain regions around the continent, where they have examined localised surface waters (Cincinelli et al., 2017; Lacerda et al., 2019), sediments (Munari et al., 2017; Reed et al., 2018), or the abundance and impacts of microplastics upon a single species (Dawson et al., 2018; Bessa et al., 2019). All of these examples have provided evidence for the presence of microplastics, however the estimated abundance differs significantly, largely as a result of the various sampling and analyses used. Inclusive of all samples between 2009/10 - 2017/18, regardless of whether they contained synthetic particles or not, there was an average of 1.99 particles $\mathrm{km}^{-1}$, of which ranged between $0.33-4.84$ particles $\mathrm{km}^{-1}$. As a concentration, this load was extremely low, averaging $1.99 \mathrm{e}-6$ particles per $\mathrm{m}^{3}$. In comparison, a paper examining near-shore and off-shore microplastic abundances in the Ross Sea reported between $0.0032-1.18$ particles $\mathrm{m}^{-3}$ through the use of a saltwater intake pump system (Cincinelli et al., 2017), whilst an alternative study using manta nets to conduct surface trawls around the Antarctic Peninsula reported average concentrations of 0.008 particles $\mathrm{m}^{-3}$, although this was inclusive of both micro- and mesoplastics ( $>5-20 \mathrm{~mm}$ ) (Lacerda et al., 2019).

A lack of cohesive sampling methodology in the field of microplastic research provides another source of variation between results of different studies, making it extremely difficult to compare between studies in similar oceanographic regions. For the examination of surface waters, three different methods are commonly used to execute transects on or just below the sea surface - neuston nets, grab systems, and Continuous Plankton Recorders - all of which have different apertures, mesh sizes, and collection techniques. Most techniques used for sampling microplastics on the sea surface or sub-surface have been adapted from their original use of collecting plankton (Robinson et al., 2014; Barrows et al., 2017; Green et al., 2018). Consequently, multiple factors such as mesh size and contamination influence the accuracy of the results gathered from each of these methods. Mesh size, for example, varies significantly across the literature, with many tows using a $333 \mu \mathrm{m}$ mesh (Miller et al., 2017), whilst CPRs use a $270 \mu \mathrm{m}$ mesh (Robinson et al., 2014) and others may use a different size altogether (Miller et al., 2017; Green et al., 2018). The size of the mesh often impacts the lower size limit you can collect, which is particularly unfavourable for examining the relative abundance of microplastics $<1 \mathrm{~mm}$. On the other hand, neuston nets and CPRs have the 
advantage of sampling over large areas compared to grab systems, which are reliant upon sampling from the shore or a boat and collect small volumes of water (Barrows et ai., 2017). In saying that, further variability arises due to neuston nets conducting transects right at the sea surface, while CPRs are towed $\sim 10 \mathrm{~m}$ beneath the surface. These examples are just some of the ways that the different methods of sea surface sampling differ, however they all contribute to a high variance in results and therefore a limited ability to effectively compare results between samples collected using different methodologies.

\section{Temporal variation}

This study indicates that temporal changes to surface water microplastic abundance are likely driven by environmental factors which are extremely variable. As opposed to what was hypothesized, microplastic abundance did not increase between the austral summer of 2009/10 and 2017/18, despite global production of plastic materials continuing to grow (PlasticsEurope, 2019). One possibility is that this yearly variation is related to El Niño and La Niña events, as the two years with the highest average microplastic load (2009/10 \& 2015/16) are also years that have experienced significant El Niño events (Welhouse et al., 2016; Ministry for the Environment, 2017). On the other hand, La Niña events appear to correlate with years that have a more moderate average number of microplastics $(11-14$ particles per $5 \mathrm{~nm}$ transect) and the lowest average microplastic load, which occurred in 2012/13, correlates to a neutral year with no obvious La Niña or El Niño trade winds. The El Niño-Southern Oscillation (ENSO) is a significant climate cycle that operates on decadal and sub-decadal periods (Welhouse et al., 2016), with primary effects felt across the Pacific Ocean (Turner, 2004). However, effects of the phenomenon have been documented in many other regions of the globe, including Antarctica. El Niño events are thought to account for an estimated $31 \%$ of the altered sea surface temperature conditions, along with higher pressure areas in the West Antarctic (Welhouse et al., 2016). La Niña events, on the other hand, are reportedly associated with negative temperature anomalies around the Ross Sea (Welhouse et $a l ., 2016)$. In addition to changes in temperature, El Niño and La Niña events can alter other aspects of the Antarctic climate, including winds and ocean currents. As reported by Kim \& Orsi (2014), the ACC fronts tend to respond to both ENSO and SAM (the Southern Hemisphere annular mode), with localised variations in features such as surface wave height - possibly resulting in increased mixing of synthetic particles. Furthermore, ENSO and SAM variation has been widely documented to result in significant oceanographic changes throughout the ACC system, with positive SAM and La Niño events driving polar lows and 
forcing upwelling, whilst El Niño and negative SAM causing the opposite; fewer storms and a reduction in upwelling (Marshall et al., 2004; Yuan, 2004; Martinson, 2012). Wide-scale alterations such as these are likely to have some impact upon the circulation of microplastics throughout the Southern Ocean, with rates of deposition and typical patterns of dispersal likely interrupted. Interestingly, anomalies in ENSO events throughout this sampling period seem to correlate with the years that experienced the highest and lowest microplastic loads in the sub-surface waters, respectively. These climate events are not likely to be the only environmental drivers of yearly variation in microplastic abundance, but they do indicate that further investigations into similar large-scale oceanic circulation trends are warranted.

As hypothesized, monthly variation between average microplastic occurrence was minimal. This was to be expected, as sampling could only occur during the Austral Summer months of each year - primarily between November and February. To gain a more complete perspective of the monthly variation for surface water microplastic abundance, future studies would ideally need to examine the abundance across all 12 months. This would provide information on whether there are any significant temporal differences in microplastic abundance on a smaller scale. So far, numerous polar studies in the Arctic and Antarctic have illustrated the ability of sea ice to take up high concentrations of microplastics during the winter months (Obbard, et al., 2014; Peeken et al., 2018; Geilfus et al., 2019). In addition, microplastic load is likely to change throughout the year with the contributing factor of winter storms, and the resultant deepening of the surface mixing layer (Nicholson et al., 2016). Although studies have not yet focussed on the change in microplastic abundance within Antarctic waters throughout all 12 months - likely due to the logistical difficulties in carrying out sea-based research during the Antarctic winter and the high frequency of winter storms - it is a reasonable assumption that microplastic loads in Antarctic waters may experience high levels of variability throughout the year.

\section{Spatial variation}

In a similar vein to the temporal variation observed within this study, there are no clear increasing or decreasing trends regarding the levels of microplastic abundance between the different oceanographic zones. Instead, microplastic abundance was found to be relatively similar in its distribution across most of the oceanographic zones, which differed to the results reported in Suaria et al. (2020). This study collected 40 neuston net samples from the surface waters of Antarctica, during a circumnavigation of the continent. Although the primary focus was not to analyse the differences in microplastics between various latitudinal 
zones, their results suggested that microplastic abundance was an order of magnitude lower in latitudinal zones below the Sub-Tropical Front (STF), where this front acts like a boundary. The results from this thesis directly contradict this conclusion, as the long, continuous transects executed between oceanographic zones detected no significant difference in abundance immediately above or below the STF. This contrasts with the original hypothesis, indicating that proximity to an urbanised nation such as New Zealand does not have a strong impact upon microplastic distribution. Several factors may be driving these results, particularly environmental variables such as oceanic currents. The land mass of Antarctica may be geographically isolated from all other continents, but the Antarctic Circumpolar Current (ACC) connects the Southern Ocean with all other major oceanic systems. Consequently, it is likely that the currents which circulate around the continent also bring synthetic particles to the area, as microplastics are typically buoyant with the ability to undergo long periods of dispersal (Obbard, 2018). Studies such as Obbard (2018) suggest that the incidence of man-made microplastics in polar waters is primarily the result of long-range oceanic transport through global current systems, waves, and wind, as opposed to local inputs from production and human usage. This long-range transport to remote polar regions generally enhances the occurrence of microparticles instead of larger debris, as these smaller items are thought to be submerged within the sub-surface oceanic layer during transport, consequently taking longer to reach the polar environments, simultaneously being subjected to fragmentation and degradation as well (Lebreton \& Borrero, 2013; Desforges et al., 2014; Obbard, 2018). Therefore, the Antarctic Circumpolar Current not only transports microplastics to the Southern Ocean but is also responsible for mixing of these synthetic particles through the three main oceanic fronts, which are further described in Orsi et al. (1995) and Solokov \& Rintoul (2009).

In conjunction with occupying numerous oceanographic zones, the Southern Ocean provides a habitat for a unique ecosystem, with many endemic species that have adapted to the harsh environment. Overall, this study provides evidence for microplastics occurring within the surface waters of every zone between New Zealand and the Ross Sea. Consequently, species that carry out functional roles within the sub-surface of the water column are at a higher risk of direct interactions with these synthetic particles, particularly if they feed within this part of the water column and are filter feeders. Euphausia Superba (Antarctic Krill) are one such species, notable in the Southern Ocean for occupying a keystone role in the ecosystem, comprising the main dietary component of higher trophic levels such as whales and penguins, 
for example (Laws, 1977; Bernard \& Steinberg, 2013). This species has an alternating seasonal feeding regime, primarily consuming phytoplankton in the summer months and a range of zooplankton and copepods come winter (Price et al., 1988; Bernard \& Steinberg, 2013). However, in conjunction with their prey items, E. superba have been shown to ingest microplastic particles from the water column, then expel most of these particles as smaller nanoplastics $(<1 \mu \mathrm{m})$ (Dawson et al., 2018). Since Antarctic krill are an integral prey item for many other Antarctic marine species, the uptake of synthetic particles increases the likelihood of microplastics being passed up the food web. On the other hand, the excretion of plastic nanoparticles may provide this pollutant with new ways to enter the food web, such as ingestion by zooplankton and the ability to cross physical barriers (Dawson et al., 2018). In addition, the current literature demonstrates that the sea surface is not the end point for microplastics in the marine environment; instead they drift down to the benthos (Munari et al., 2017; Reed et al., 2018), interact with biota (Bessa et al., 2019; Sfriso et al., 2020), or in the case of polar regions, also incorporate into sea ice (Obbard et al., 2014; Kelly et al., 2020). Consequently, the presence of microplastics within the sea surface indicates that it is likely to be found elsewhere in the Antarctic marine environment, with the possibility for wide-reaching implications upon the entirety of the Southern Ocean's ecosystem.

\section{Conclusion}

Although definitive trends in microplastic load were not detected in this long-term temporal and spatial study between New Zealand waters and the Ross Sea Region of New Zealand, these results have illustrated that microplastics are, indeed, present in these remote waters likely as a result of long-range oceanic transport. The quantity of surface water microplastics is shown to be lower than that in other regions of the world, but synthetic particles were found throughout all sampled years (2009/10 - 2017/18), as well as in every oceanographic zone between New Zealand and the Ross Sea Region. This is the first multi-year microplastic study to have been carried out in the Southern Hemisphere, and the first in this geographical region to examine latitudinal spatial distribution of the synthetic particles to this extent.

Despite the need for further research to support these findings using FTIR spectroscopy, this study has provided an essential baseline for understanding the occurrence and dispersal of floating microplastic debris in a remote area of the globe. 


\section{Temporal surveys of microplastic load in sediment, surface water, and mussel (Mytilus galloprovincialis) tissue in Wellington Harbour}

\section{Abstract}

This study aimed to take a multi-pronged approach to microplastic assessment in Wellington Harbour, through undertaking temporal and fine-scale spatial microplastic surveys on the sea surface, beach sediments, and within the tissues of Mytilus galloprovincialis mussels.

A series of baseline surveys were conducted every three months between February 2019 and February 2020. Beach sediments and M. galloprovincialis individuals were each collected from three sites around Wellington Harbour, with collections increasing to weekly surveys from August 2019, to assess temporal variation on a finer scale. Sea surface tows were conducted once every three months throughout the year, at two different locations within the harbour. The total microplastic abundance in each sample was recorded, along with size, colour, and morphotype of the synthetic particles.

Mussel tissues contained an average of $0.30 \pm 0.04$ particles $\mathrm{g}^{-1}$ (wet weight) and were less temporally and spatially variable than beach sediments, which had an average of $124.9 \pm 35.7$ particles $\mathrm{kg}^{-1}$ (wet weight). Spatial variation was observed throughout beach sediments, although differences among sites did not follow a consistent pattern throughout the span of the study. Surface water microplastic load appeared to correlate with the temporal peaks in mussel tissue, indicating a possible relationship between levels in the environment and the ability for transferral to coastal marine organisms. Microfibres were the predominant particle morphotype found within every source, whilst microplastic size was distributed far more evenly throughout the three categories. These responses suggest that microplastics are, indeed, a globally pervasive pollutant which infiltrate numerous marine habitats and interact with organisms. 


\section{Introduction}

In New Zealand, the ocean is central to daily life, with many individuals earning a living from it, as well as participating in countless recreational activities around the coastline. With an estimated 18,000 km of coastline in various forms that include open coast, harbours, estuaries, and lagoons (Hart \& Bryan, 2008), New Zealand's society is unequivocally linked to, and surrounded by, the marine environment, and the coastal ecosystem is the primary interface between marine and terrestrial habitats. This results in the ecosystem being subject to many different processes, and consequently providing a pathway for pollutants like plastics to interchange between land and oceanic environments.

Research on microplastic load in New Zealand, including its abundance, distribution, and effects upon marine and intertidal species, is limited. Although some of the very first papers to ever document microplastic occurrence were carried out in New Zealand during the 1970's (Gregory, 1977; Gregory, 1978), little progress has been made since then. These initial studies surveyed a range of beaches around the New Zealand coastline, particularly within the Auckland, Wellington, and Canterbury regions, and provided some of the first direct evidence for microplastic contamination in the marine environment. Almost 40 years later, two more publications focussing on the occurrence of microplastics around New Zealand's coastlines. Clunies-Ross et al. (2016) was able to quantify both primary and secondary sources of microplastic pollution within Canterbury, whilst Bridson et al. (2020) focussed upon the microplastic load on Auckland beaches. All four of these New Zealand microplastic research examples published to date have placed a primary focus on beach sediments, as opposed to the abundance within other habitats or marine biota. Beaches are considered to be sinks for oceanic plastic pollution, particularly microplastics, as onshore winds push the buoyant particles onto the shore, dropping them at the high tide line (Moore, 2008; CluniesRoss et al., 2016). Consequently, the top layers of beach sediment provide a valuable insight into the abundance of microplastic particles that inhabit the surrounding waters. Microplastics present a unique problem once on the shoreline, however, as unlike macroplastic, they are often difficult to distinguish in size from sand grains and therefore become easily incorporated into the beach sediments (Young \& Elliott, 2016) (Figure 3.1). 

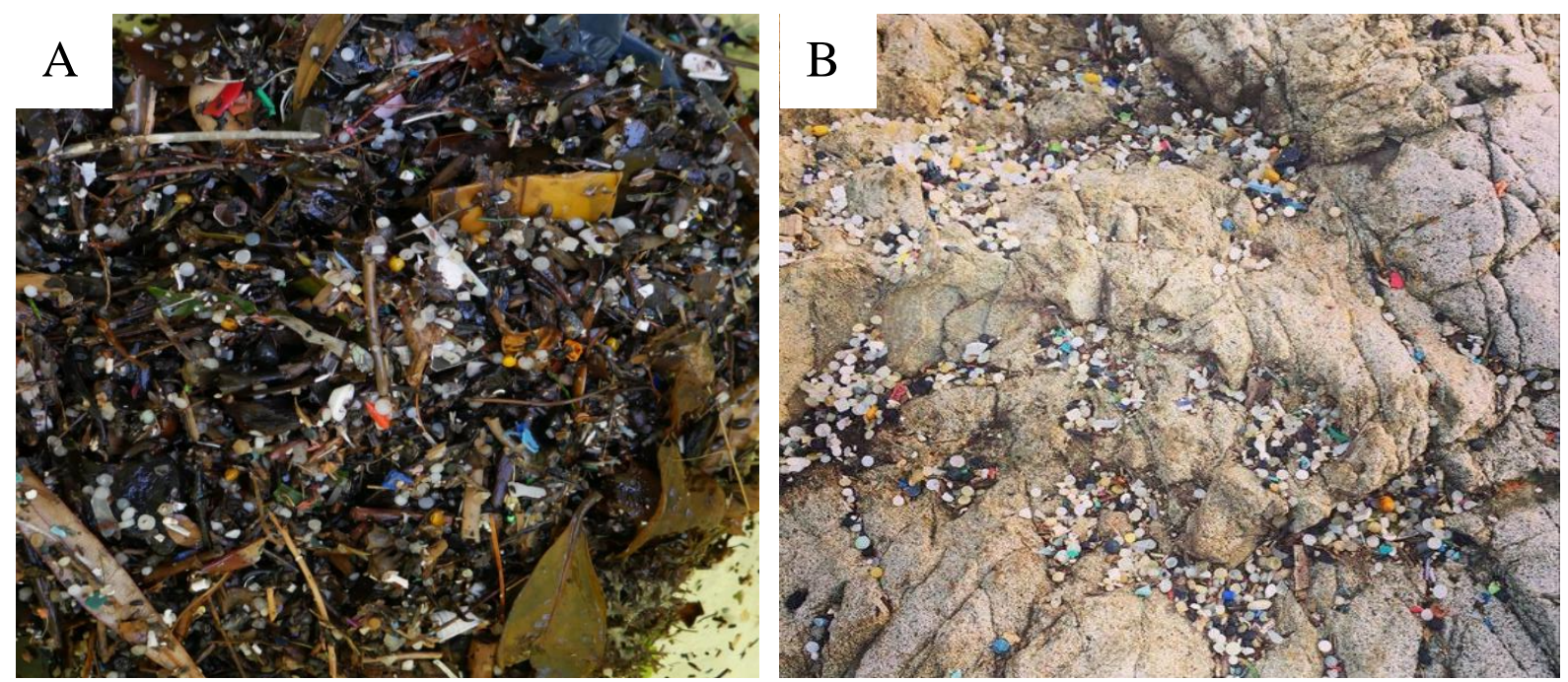

Figure 3.1: Microplastics found on Evan's Bay Beach, Wellington, where A) depicts the difficulty of extracting synthetic particles from organic matter and B) demonstrates the occurrence of microplastics in situ. Image credit: A) Sea Shepherd New Zealand, B) Caitlyn Shannon.

Consequently, although it is still limited, our knowledge of microplastics on beaches far surpasses the current understanding of surrounding environments like sea surface waters or the pollutant load within coastal marine organisms. This extension to other habitats, along with an expansion of knowledge throughout various regions around the country, is integral if comparisons to the global microplastic load are to be made. Presently, there is only one paper which examines the occurrence of microplastics within New Zealand coastal organisms. Webb et al. (2019) reported an abundance of between 0 - 1.5 particles per individual within the Perna canaliculus (Green-lipped mussel) species, around the coastline of New Zealand. With exception to this paper, the only other knowledge of microplastic occurrence and impacts of microplastics upon our coastal environment has examined the freshwater inputs from urban rivers and streams (Dikareva \& Simon, 2019; Mora-Teddy \& Matthaei, 2020). With such a limited grasp upon microplastic abundance, distribution, and its impacts on the New Zealand ecosystem, comparisons to the global pollutant load cannot be made at this time.

Globally, surface waters are commonly associated with plastic debris of all size classes. Estimates of floating plastic pollution provide a valuable insight to the levels of plastic pollution permeating into other marine environments and biota, as the buoyancy of the pollutant means it often circulates at the surface of the water column before undergoing vertical mixing (Ye \& Andrady, 1991; Morishige et al., 2007; Maes et al., 2017). Research examining the extent of floating plastic debris - both macro and micro - has been carried out for decades using many different sampling methodologies. One recent study has even evaluated the presence of floating plastic debris over the span of 60 years, to investigate 
temporal trends over an extended period (Ostle et al., 2019). However, like most research on marine plastic pollution, most of the work has been typically carried out in the Northern Hemisphere. Studies examining abundance and distribution on the sea surface in the Southern Hemisphere are limited (Avio et al., 2017); for example there have been a few studies carried out in South Africa (Ryan, 1988; Nel \& Froneman, 2015), Australia (Reisser et al., 2013; Hall et al., 2015), and Brazil (Lima et al., 2014), as well as the South Pacific subtropical gyre (Eriksen et al., 2013). Yet, these studies are integral to forming a more comprehensive understanding of how microplastics move throughout the oceans.

The occurrence of microplastics within marine organisms is another key facet of plastic pollution research. In contrast to the identification of microplastics in beach sediments and throughout the sea surface, research upon organisms elevates the field to a deeper level of understanding. Such studies promote a widening of knowledge from the rudimentary understanding that this pollutant is found within our marine environments, to an awareness that it is also infiltrating and impacting biological communities, and therefore conceivably also interacting with humans. The current global estimates of microplastics in the marine environment certainly pose a significant problem in themselves, as the high volume likely increases the possible interactions they have with the surrounding ecosystem for many years to come, but these issues are exacerbated with the current knowledge that the particles are able to enter the food web and cause physiological, behavioural, and structural difficulties for various marine organisms including invertebrates (Besseling et al., 2013; Wright et al., 2013; Galloway \& Lewis, 2016) and fish (Critchell \& Hoogenboom, 2018).

Bivalves such as mussels are useful bioindicators for assessing microplastic occurrence in coastal marine ecosystems, as well as indicating the level of transfer between the surrounding environment and marine biota. In addition, bivalves are filter-feeders with a global distribution (Chae \& An, 2020). Suspension and filter-feeders are vulnerable to microplastic ingestion, as they continually filter larger volumes of water and are generally limited in their ability to selectively ingest particles (Kinjo et al., 2019). Filter-feeders also tend to feed upon organisms that occupy a similar size range to microplastics, making it even more difficult to discriminate between food and synthetic particles. In fact, one study has demonstrated that when mussels are simultaneously exposed to alga and microplastics, the organisms are more likely to retain the plastic particles for longer before excreting them, compared to when they were exposed to microplastic without the presence of alga (Chae \& An, 2020). Consequently, 
filter feeders like mussels may be more susceptible to retaining microplastics for longer periods when there is also a high volume of food sources in the surrounding environment.

In New Zealand, three mussel species occupy the intertidal and shallow subtidal zones. The ribbed mussel (Aulacomya maoriana), the green-lipped mussel (Perna canaliculus), and the Mediterranean blue mussel (Mytilus galloprovincialis) co-exist in many different hard-shore environments along New Zealand's coastline, where they have similar ecological functions as primary consumers and sessile filter-feeders (Gardner, 2002). The New Zealand coastline provides an interface between the marine and terrestrial environment, so is often highly urbanised. Consequently, the coastal ecosystem experiences significant pollution from sources such as plastic, heavy metals, and sedimentation - to name a few (Vikas \& Dwarakish, 2015). Coastal-dwelling species such as mussels are subjected to these pollutants on a regular basis, thus placed under significant stress and the possibility of trophic transfer throughout the food web. Mytilus galloprovincialis mussels are a particularly good model species for the investigation of microplastic occurrence, as they have a global distribution, meaning that there are comparisons that can be made from other studies. Additionally, as Li et al. (2019) states, mussels are likely to be a significant source of microplastic transferral to humans, as they are a common seafood that is typically consumed whole.

Temporal and spatial studies allow us to better elucidate the full extent of microplastic load in the marine environment, however currently, studies that consider the impacts of space and time are not commonplace. A study conducted by Baechler et al. (2020) has reported a difference in microplastic abundance within Pacific oysters (Crassostrea gigas) and Pacific razor clams (Siliqua patula) across different seasons, at different sites across the Oregon coastline. Consequently, we can see that attempts are being made to characterise spatial and temporal trends in microplastic load within the Northern Hemisphere, so it is valuable to undertake similar studies throughout coastal environments in the Southern Hemisphere enabling comparisons to be made for future mitigation efforts.

Wellington Harbour is a semi-enclosed harbour composed of a roughly circular shape at the southern-most tip of the North Island, New Zealand (Kröger et al., 2006). It has a total area of approximately $85 \mathrm{~km}^{2}$ (Booth, 1975) and a benthos made up of soft sediment, particularly in the deeper parts of the harbour (Van der Linden, 1967). Towards the harbour entrance and around nearshore areas, however, the sediment layer is reported to be coarser (Carter, 1977; Kröger et al., 2006). A relatively shallow harbour, the average depth is $14 \mathrm{~m}$, but it reaches 
32 m South of Matiu-Somes Island (Heath, 1977; Kröger et al., 2006) and is considered wellmixed (Kröger et al., 2006). Its main source of fresh water is the Hutt River, which itself is subject to relatively high levels of pollution of various kinds (Booth, 1975), including inputs of plastic pollution (Mora-Teddy \& Matthaei, 2020). As a heavily urbanised harbour with significant man-made alterations, it is likely that there are high levels of microplastic pollution in all aspects of the habitat - whether that be the sea surface, beach sediments, or in the tissues of coastal organisms that inhabit Wellington Harbour.

This study aimed to provide the first quantitative baseline survey of microplastic debris in Wellington Harbour, using a multi-pronged approach. An emphasis was placed upon collecting data from multiple sources, including surface water, the shoreline, and the tissues of Mytilus galloprovincialis, for the purpose of addressing the following questions: does larger-scale (3-monthly) and shorter-scale (weekly) temporal variation play a role in determining microplastic abundance within Wellington Harbour? Do all three sources show coherent patterns of microplastic abundance and distribution within the harbour? Finally, is the level of microplastic pollution found in Wellington's surface waters, beaches, and mussels similar to abundances found elsewhere in New Zealand and the Southern Hemisphere? 


\section{Methods}

\section{Sample collection}

Samples were collected between the $7^{\text {th }}$ of February 2019 and the $15^{\text {th }}$ of February 2020, from a total of three beach sites, three mussel collection sites, and two surface water tow sites. Samples were collected every three months for a year, with shoreline and mussel surveys occurring in February, May, August, and November, while surface water tows occurred in March, June, September, and December. For the first two sediment and mussel collections (February \& May 2019), only one sampling event took place at each site per month. To better elucidate variability over shorter time scales, samples were collected once a week for three weeks at each beach and mussel collection site in August (2019), November (2019), and February (2020). During all field collections, non-synthetic clothing was worn, so to minimise contamination.

Beach sampling

Beach samples were collected during low tide from Oriental Bay, Balaena Bay, and Seatoun Beach (Figure 3.2). Three replicate samples were collected at what was visually determined as the most recent high tide line, which is known to be the area on a shoreline to accumulate the highest amount of plastic debris (Hidalgo-Ruz et al., 2012). To ensure sampling was unbiased, samples were taken at a random distance apart. This was determined by throwing a sediment corer (10 cm diameter) and collecting sediment from the point on the high tide line where it landed. The corer was marked with centimetre notches, and the first $5 \mathrm{~cm}$ of sediment were collected. The total sediment volume collected for each sample was $\sim 400 \mathrm{~cm}^{3}$ $\left(V=\pi 5^{2} 5\right)$. Samples were returned to the laboratory for analysis.

\section{Mussel sampling}

Individual mussels (Mytilus galloprovincialis) were collected at low tide from rocky substrata at three sites around the Wellington Harbour, all with high mussel abundance; Oriental Bay, Kau Point, and Scorching Bay (Figure 3.2). At each location, 5 mussels with a shell length of $\geq 30 \mathrm{~mm}$ (measured with calipers to the nearest $0.1 \mathrm{~mm}$ ) were collected from the substrate and placed in a small bag, before being returned to the laboratory for processing.

\section{Surface water sampling}

Small boats belonging to the Victoria University Coastal Ecology Laboratory (VUCEL) were used to collect plankton along two $200 \mathrm{~m}$ long transects: one from the South-West of MatiuSomes Island (S $41^{\circ} 15, \mathrm{E} 174^{\circ} 51$ ), in the middle of Wellington Harbour, and one from the mouth of Evans Bay (S $41^{\circ} 17 \mathrm{E} \mathrm{174}{ }^{\circ} 49$ ) (Figure 3.2). The vessel cruised at a speed of $\sim 5$ 
knots during the collection, while a neuston net was towed behind it. Seawater was filtered through a $250 \mu \mathrm{m}$ mesh collecting sieve, with organic and inorganic material collected in a collecting tube. After the transect had been completed, the material in the collecting tube was transferred into a bucket and the tube was rinsed to collect all organisms and particles. Samples were then taken back to VUCEL for further filtering and laboratory analysis. The tows were carried out using a neuston net, which is traditionally used to capture plankton, but also commonly used for obtaining surface water microplastics (Barrows et al., 2017; Green et al., 2018). Due to logistical limitations, only one transect was carried out at each of the two sites every three months - these occurred on the same day. To minimise contamination between the two sites, the net and collecting mesh were both rinsed with fresh water before the commencement of the tow at the second site (Löder \& Gerdts, 2015). 


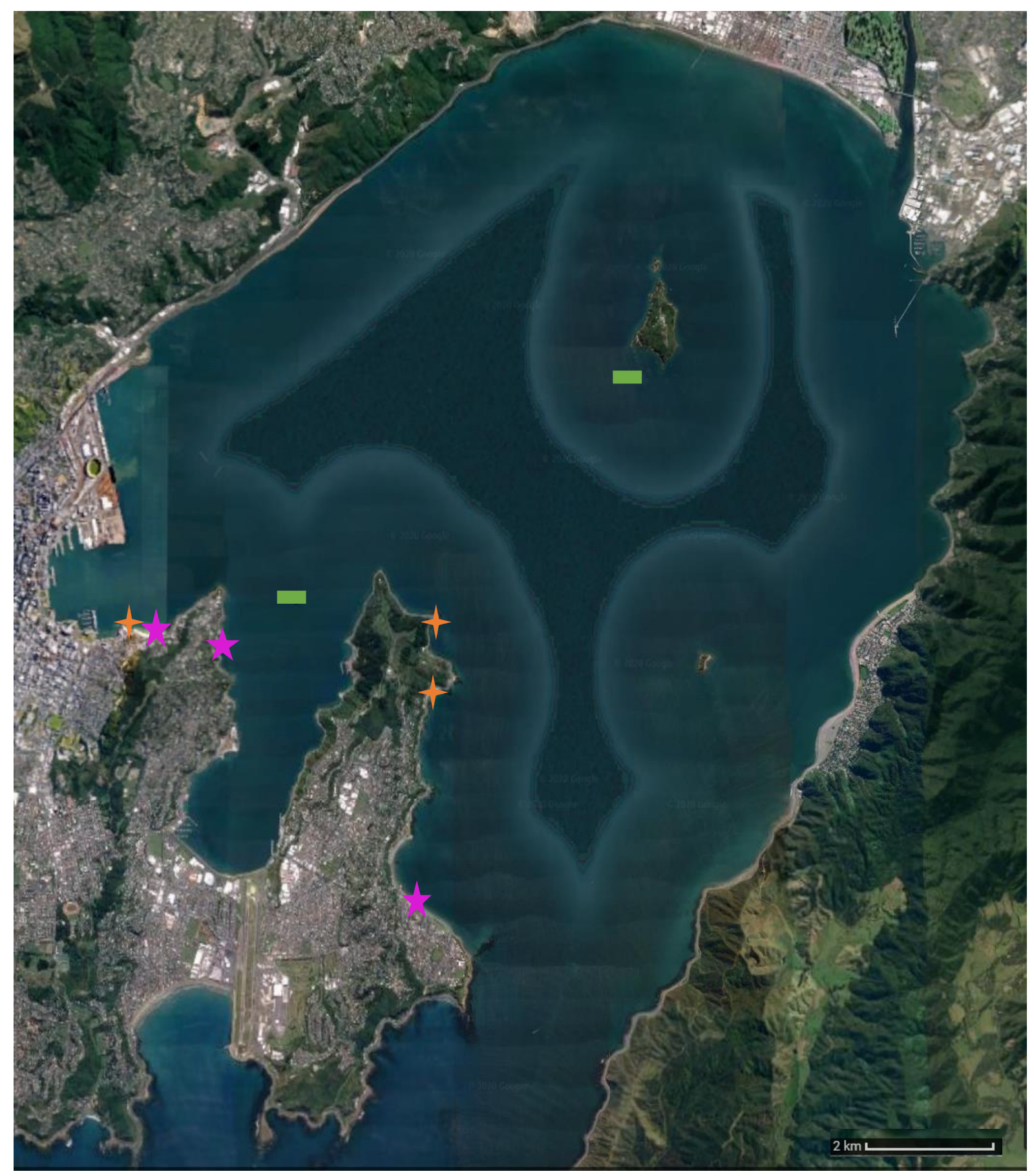

Figure 3.2: Map of sites sampled within Wellington Harbour, where pink symbols represent beach sediment survey sites, orange represents $M$. galloprovincialis mussel sites, and green demonstrates surface water transects. Retrieved from Google Earth 21/05/2020. 


\section{Laboratory analysis}

Beach samples

Once in the laboratory, a density-separation method was used to extract any synthetic particles from the sediment collected in the field. This method was adapted from techniques first used by Thompson et al. (2004) and Claessens et al. (2011). For every $200 \mathrm{~g}$ of sediment, $400 \mathrm{~mL}$ of super-saline $\mathrm{NaCl}$ solution was added. Beakers were then manually stirred and shaken for 30 seconds (Clunies-Ross et al., 2016), and then the contents allowed to settle for 1 minute. The top layer of debris was then siphoned off and filtered through a 75 $\mu \mathrm{m}$ sieve. This process of manually stirring, settling, then filtering was repeated until there was only a thin layer of $\mathrm{NaCl}$ solution left above the sediment $(1-2 \mathrm{~mm})$, with the leftover sediment then discarded. The process was repeated until all the sediment from each sample had been density-separated and filtered.

Mussel samples

After field collection, the mussels were returned to the laboratory and placed in the freezer for 48 hours. 1 hour before processing, they were removed from the freezer to thaw out. At this time, shell length was confirmed using calipers and they were placed in individual jars. To minimise contamination from particles in the air, each jar was covered in cling wrap during thawing and digestion. After the mussels had thawed out sufficiently, the flesh was removed from the shells and weighed at wet weight .

To prepare for mussel digestion, a $10 \% \mathrm{KOH}$ solution was made, using $\mathrm{KOH}$ pellets and distilled water in a 1L flask, following an adapted protocol described in Miller et al. (2017), used in Tanaka \& Takada (2016) and Wagner et al. (2017). The 10\% KOH solution was poured into each jar until the mussel tissues were completely covered (Figure 3.3). At this stage, the cling wrap was added, and the tissues were left at room temperature for a total of 2 weeks, stirring every few days. After two weeks, all M. galloprovincialis tissue had been digested, leaving only inorganic particles. To remove these and analyse them, the $\mathrm{KOH}$ solution was filtered through a $75 \mu \mathrm{m}$ sieve, and the collected particles rinsed with distilled water before being transferred to a petri dish for examination under the microscope. 

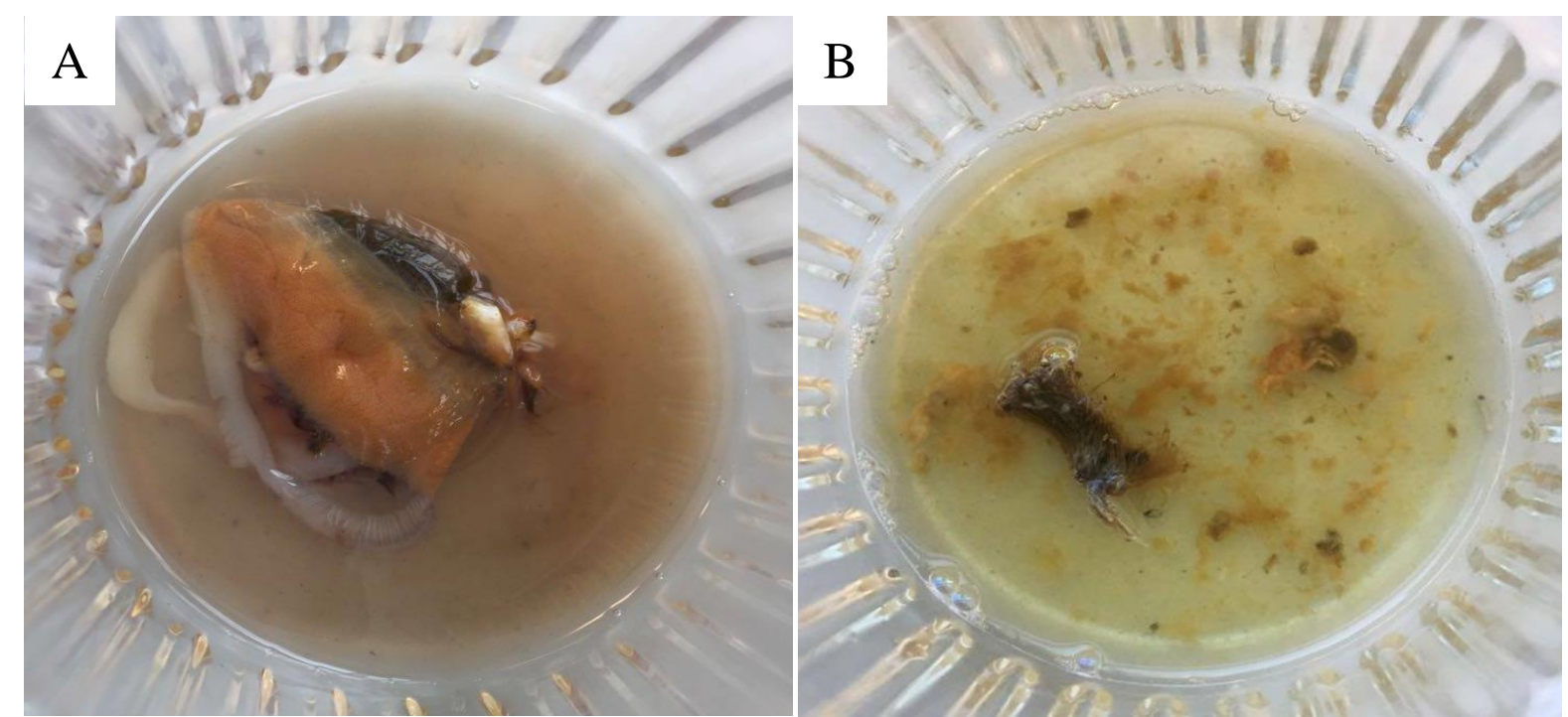

Figure 3.3: Mussel digestion process, including A) at the commencement of digestion, as the $10 \% \mathrm{KOH}$ solution was being added, and B) after a week of digestion, where there was only a small amount of soft tissue left, along with byssal threads and inorganic materials. At the end of the digestion process, there was no soft tissue left, and the byssal threads had dispersed.

\section{Water surface samples}

Once in the laboratory, each sample was filtered further through a $100 \mu \mathrm{m}$ sieve, again using the adapted density-separation and filtering methodology first described in Thompson et al. (2004) and Claessens et al. (2011). A siphon was again used to collect particles and filter them, before the particles were transferred to a petri dish using distilled water. These samples were then ready for examination under the microscope.

\section{Microscope analysis}

Once filtered, each sample was transferred to a petri dish, using distilled water. These were then visually examined under a stereo microscope at $15 x$ magnification. Items were characterised in the same way as the previous data chapter, with three size classes - small $(<1$ $\mathrm{mm}$ ), medium (1-2 mm), and large (2-5 mm). Type of particle was also recorded, with categories for fibres, fragments, foil, paint, and macroplastic. Additionally, the colour of each particle was noted. Items were verified as synthetic by attempting to break apart the item with forceps, as well as the visual analysis. If the object was plastic, it would not break under pressure of the forceps. After examination, samples were again rinsed through the $75 \mu \mathrm{m}$ filter then transferred to a collection tube and preserved with $40 \%$ ethanol.

\section{Statistical analyses}

All analyses were conducted in R V3.6.3 (R Core Team 2020) using RStudio v1.2.5033 (RStudio team, 2020). Pearson's Chi-squared tests were used to test morphotype, size, and 
colour of synthetic particles collected during the study. Additionally, a generalized linear model (GLM) with a Poisson distribution was used to test for temporal and spatial variation within the M. galloprovincialis tissue samples and beach sediment samples, due to nonnormal distribution of count data. Tests were conducted for temporal variation, both between months (February 2019 - February 2020), and between weeks for the applicable collections that occurred during August 2019 - February 2020. Tests for spatial variation were conducted for the three different sites within a collection month - Oriental Bay (OB), Kau Point (KP), and Scorching Bay (ScB) for mussels, and Oriental Bay (OB), Balaena Bay (BB), and Seatoun Beach (ST) for beach sediments. Results were reported on a log scale.

Finally, due to a small sample size $(\mathrm{n}=8)$ and non-normal distribution, a Kruskal-Wallis test was conducted to quantify temporal differences between the surface water tows, using the two sites (Evans Bay \& Matiu-Somes Island) as the two replicates. 


\section{Results}

\section{Mytilus galloprovincialis}

Monthly variation

Mean microplastic abundance within $M$. galloprovincialis individuals was highly variable, dependent upon the month of sampling. February 2019 was significantly different to all other months (Table 3.1), with values approximately 5 times higher than May 2019, and up to 13 times greater than all other sampled months (Figure 3.4). In addition, there was also a significant difference between May 2019 and all subsequent months (Table 3.1), with mean microplastic abundance was twice as high (Figure 3.4).

Table 3.1 Results of between-month variation (February 2019, May 2019, August 2019, November 2019, and February 2020) on microplastic abundance within pooled $M$. galloprovincialis samples, where * indicates significant differences at $\mathrm{p}=0.05$.

\begin{tabular}{|l|c|c|c|c|c|}
\hline Month & Estimate & SE & Z.ratio & P.value & \\
\hline Aug19 - Feb19 & -2.4155 & 0.102 & -23.790 & $<0.0001$ & $*$ \\
\hline Aug19 - Feb20 & -0.0081 & 0.127 & -0.064 & 1.0000 & \\
\hline Aug19 - May19 & -0.6039 & 0.147 & -4.122 & 0.0004 & $*$ \\
\hline Aug19 - Nov19 & 0.2375 & 0.136 & 1.749 & 0.4039 & \\
\hline Feb19 - Feb20 & 2.4074 & 0.101 & 23.786 & $<0.0001$ & $*$ \\
\hline Feb19 - May19 & 1.8116 & 0.125 & 14.545 & $<0.0001$ & $*$ \\
\hline Feb19 - Nov19 & 2.6530 & 0.112 & 23.740 & $<0.0001$ & $*$ \\
\hline Feb20 - May19 & -0.5958 & 0.146 & -4.073 & 0.0004 & $*$ \\
\hline Feb20 - Nov19 & 0.2456 & 0.136 & 1.812 & 0.3667 & \\
\hline May19 - Nov19 & 0.8414 & 0.154 & 5.472 & $<0.0001$ & $*$ \\
\hline
\end{tabular}

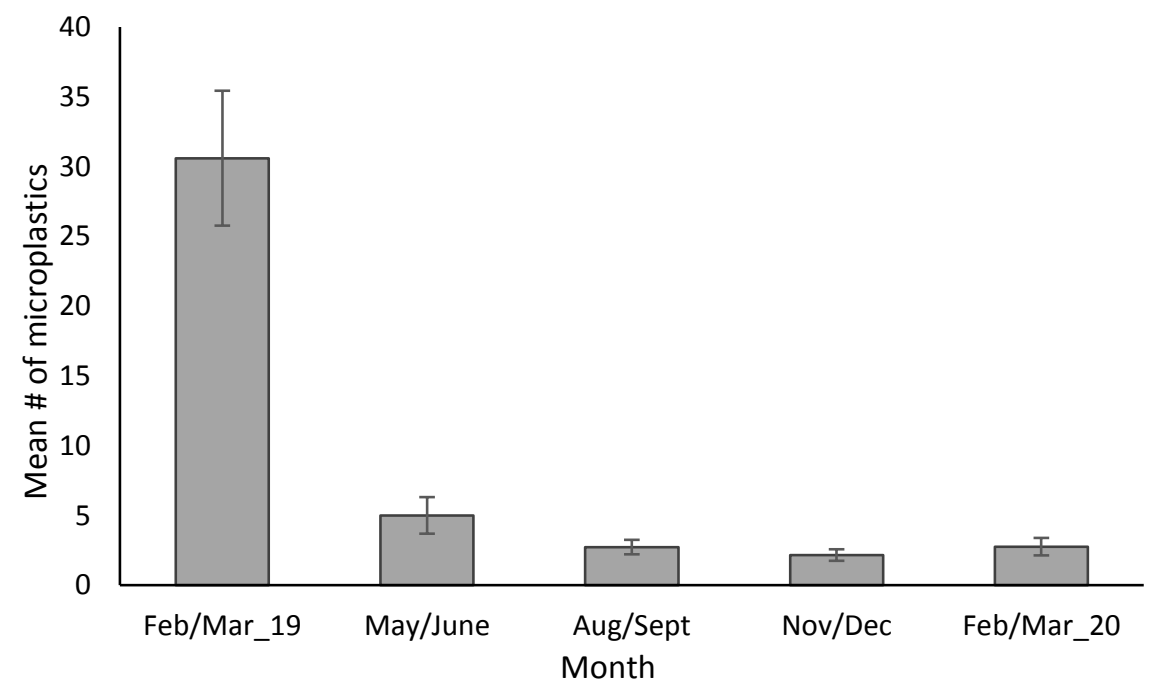

Figure 3.4: Mean (+/- 95\% confidence interval) number of microplastics observed within M. galloprovincialis samples collected in February 2019, May 2019, August 2019, November 2019, and February 2020. 


\section{Weekly variation}

M. galloprovincialis tissues had a statistically similar microplastic load throughout the three collections in August 2019 and November 2019 (Table 3.2). In contrast, the third week of sampling in February 2020 was significantly different to week 1 and 2 (Table 3.2), with $M$. galloprovincialis mussels containing approximately half the amount of microplastics observed in the previous weeks within their tissues (Figure 3.5).

Table 3.2: Results of a pairwise comparison, showing between-week variation of microplastic abundance within M. galloprovincialis samples, where $*$ indicates significant differences at $\mathrm{p}=0.05$. Collections $\mathrm{A}-\mathrm{C}$ represent weeks $1-3$, respectively.

\begin{tabular}{|l|c|c|c|c|c|c|}
\hline Month & Collection & Estimate & SE & Z.ratio & P.value & \\
\hline Aug-19 & A - B & 0.2029 & 0.213 & 0.952 & 0.6071 & \\
\hline & A - C & 0.3655 & 0.223 & 1.637 & 0.2299 & \\
\hline & B - C & 0.1625 & 0.233 & 0.697 & 0.7654 & \\
\hline Nov-19 & A - B & 0.2162 & 0.25 & 0.867 & 0.6614 & \\
\hline & A - C & 0.1178 & 0.243 & 0.485 & 0.8785 & \\
\hline & B - C & -0.0984 & 0.256 & -0.384 & 0.9220 & \\
\hline Feb-20 & A - B & 0.2007 & 0.201 & 0.998 & 0.5779 & \\
\hline & A - C & 0.8293 & 0.245 & 3.390 & 0.0020 & $*$ \\
\hline & B - C & 0.6286 & 0.253 & 2.487 & 0.0344 & $*$ \\
\hline
\end{tabular}

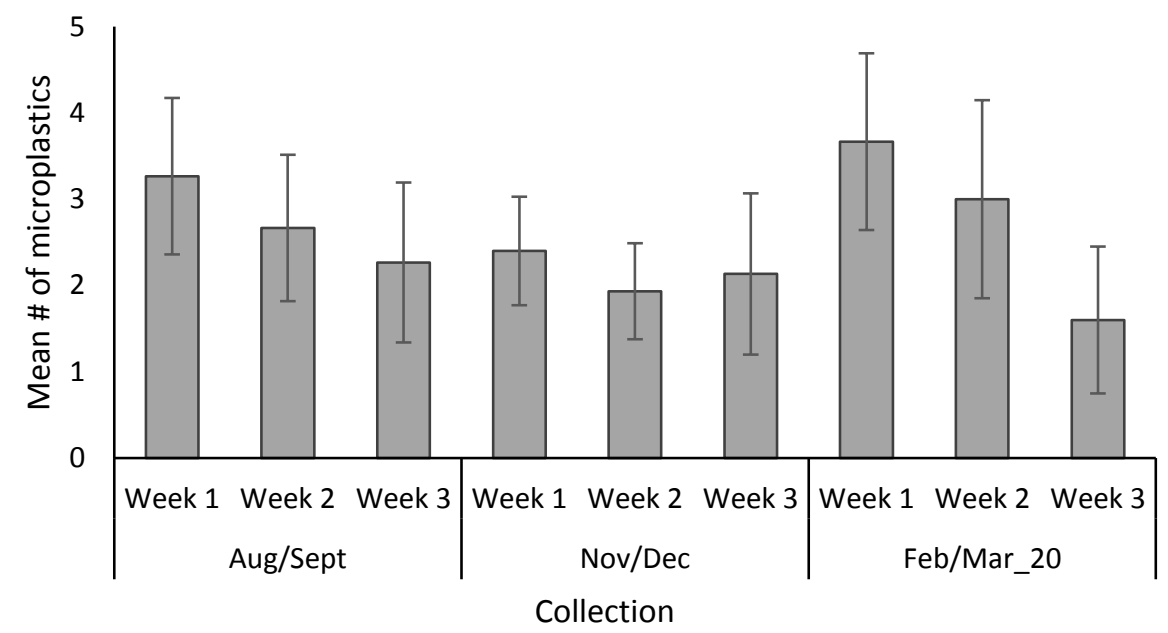

Figure 3.5: Mean (+/- 95\% confidence interval) number of microplastic particles within M. galloprovincialis tissues, with variation observed between weekly collections in Aug/Sept '19, Nov/Dec '19, and Feb/Mar '20. 
Spatial variation

For M. galloprovincialis samples, the monthly mean microplastic abundance was not heavily influenced by site. The only significant differences between site occurred within the month of August 2019, where the mean microplastic abundance differed between Kau Point and Oriental Bay individuals (Table 3.3), with mean microplastic abundance greater in individuals collected from Oriental Bay (Figure 3.6). Within all other months sampled, mean microplastic abundance was comparable between Kau Point, Oriental Bay, and Scorching Bay (Figure 3.6).

Table 3.3: Results of a pairwise comparison, examining between-site variation (Kau Point, Oriental Bay, and Scorching Bay) of microplastic abundance within M. galloprovincialis samples, with $*$ indicating significant differences at $\mathrm{p}=0.05$.

\begin{tabular}{|c|c|c|c|c|c|}
\hline Month & Site & Estimate & SE & Z.ratio & P.value \\
\hline \multirow{3}{*}{ Feb19 } & $\mathrm{KP}-\mathrm{OB}$ & -0.00717 & 0.120 & -0.060 & 0.9980 \\
\hline & $\mathrm{KP}-\mathrm{SCB}$ & -0.25848 & 0.113 & -2.289 & 0.0575 \\
\hline & $\mathrm{OB}-\mathrm{SCB}$ & -0.25131 & 0.113 & -2.230 & 0.0662 \\
\hline \multirow[t]{3}{*}{ May19 } & $\mathrm{KP}-\mathrm{OB}$ & -0.42286 & 0.295 & -1.433 & 0.3241 \\
\hline & KP - SCB & -0.35140 & 0.299 & -1.173 & 0.4690 \\
\hline & $\mathrm{OB}-\mathrm{SCB}$ & 0.07146 & 0.267 & 0.267 & 0.9614 \\
\hline \multirow[t]{3}{*}{ Aug19 } & $\mathrm{KP}-\mathrm{OB}$ & -0.62415 & 0.226 & -2.759 & 0.0160 \\
\hline & $\mathrm{KP}-\mathrm{SCB}$ & -0.20972 & 0.246 & -0.854 & 0.6696 \\
\hline & $\mathrm{OB}-\mathrm{SCB}$ & 0.41443 & 0.212 & 1.956 & 0.1233 \\
\hline \multirow[t]{3}{*}{ Nov19 } & $\mathrm{KP}-\mathrm{OB}$ & -0.19237 & 0.235 & -0.818 & 0.6918 \\
\hline & $\mathrm{KP}-\mathrm{SCB}$ & 0.31845 & 0.268 & 1.187 & 0.4609 \\
\hline & $\mathrm{OB}-\mathrm{SCB}$ & 0.51083 & 0.258 & 1.978 & 0.1175 \\
\hline \multirow[t]{3}{*}{ Feb20 } & KP - OB & 0.18232 & 0.214 & 0.852 & 0.6708 \\
\hline & $\mathrm{KP}-\mathrm{SCB}$ & 0.28768 & 0.220 & 1.305 & 0.3925 \\
\hline & $\mathrm{OB}-\mathrm{SCB}$ & 0.10536 & 0.230 & 0.459 & 0.8906 \\
\hline
\end{tabular}




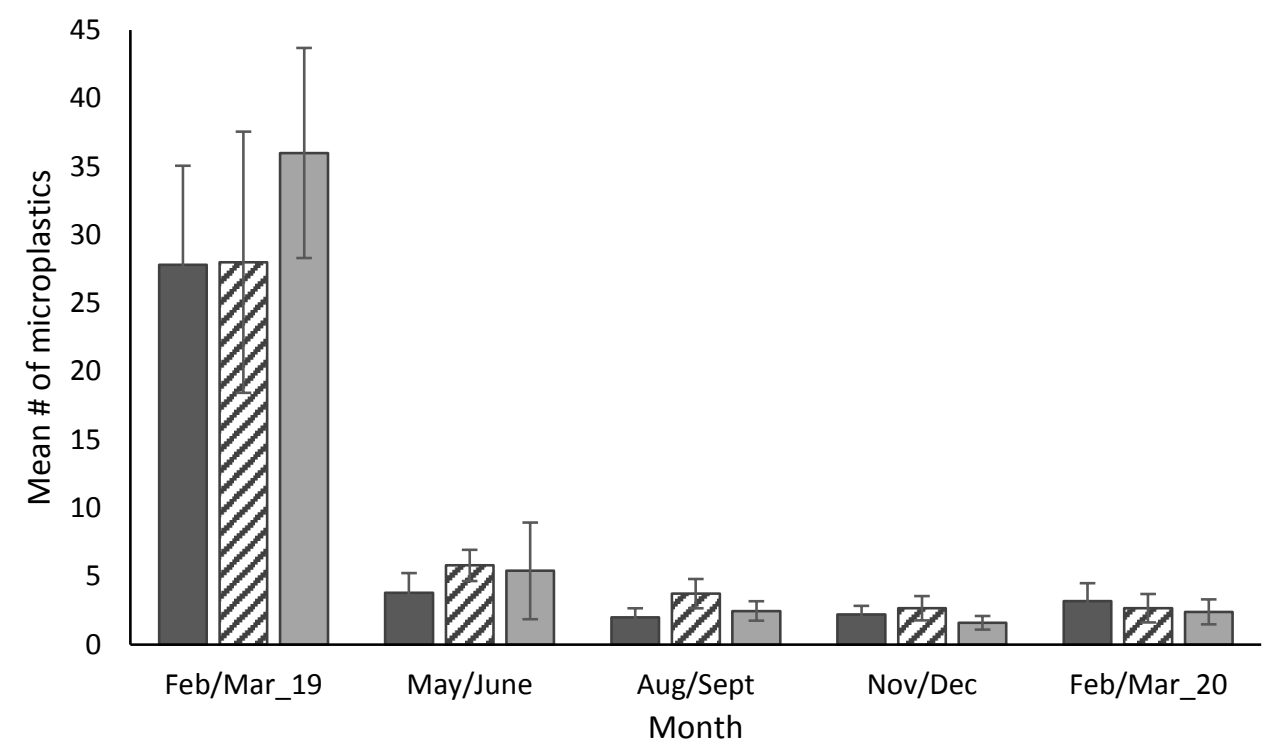

Figure 3.6: Average (+/- 95\% confidence interval) microplastic abundances per mussel between sites within each collection month, where black bars represent Kau Point, striped bars represent Oriental Bay, and grey bars represent Scorching Bay.

\section{Beach sediment}

Monthly variation

Similar to the mean microplastic abundance within M. galloprovincialis tissues, the pollutant load in beach sediment cores (each sample $\sim 400 \mathrm{~cm}^{3}$ ) was also highly variable. However, average microplastic load peaked in May 2019, as opposed to February 2019 (Figure 3.7).

Sediments collected in May 2019 were up to 11 times greater than the smallest monthly average, in November 2019 (Figure 3.7). A pairwise comparison between months indicated that all sampled months were significantly different than each other (Table 3.4).

Table 3.4: Results of between-month variation (February 2019, May 2019, August 2019, November 2019, and February 2020) on microplastic abundance within pooled beach sediment samples, where * indicates significant differences at $\mathrm{p}=0.05$.

\begin{tabular}{|l|c|c|c|c|c|}
\hline Month & Estimate & SE & Z.ratio & P.value & \\
\hline Aug19 - Feb19 & -0.347 & 0.0520 & -6.669 & $<0.0001$ & $*$ \\
\hline Aug19 - Feb20 & 0.333 & 0.0455 & 7.320 & $<0.0001$ & $*$ \\
\hline Aug19 - May19 & -1.448 & 0.0392 & -36.941 & $<0.0001$ & $*$ \\
\hline Aug19 - Nov19 & 0.951 & 0.0555 & 17.130 & $<0.0001$ & $*$ \\
\hline Feb19 - Feb20 & 0.680 & 0.0554 & 12.276 & $<0.0001$ & $*$ \\
\hline Feb19 - May19 & -1.101 & 0.0503 & -21.876 & $<0.0001$ & $*$ \\
\hline Feb19 - Nov19 & 1.297 & 0.0638 & 20.323 & $<0.0001$ & $*$ \\
\hline Feb20 - May19 & -1.781 & 0.0436 & -40.860 & $<0.0001$ & $*$ \\
\hline Feb20 - Nov19 & 0.617 & 0.0587 & 10.519 & $<0.0001$ & $*$ \\
\hline May19 - Nov19 & 2.399 & 0.0539 & 44.494 & $<0.0001$ & $*$ \\
\hline
\end{tabular}




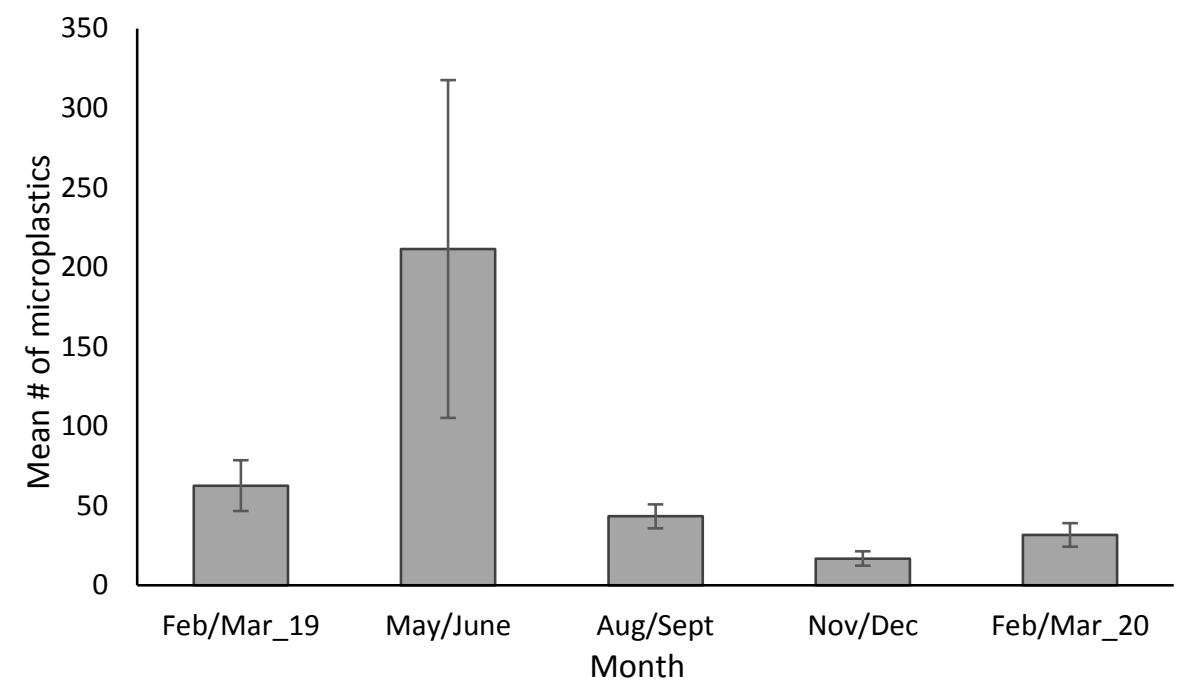

Figure 3.7: Mean (+/- 95\% confidence interval) abundance of microplastics observed within beach sediment samples of approximately $400 \mathrm{~cm}^{3}$, collected in February 2019, May 2019, August 2019, November 2019, and February 2020.

\section{Weekly variation}

Average microplastic abundance in beach sediment cores (each sample $\sim 400 \mathrm{~cm}^{3}$ ) was slightly more variable on a weekly basis than in $M$. galloprovincialis tissues. There were no statistically significant differences between weeks in August 2019 (Table 3.5), however week 1 in November 2019 had a higher amount of microplastics on average compared to week 2 (Table 3.5). In addition, week 1 of February 2020 had a higher number of microplastics contained within the sediments than both subsequent weeks of the same month. (Figure 3.8).

Table 3.5: Results of between-week variation (Weeks 1, 2, and 3 respectively) on microplastic abundance within beach sediment samples of approximately $400 \mathrm{~cm}^{3}$, collected in August 2019, November 2019, and February 2020. * indicates significant differences at $\mathrm{p}=0.05$.

\begin{tabular}{|l|c|c|c|c|c|c|}
\hline Month & Collection & Estimate & SE & Z.ratio & P.value & \\
\hline Aug19 & A - B & -0.0126 & 0.0710 & -0.178 & 0.9828 & \\
\hline & A - C & 0.0441 & 0.0720 & 0.612 & 0.8135 & \\
\hline & B - C & 0.0567 & 0.0718 & 0.79 & 0.7094 & \\
\hline Nov19 & A - B & 0.2896 & 0.1169 & 2.487 & 0.0353 & $*$ \\
& A - C & 0.0918 & 0.1107 & 0.829 & 0.6849 & \\
\hline & B - C & -0.1978 & 0.1193 & -1.659 & 0.2212 & \\
\hline Feb20 & A - B & 0.7975 & 0.0852 & 9.365 & $<0.0001$ & $*$ \\
\hline & A - C & 0.7441 & 0.0836 & 8.897 & $<0.0001$ & $*$ \\
\hline & B - C & -0.0535 & 0.0987 & -0.543 & 0.8503 & \\
\hline
\end{tabular}




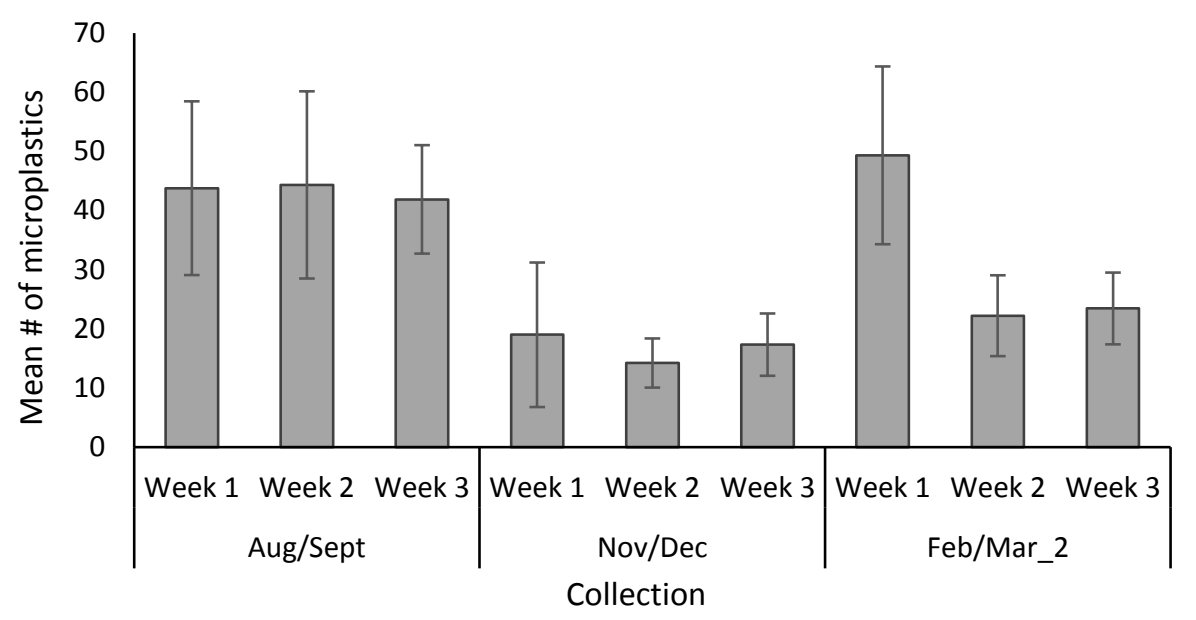

Figure 3.8: Average (+/- 95\% confidence interval) abundance of microplastic particles within beach sediment samples of approximately $400 \mathrm{~cm}^{3}$, with variation observed between weekly collections in Aug/Sept '19, Nov/Dec '19, and Feb/Mar'20.

Spatial variation

In contrast to M. galloprovincialis samples, microplastic abundance within beach sediments appears to be more spatially variable within months, with site variability observed in three out of five months. In February 2019, microplastic abundance was significantly different at Oriental Bay, while in May 2019 each site was dissimilar in microplastic load from the others (Table 3.6), with Seatoun having the greatest difference. Values in Seatoun during May 2019 were up to two times greater than average microplastic abundance in Balaena Bay or Oriental Bay (Figure 3.9). Thirdly, in February 2020, Balaena Bay differed from both other sites (Table 3.6), with less microplastics on average in its sediments than the other two sites (Figure 3.9). Consequently, the sites where difference in microplastic abundance was observed was not ubiquitous across all sampled months. 
Table 3.6: Results of between-site variation (Balaena Bay, Oriental Bay, and Scorching Bay) on microplastic abundance within beach sediment samples of approximately $400 \mathrm{~cm}^{3}$ across all collection months. * indicates significant differences at $\mathrm{p}=0.05$.

\begin{tabular}{|l|c|c|c|c|c|c|}
\hline Month & Site & Estimate & SE & Z.ratio & P.value & \\
\hline Feb19 & BB - OB & -0.2877 & 0.0986 & -2.918 & 0.0099 & $*$ \\
\hline & BB - ST & 0.2231 & 0.1118 & 1.996 & 0.1132 & \\
\hline & OB - ST & 0.5108 & 0.1054 & 4.846 & $<0.0001$ & $*$ \\
\hline May19 & BB - OB & 0.4316 & 0.0724 & 5.964 & $<0.0001$ & $*$ \\
\hline & BB - ST & -0.8262 & 0.0544 & -15.174 & $<0.0001$ & $*$ \\
\hline & OB - ST & -1.2577 & 0.0639 & -19.698 & $<0.0001$ & $*$ \\
\hline Aug19 & BB - OB & -0.0153 & 0.0715 & -0.215 & 0.9749 & \\
\hline & BB - ST & 0.0000 & 0.0718 & 0.000 & 1.0000 & \\
\hline \multirow{2}{*}{ Nov19 } & OB - ST & 0.0153 & 0.0715 & 0.215 & 0.9749 & \\
\hline & BB - OB & -0.1881 & 0.1123 & -1.675 & 0.2150 & \\
\hline & BB - ST & 0.0715 & 0.1196 & 0.597 & 0.8215 & \\
\hline Feb20 & OB - ST & 0.2595 & 0.1145 & 2.265 & 0.0608 & \\
\hline & BB - OB & -0.4580 & 0.0882 & -5.195 & $<0.0001$ & $*$ \\
\hline & BB - ST & -0.3991 & 0.0892 & -4.474 & $<0.0001$ & $*$ \\
\hline & OB - ST & 0.0589 & 0.0788 & 0.748 & 0.7348 & \\
\hline
\end{tabular}

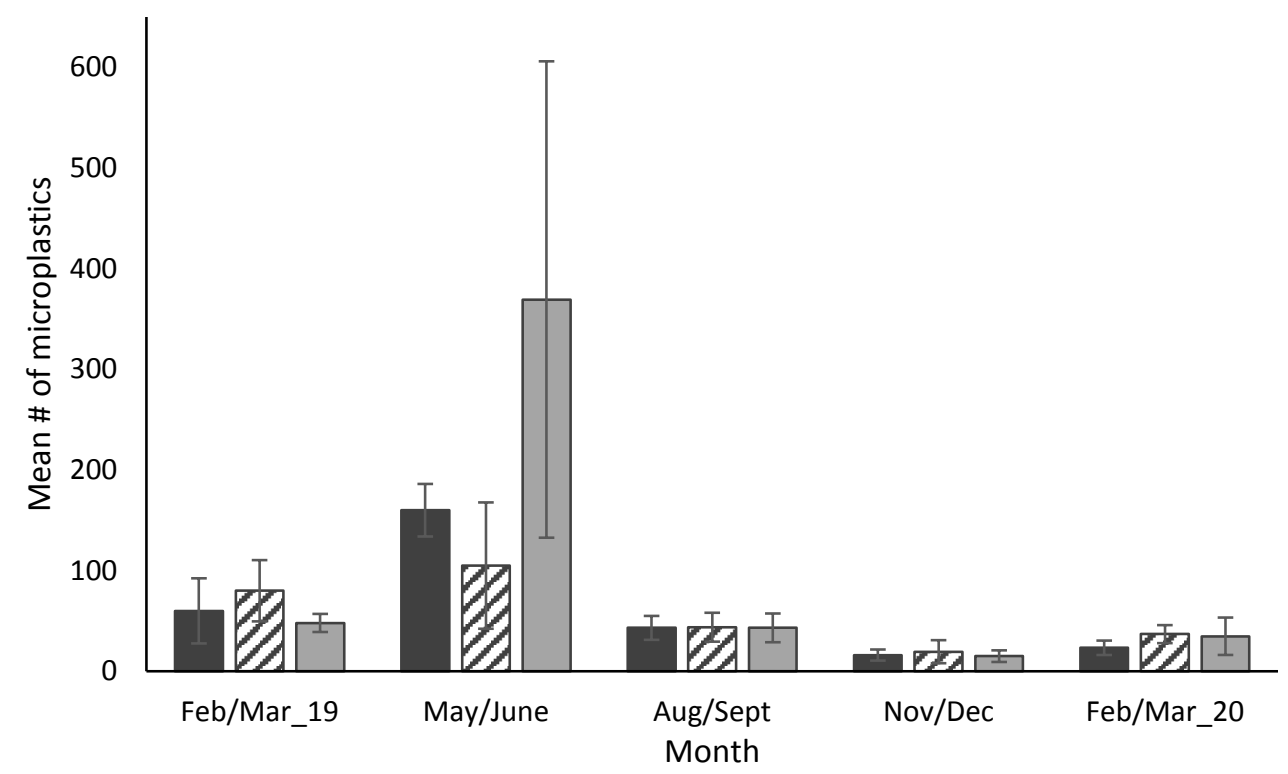

Figure 3.9: Average (+/- 95\% confidence interval) microplastic abundances between sites within each sediment collection month, where black bars represent sediment cores (approximately $400 \mathrm{~cm}^{3}$ ) collected in Balaena Bay, striped bars represent Oriental Bay, and grey bars represent Seatoun.

\section{Surface water tows}

Microplastic abundance between the months of March - November 2019 appeared to be dynamic (Figure 3.10), with the highest number of synthetic particles within a single $200 \mathrm{~m}$ long neuston net transect recorded in March 2019, at Matiu-Somes Island ( $\mathrm{n}=107)$. The lowest number of particles collected in a single tow occurred during September 2019 - also at 
Matiu-Somes Island $(n=19)$. Despite the apparent differences between the sample months, a Kruskal-Wallis test suggests that there is no significant difference in microplastic abundance between different months $(p=0.129)$. Spatially, Figure 3.10 suggests there may be similarities between Evans Bay and Matiu/Somes Island, as the tows produced comparable amounts of microplastic particles within each month that was sampled. These results must be interpreted with caution, however, due to the small sample size of water surface tows able to be collected during the study.

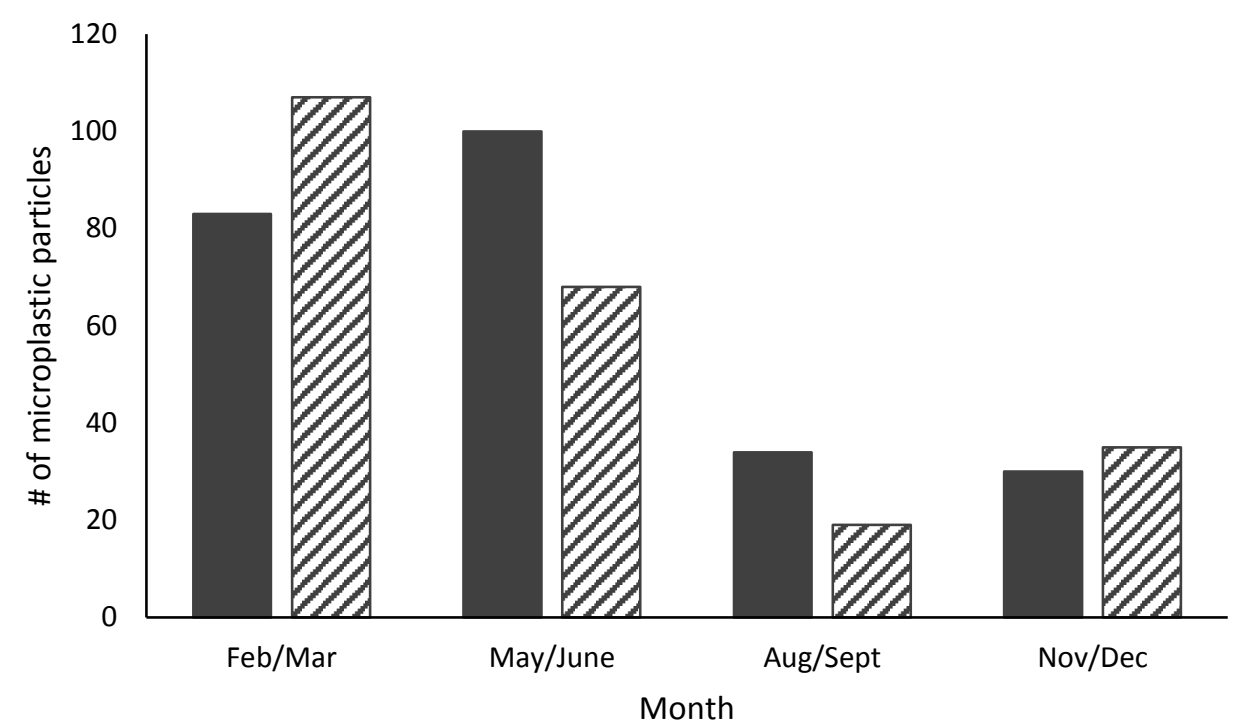

Figure 3.10: Total microplastic abundance per 200 m neuston net transect between collection sites, at each 3monthly sampling tow, where black bars represent Evans Bay and striped bars represent Matiu-Somes Island.

\section{Plastic characteristics}

Type of particle
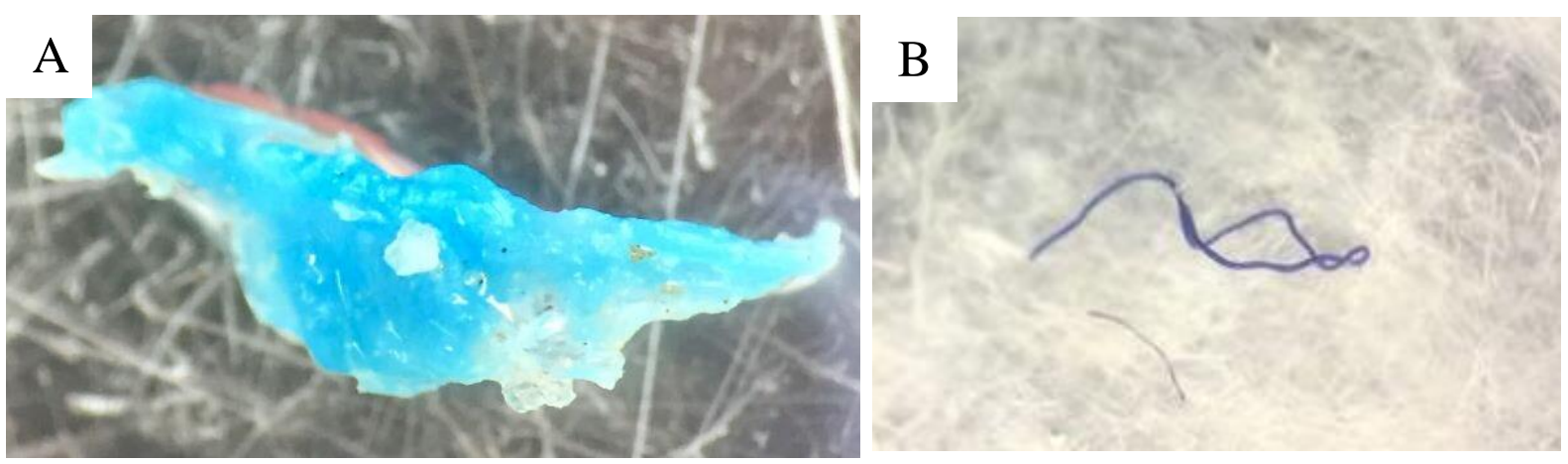

Figure 3.11: Two examples of synthetic particles collected within this study, where A) was a large blue fragment found in a M. galloprovincialis individual, whilst B) shows two fibres (black and blue) of medium and small sizes respectively, found within sea surface samples. 
Multiple types of inorganic particles were found in all three sources of collection for this study, including those shown in Figure 3.11. Synthetic fibres were the predominant plastic type throughout all three sources, accounting for $90.5 \%$ of all synthetic particles within sediments collected along the high tide line, $94.2 \%$ in surface water tows, and $95.8 \%$ within M. galloprovincialis tissue. Plastic fragments were the second-most abundant particle type in all three sources, although these accounting for a mere $3.6 \%$ of total inorganic particles in $M$. galloprovincialis, $5.2 \%$ of surface water samples, and $9.2 \%$ of particles collected within sediments. All other occurrences of various inorganic particles within M. galloprovincialis, sediment, and surface water tows are negligible (Table 3.7), with synthetic fibres and plastic fragments the only consistent types of microplastic found throughout the study (Figure 3.12). The difference in percentage of each particle type was significant in the three sources $\left(\mathrm{x}^{2}(4)\right.$ $=38.939, \mathrm{p}=<0.0001)$, particularly as microfibres comprised the highest percentage in $M$. galloprovincialis samples, while microplastic fragments were more common in beach sediment samples as opposed to the other two sources (Figure 3.12).

Table 3.7: Count data investigating total number of synthetic particles within $M$. galloprovincialis tissues, sediment, and water tows collected during the scope of this study.

\begin{tabular}{|l|c|c|c|c|c|c|c|c|}
\hline & Bead & Fabric & Fibre & Foil & Fragment & Macro & $\begin{array}{c}\text { Virgin } \\
\text { pellet }\end{array}$ & Paint \\
\hline Mussel & 1 & 0 & 845 & 1 & 32 & 3 & 0 & 0 \\
\hline Sediment & 0 & 0 & 4495 & 0 & 458 & 12 & 3 & 1 \\
\hline Water & 0 & 1 & 451 & 0 & 25 & 2 & 0 & 0 \\
\hline
\end{tabular}

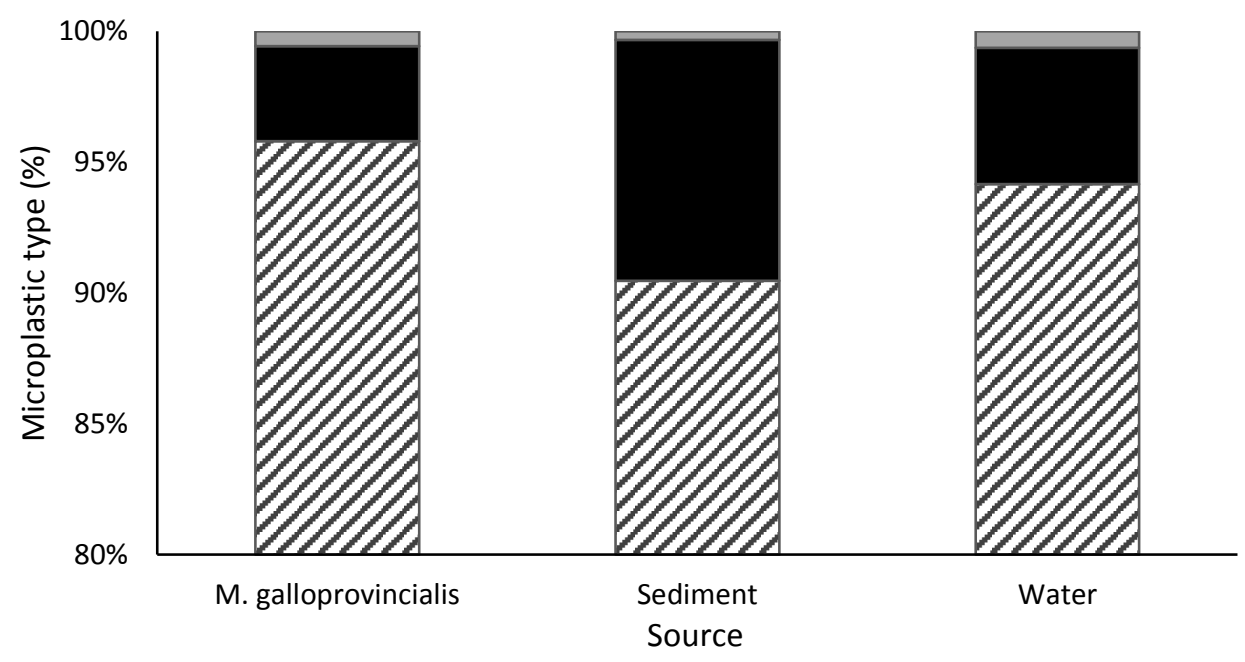

Figure 3.12: Percentages of the total count data between February 2019 and February 2020, for all different plastic type. Data is pooled across sources. Striped bars represent the percentage of microfibres, black bars represent the percentage of fragments, and open bars represent the percentage of all other plastic types - beads, fabric, foil, macroplastic, virgin plastic pellets, and paint chips. 
Size of plastic particles

A total of 6,312 synthetic particles were detected within the samples collected for this study. Of these, medium-sized microplastics (1-2 mm) were most common throughout all three sources; $M$, galloprovincialis tissues, beach sediments, and surface water tows (Table 3.8). This size category comprised between $40-44 \%$ of all synthetic particles observed, while small and large particles were more widely varied between the three sources (Figure 3.13). The difference in the proportions was shown to be significant between size classes and the three sources $\left(\mathrm{x}^{2}(4)=51.828, \mathrm{p}=<0.0001\right)$.

Table 3.8: Count data investigating size distributions of synthetic particles within $M$. galloprovincialis tissues, sediment, and water tows collected during the scope of this study. Count data not inclusive of macroplastic particles $>5 \mathrm{~mm}$ in length or diameter.

\begin{tabular}{|l|c|c|c|}
\hline & Small & Medium & Large \\
\hline Mussel & 208 & 355 & 316 \\
\hline Sediment & 1501 & 2215 & 1240 \\
\hline Water & 128 & 201 & 148 \\
\hline
\end{tabular}

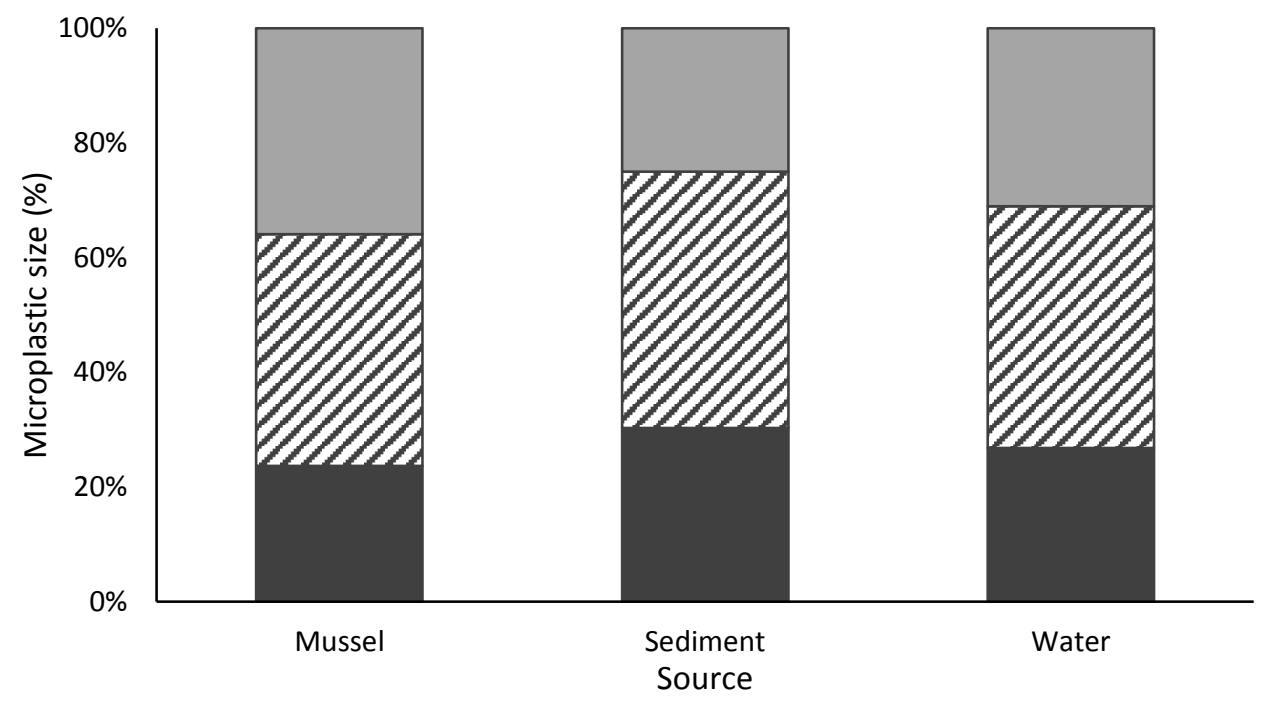

Figure 3.13: Microplastic size distributions within M. galloprovincialis, sediment, and surface water tows, expressed as a percentage. Black bars represent the percentage of small particles $(<1 \mathrm{~mm})$, striped bars represent medium $(1-2 \mathrm{~mm})$, and grey bars represent large particles $(>2-5 \mathrm{~mm})$.

\section{Colour of particles}

The colours of synthetic particles were found to range significantly throughout $M$.

galloprovincialis, beach sediment, and water surface samples. Black and blue microplastics were the most prevalent varieties, accounting for between $25-52 \%$ of each source. All other colours found within the samples were far less predominant, as demonstrated in Figure 3.14. The difference in percentage of each particle colour (black, blue, colourless, and other) was significant in the three sources $\left(x^{2}(6)=294.52, p=<0.0001\right)$, supporting the count data 
shown in Table 3.9. Black particles were particularly of highest prevalence in the sediment and water samples, while blue particles comprised a far greater proportion of the colours found within M. galloprovincialis samples.

Table 3.9: Count data investigating colour distributions of synthetic particles found within M. galloprovincialis tissues, sediment, and water tows collected during the scope of this study.

\begin{tabular}{|l|c|c|c|c|c|c|c|c|c|}
\hline & Black & Blue & Colourless & Green & Orange & Purple & Red & White & Yellow \\
\hline Mussel & 229 & 461 & 126 & 10 & 10 & 2 & 41 & 3 & 1 \\
\hline Sediment & 2350 & 1981 & 183 & 61 & 39 & 25 & 145 & 149 & 36 \\
\hline Water & 229 & 130 & 37 & 13 & 13 & 5 & 33 & 11 & 8 \\
\hline
\end{tabular}

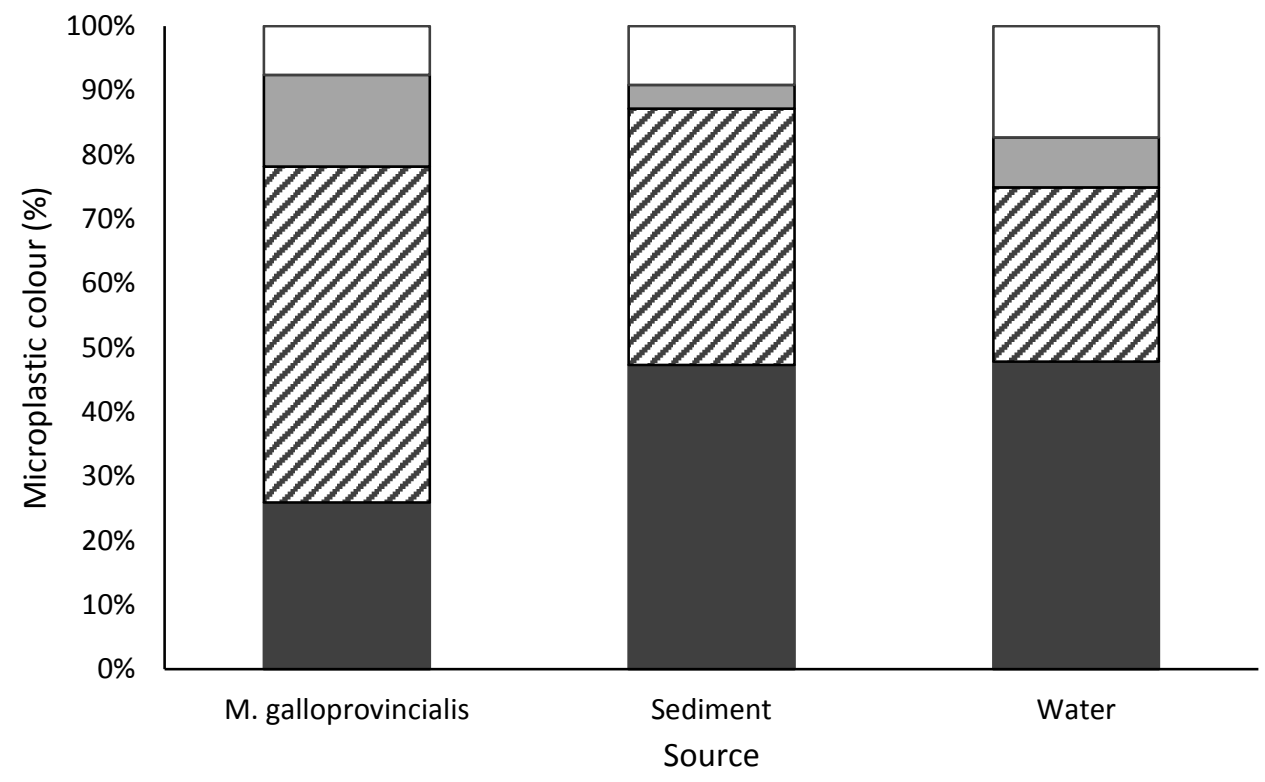

Figure 3.14: Microplastic colour distributions within M. galloprovincialis, sediment, and surface water tows, expressed as stacked percentages of the total count data for each source. Black bars represent the percentage of black particles, striped bars represent blue particles, grey bars represent colourless particles, and open bars represent the total percentage of all other colours (green, orange, pink, purple, red, white, and yellow). 


\section{Discussion}

This study illustrated that microplastic abundance within Wellington Harbour is highly dynamic on a variety of spatial and temporal scales, both within and among the three different sources examined: M. galloprovincialis tissues, beach sediments, and surface water tows. As hypothesized, the abundance and distribution of microplastic pollution was reasonably variable between the months and sites sampled, however less so between weeks. Furthermore, tissues of $M$. galloprovincialis individuals had a low abundance of microplastic particles on average, as hypothesized, although the pollutant load within all three sources were relatively on par with what has been found elsewhere in the world's coastal environments. This difference between sources is likely due to each mussel filtering a relatively small volume of seawater, in addition to their ability to egest synthetic particles within a relatively short period following ingestion (Woods et al., 2018; Gonçalves et al., 2019). The peak microplastic load for M. galloprovincialis tissues and surface water tows was observed in the samples collected during February/March, however for beach sediments the highest level of plastic pollution was observed in May/June. This may indicate that microplastics in Wellington Harbour do not follow the same temporal trend across all sources, or that different environmental factors impact the various habitats and organisms in separate ways.

Spatial differences were not as pronounced across the board as the temporal variation that occurred. This was particularly true for the M. galloprovincialis tissues, as Scorching Bay samples were similar to the other sites over all months. Oriental Bay individuals contained more synthetic particles than those collected from Kau Point in August 2019, but this was the only instance of significant variation. Interestingly, beach sediments experienced much higher levels of spatial variation, occurring over all three sites. This may also be due to environmental drivers that affect loading of plastic in beach sediment, however human interaction with beach surfaces may also play a role (Barnes et al., 2009; Agamuthu et al., 2019).

As hypothesized, microfibres were the most common type of synthetic particle detected in all three sources. Furthermore, the colour and size of particles ranged significantly throughout mussel tissue, beach sediment, and water surface samples. Black and blue particles were highly abundant in all three sources, whilst overall, size was the particle characteristic that was most evenly distributed, with particles measuring between $1-2 \mathrm{~mm}$ in length found to be the most prevalent size class observed in all three sources. 


\section{Microplastic abundance \& distribution in Mytilus galloprovincialis}

Mussels are ecologically significant in coastal marine ecosystems, and an integral role in benthic-pelagic coupling as a primary consumer that directly interacts with the surrounding environment. Consequently, it has been suggested that they are valuable bioindicators of microplastic pollution (Beyer et al., 2017; Brate et al., 2018; Li et al., 2019; Scott et al., 2019), thus helping to demonstrate the rate at which microplastics can enter the food web.

In this multi-pronged survey of Wellington Harbour, it is significant that synthetic particles were found within the tissues of M. galloprovincialis, which has not been documented in the Southern Hemisphere until now. This suggests that the uptake of microplastic pollutants can occur through either ingestion or adherence to their tissues (Kolandhasamy et al., 2018; Webb et al., 2019), but the majority of particles are egested as opposed to accumulating in the organism's internal tissues (Capolupo et al., 2018; Gonçalves et al., 2019).

Some laboratory studies have begun to look at the accumulation vs. egestion of pollutants such as microplastics and heavy metals, within various mussel species. Estimates vary regarding how long microplastics are able to persist in mussels, but one such study reports that particles translocated from the digestive system to the circulatory system of Mytilus edulis and remained there for over 48 days (Browne et al., 2008). In contrast, a different study reported that after introducing 30 microfibres $\mathrm{mL}^{-1}$ to $M$. edulis mussels, approximately $71 \%$ of these were quickly released as pseudofeces, and $9 \%$ ingested after a period of 3 hours (Woods et al., 2018). For M. galloprovincialis mussels, laboratory studies have focused upon microplastics such as polystyrene up until this point, with one paper providing evidence for rapid processing and egestion of the particles (Gonçalves et al., 2019). However, microplastics were still retained within the digestive system for 7 days after ingestion (Gonçalves et al., 2019). On the other hand, a larval study demonstrated that polystyrene microplastics were retained for up to 8 days in the digestive tract after ingestion (Capolupo $e t$ al., 2018). Both studies provided evidence for microplastics remaining in the digestive tract only, rather than being translocated to the gills or other internal tissues; indicating that microplastics are preferentially taken up when feeding (Rivera-Hernández et al., 2019). Since M. galloprovincialis mussels were digested whole during this study, an individual analysis of where the microplastic particles were located was unable to occur; in future studies this would provide evidence for short-term versus long-term retainment. 
Interestingly, spatial trends indicated that microplastic load within M. galloprovincialis mussels around different Wellington Harbour sites that are on average $1.3 \mathrm{~km}$ apart (straightline distance) do not vary much. These results indicate that variation across the scale of sites separated by a few kilometres is less important than temporal variation in contributing to patterns of microplastic abundance in M. galloprovincialis mussels in Wellington Harbour. This result is similar to the spatial patterns discussed in Webb et al. (2019), where microplastic abundance within $P$. canaliculus samples collected from around New Zealand (including the Auckland, Wellington, and Canterbury regions) was not found to be significantly associated with location. Although this study looked at finer spatial trends in comparison to Webb et al. (2019), it can still be suggested that the same principles apply. As a semi-enclosed harbour, Wellington Harbour experiences high levels of urbanisation, however the intensity of human activity is likely to be more constant than other coastal areas in the Northern Hemisphere that have reported significant spatial trends of microplastic abundance for various mussel species. For example, Li et al. (2016) conducted a study across approximately $2 / 3$ of the total mainland coastline China, looking at the microplastic pollution load within the Mytilus edulis population. Their results suggested that the microplastic load was significantly higher in areas that undergo intensive human activities, and less so in the more remote areas. These differences could be - in part - due to differences in sampling methodologies, but it is also feasible that there may be higher levels of variability in pollutant loads across regions with intensive human activity.

Apart from the mussel samples collected in February 2019, there was generally a low abundance of microplastic particles contained within $M$. galloprovincialis tissues. The microplastic load ranged between 0 - 11 (May 2019 - February 2020 samples), with an average of 2.8 particles per individual or $0.30 \pm 0.04$ particles $\mathrm{g}^{-1}$ (wet weight). These results are within a similar range to other mussel studies, both within New Zealand and globally. In New Zealand, Webb et al. (2019) reported 0 - 1.5 particles per Perna canaliculus mussel, while for the M. edulis spp. some reports suggest a microplastic load in the range of $0.36 \pm$ 0.07 particles $\mathrm{g}^{-1}$ from a mussel farm in Germany (Van Cauwenberghe \& Janssen, 2014) or $0.3 \pm 0.2$ particles $\mathrm{g}^{-1}$ on the French/Belgian/Dutch coastline (Van Cauwenberghe et al., 2015). For M. galloprovincialis mussels, one study reported that this species may contain up to $2.33 \pm 0.2$ particles $\mathrm{g}^{-1}$ for individuals along the South African coastline (Sparks, 2020), while a study on coast of the Adriatic Sea reported $1.06-1.33$ fragments $g^{-1}$ and $0.62-0.63$ fibres $\mathrm{g}^{-1}$ (Gomiero et al., 2019). In saying this, however, many variables are at play when 
investigating microplastic abundance in bivalves and other taxa. Geographic region is likely of high importance, as some coastal areas may be more heavily influenced by urbanisation, or subject to more pronounced environmental drivers. Furthermore, as there is no standard laboratory protocol for assessing microplastic load in mussel species, many different digestion methods are used, which may yield varying results. Until recently, for example, the use of Nitric acid was popular for digestion of soft tissue, however it has since been reported that this method results in degradation of some synthetic particles (Claessens et al., 2013; Dehaut et al., 2016; Karami et al., 2017). Regardless, these results are generally in line with those found in other published studies, suggesting that the maximum processing rates of microplastic particles are similar throughout the world and across multiple mussel species.

\section{Microplastic abundance \& distribution in beach sediments}

This thesis has provided the first effort to quantify microplastic loads in Wellington beach sediments in the $21^{\text {st }}$ century. The substantial quantity of particles found in this study is likely due to a combination of factors, but environmental drivers are thought to be highly influential. Wave stress and regular high tides, for example, are generally considered to be integral factors, as they push the particles onto the shore, resulting in a high concentration (Young \& Elliott, 2016). Using sediment cores with an approximate volume of $400 \mathrm{~cm}^{3}$ per sample, the extrapolated average abundance of microplastics within sandy beach sediments was $124.9 \pm 35.7$ particles $\mathrm{kg}^{-1}$ (wet weight). This estimation is on the lower end of global beach sediment microplastic approximations in the Northern Hemisphere, but surprisingly appears to be higher than the abundances reported in other Southern Hemisphere studies including those carried out in other regions of New Zealand. Clunies-Ross et al. (2016) reported $0-45.4$ particles $\mathrm{kg}^{-1}$ within the Canterbury region, while Bridson et al. (2020) only reported an average of 6 particles $\mathrm{kg}^{-1}$ in the Auckland region. In comparison, a study in Belgium reported 53 - 390 particles $\mathrm{kg}^{-1}$ (Claessons et al., 2011), therefore bearing more similarities to the results from this study.

The large abundance in Wellington Harbour may possibly indicate that there are higher levels of microplastic pollution within the region's marine environment. In saying that, however, at this stage it cannot yet be determined whether the microplastic particles examined during this study stem from a local origin such as the Hutt River and urban inputs around the region, or whether they come from further afield - flowing into the harbour via the Cook Strait entrance. 40 years ago, Gregory (1978) demonstrated that one microplastic type, virgin plastic pellets, were of the highest abundance around locales with large populations - like 
Wellington - indicating that the plastics may have local origins. More recently, microplastics were found in urban streams around New Zealand, including from the Hutt River, therefore supporting the idea that at least some plastic inputs occur upstream (Mora-Teddy \& Matthaei, 2020). Bridson et al. (2020) however, suggests that a significant proportion of the microplastic load found around New Zealand may originate from nations such as Australia and the South-east of Asia. This is particularly likely when considering the major oceanic circulation systems in the Southern Hemisphere, where the New Zealand archipelago encounters the East Australian current (Bridson et al., 2020), as well as the report from Eriksen et al. (2014), where New Zealand is included in an accumulation zone for floating plastic litter. Regardless of whether microplastics found in Wellington Harbour originate locally or from afar, it is still possible that once they are in the harbour, they are retained in the region for a significant period.

Wellington Harbour is considered a well-mixed system (Maxwell, 1956; Gilmour, 1960; Booth, 1975), with most local discrepancies quickly dispersed throughout the $76 \mathrm{~km}^{2}$ area. However, Booth (1975) also reported that the harbour is relatively cut off from the Cook Strait, with much of the mixing occurring within the constraints of the Harbour. This does suggest that it would be possible for microplastics to have a long residence time inside the Harbour's system, with the possibility of also collecting within the semi-enclosed region. Consequently, if pollutant loads are significant with the additional ability to collect over time, it is probable that microplastic sinks such as beaches are a common deposition point for the particles. On the other hand, environmental variables further complicate the issue, in that beaches may not be permanent sinks. Moore (2008) reports that onshore winds will often push floating debris onto shorelines, whilst offshore winds will have the opposite effect. Furthermore, a lack of wind promotes the accumulation of synthetic particles on the coastline as they have time to settle into the sediment, whilst strong winds often displace the plastics possibly resuspending the particles back into the water column (Oigman-Pszczol \& Creed, 2007; Costa et al., 2011; Agamuthu et al., 2019). These variables make it extremely difficult to accurately predict the spatial and temporal trends of microplastic abundance and distribution, even in semi-enclosed environments such as Wellington Harbour.

There was a higher degree of spatial variation in microplastic abundance for beaches than mussels, despite the similar, relatively close distances between sites (approximately $1.5 \mathrm{~km}-$ straightline distance). Differing levels of human activity throughout the year has often been attributed to this changeable load in various studies (Bridson et al., 2020), as movement of 
particles on the top layers of beach sediment often results in smaller items being dispersed or buried (Agamuthu et al., 2019). However, other contributing factors to this variation are likely to be differences amongst rates of sediment erosion, the variable topography of the beaches (Ribic et al., 2012; Agamuthu et al., 2019), and the direction that the beach faces in relation to the prevailing Wellington winds. In this study, the approximate directions of each beach differ, with Oriental Bay beach facing North, Seatoun beach facing North-East, and Balaena Bay facing South-East. As stated in Oigman-Pszczol \& Creed (2007), Costa et al. (2011), and Agamuthu et al. (2019), beaches that are not as readily exposed to prevailing winds often accumulate microplastics to a greater degree, as the lack of wind force enables the pollutants to settle on the coastline. Therefore, the differing coastline directions, in conjunction with some or all of the other social and environmental factors, may contribute to the irregular spatial variation observed during this study.

\section{Microplastic abundance \& distribution in surface water tows}

Temporal trends in microplastic abundance peaked at similar periods throughout the three sources sampled. Tissues of M. galloprovincialis mussels had the highest load in February 2019, also observed in water surface tows. Beach sediments, however, had a slight delay, with their peak microplastic load occurring in the next sampling period, May 2019. Interestingly, the temporal trends seen in mussel tissues and water samples followed a similar curve to each other, while beach sediment data experienced more drastic peaks and troughs. This is possibly reminiscent of the results found in Qu et al. (2018), who report a correlation between the abundance of microplastics in surface waters and within mussels, but no correlation to the pollutant load in beach sediments within the same areas. Furthermore, Qu et al. (2018) suggest that the microplastic abundances present within mussel tissues are dependent upon the quantities in the water column. This determination cannot be made in this study, but the possibility of a correlation is intriguing, nonetheless.

This is the first study in New Zealand that has surveyed surface waters for microplastic occurrence, although unfortunately limited in scope due to logistical constraints. Worldwide, particularly within the Northern Hemisphere, surface waters have been studied extensively, providing valuable estimations of micro- and macroplastic pollution. Therefore, although the results from this study in Wellington Harbour should be interpreted with caution, it provides a baseline for future surface water studies investigating abundance and distribution of plastic in New Zealand coastal waters. These transects collected between $15-107$ particles per 200 $\mathrm{m}$, with an average of $59.5 \pm 23.8$ particles per $200 \mathrm{~m}$. Global results from sea surface tows 
are extremely variable, with one study reporting a maximum of 157,000 particles $\mathrm{km}^{-2}$ in the North-East Atlantic (Maes et al., 2017), while studies carried out by the North-Pacific gyre have previously recorded up to 300,000 particles $\mathrm{km}^{-2}$ (Moore et al., 2001). However, methodologies for assessing differences and similarities in global microplastic abundance are still varied in almost every aspect (Galgani et al., 2015). With no standard methodologies across the board, there are limitations upon creating a comprehensive understanding of marine plastic pollution, let alone taking steps to manage and reduce it. Furthermore, microplastic abundance and distribution within surface waters are again likely to be heavily impacted by environmental drivers such as vertical mixing due to wind strength, resulting in even larger variance between scientific studies.

\section{Conclusion}

This study is the first of its kind in New Zealand, and one of the first globally. Taking a multi-pronged approach to assessing microplastic pollution in a localised area provides a valuable baseline for further research. Surface waters, beach sediments, and filter-feeding bivalves such as Mytilus galloprovincialis have all been studied comprehensively in other nations, particularly throughout the Northern Hemisphere. Therefore, through investigating possible temporal and spatial patterns of microplastic abundance and distribution, future studies may build upon the initial trends observed. 


\section{General discussion}

Understanding how the abundance and distribution of microplastic debris varies in the marine environment is integral to coming up with mitigation, management, and prevention strategies. However, unless there is a global understanding of where this pollutant is, and at what concentrations, we cannot begin to effectively reduce the impacts upon affected marine species. Plastic pollution has been an ever-increasing issue since mass production began in the 1940's (Cole et al., 2011), particularly as its impacts were initially underestimated (Colton et al., 1974; Zitko \& Hanlon, 1991; Gregory, 1996). In the marine environment, the characteristics of plastic enable it to persist for an extended period of time and penetrate numerous ecosystems including the sea surface, the benthos \& deep sea, coastal sediments, polar environments, and more (e.g. Van Cauwenberghe et al., 2013; Obbard et al., 2014; Woodall et al., 2014; Cózar et al., 2015). However, most of this current information has arisen from studies carried out in the Northern Hemisphere, since it is more heavily populated and thus has a greater number of research facilities investigating plastic pollution in the oceans (Lusher, 2015; Avio et al., 2017). Consequently, until recently it has been relatively unknown as to whether oceanic currents have circulated microplastics throughout the world, or alternatively whether direct and indirect inputs of plastic pollution are as significant in the Southern Hemisphere as they are in the Northern Hemisphere.

Variation in microplastic abundance can impact the associated marine biota. If concentration of microplastic debris is high, this interaction is likely to be significant, therefore increasing the associated risk for negative effects on individuals (Agamuthu et al., 2019). Direct interactions such as ingestion or adherence to tissues are typically observed in taxa that are filter-feeders or suspension-feeders, thus occupying the lower trophic levels. However, once plastics have entered the food web, there is evidence to suggest that the particles - and the chemicals associated with them - can be transported up throughout the food web and bioaccumulate within internal tissues (Kelly et al., 2007). Such interactions have been reported to have negative impacts upon the physiology and behaviour of organisms (Andrady, 2011; Wright, 2013; Gall \& Thompson, 2015; Agamuthu et al., 2019) and also possibly human health (Van Cauwenberghe \& Janssen, 2014; Agamuthu et al., 2019) although this facet of research is still in its infancy (Vandermeersch et al., 2015).

In this study, I found that microplastics are found in many habitats throughout Wellington Harbour, as well as in the tissues of intertidal M. galloprovincialis mussels. The 
concentration within $M$. galloprovincialis specimens was comparable to the microplastic loads reported within other studies that have examined mussel species, including one that was carried out in New Zealand on P. canaliculus (Webb et al., 2019). Microplastic concentrations within beach sediments and water surface tows were also in a similar range to what other studies have reported, however on a global scale there is an extremely broad range of estimates for the concentration of microplastics in these habitats. This discrepancy is thought to be a result of the wide range of environmental variables that drive the movement of plastics within the water column and onto the beach, including wind and wave exposure, sediment erosion, and direction of the coastline, along with the inconsistency between different sampling methodologies used in various studies.

Sampling methodologies differ widely in almost every way across the breadth of current microplastic research, from field collections to laboratory analyses. For surface water sampling, this variation often arises from the type of net or collection technique used, whether that be a neuston net, Continuous Plankton Recorder, manta trawl, the 'grab' technique, or a saltwater intake pump (Figure 4.1) (Robinson et al., 2014; Setälä et al., 2016; Barrows et al., 2017; Cincinelli et al., 2017; Green et al., 2018). These all have different mesh sizes and varying success in capturing environmental microplastics. The differences are exacerbated in the laboratory setting, not only for surface water samples, but those from sediments and organisms also. The extraction of synthetic particles from different sources can be done in many ways including density flotations, acidic separations, and the digestion of soft tissue using numerous kinds of acids, alkali, and oxidation chemicals, all of which is further demonstrated by Miller et al. (2017) who has compiled a review of the methodologies used in a range of studies. This lack of consistency across the literature not only makes it difficult to know which methods to follow, but also increases the likelihood of sampling error when assessing pollutant load, simultaneously hindering the chance to make progress at all scales within the field. 


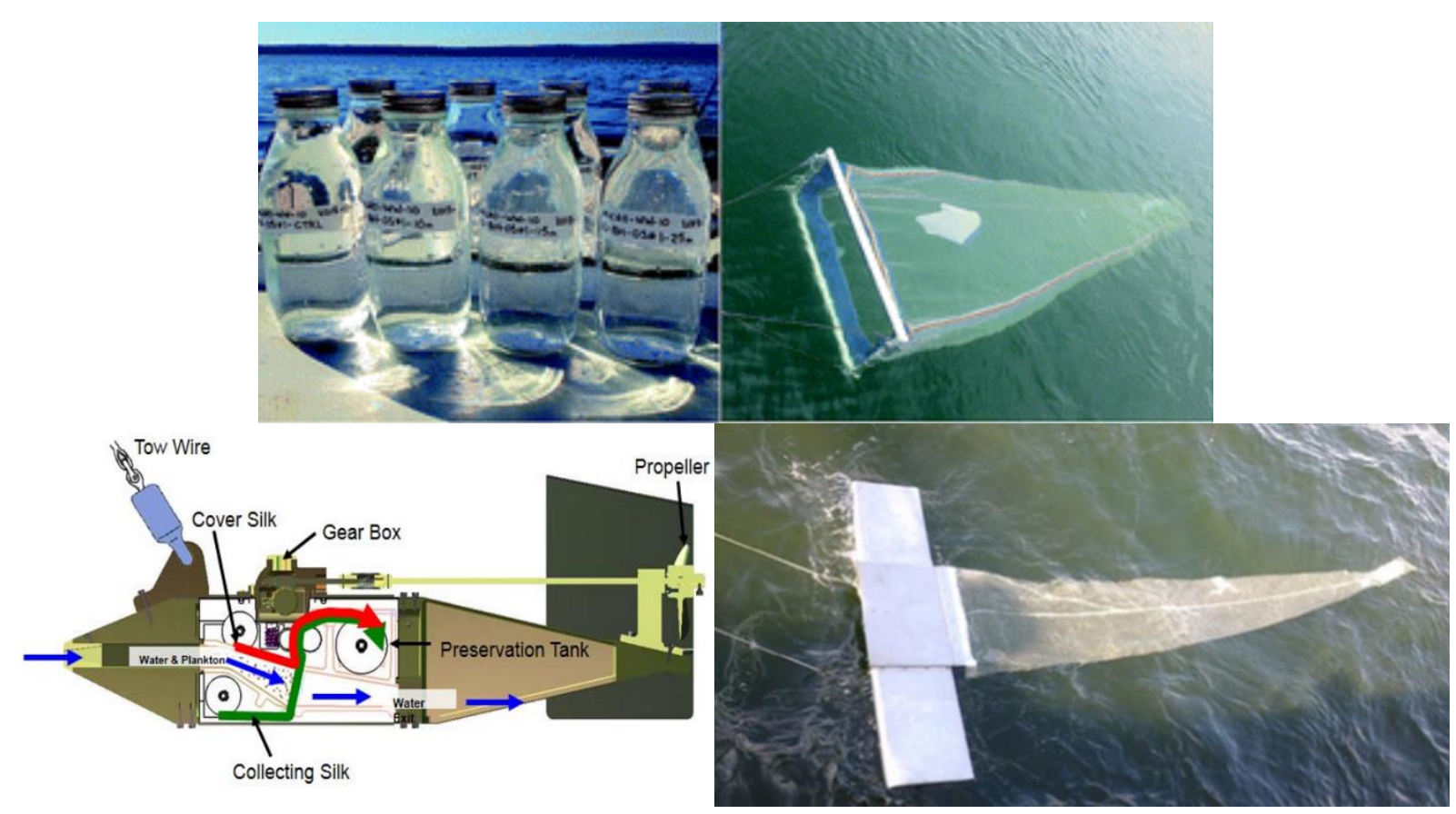

Figure 4.1: Examples of the various sea surface sampling methods that are commonly used for assessing microplastic load. A) is a 'grab' system, B) a neuston net, C) a Continuous Plankton Recorder (CPR), and D) is a manta trawl. Image credit: A) \& B) Barrows et al., 2017; C) Robinson et al., and D) Setälä et al., 2016.

In general, the abundance and distribution of microplastic particles was highly dynamic at both the relatively small scale within Wellington Harbour, and in the large scale of the surface waters between New Zealand and the Ross Sea. This high level of variability is one of the main conclusions to come from this research and is indicative of the complex processes that dictate the movement of plastic pollutants. Plastic materials of all size classes are renowned for being lightweight yet durable, which subsequently makes it difficult to predict and model where they are likely to move or end up in the world's oceans (Andrady, 2011). In saying that, this study provides preliminary evidence that both fine-scale (within an urbanised harbour) and wide-scale (across multiple oceanographic zones) spatial differences are not as pronounced as temporal differences. Spatial trends have been studies in far more depth, due to macropatterns such as the trend for plastic to accumulate in gyres and along frontal systems (Moore et al., 2001; Van Sebille et al., 2012; Fazey \& Ryan, 2016). There have only been a limited amount of studies that examine both spatial and temporal trends in microplastic abundance and distribution, however of those that do, both space and time are thought to be useful predictors to model current and future abundance of this marine pollutant (Isobe et al., 2019).

In accordance to predictions, microfibres were the most prevalent morphotype of microplastic found throughout both Wellington Harbour and the transects between New Zealand and the Ross Sea. These results were ubiquitous across sea surface tows, beach sediment surveys, and 
contamination within $M$. galloprovincialis mussels. This is consistent with reports of global microplastic estimates, some of which predict between 90 - 95\% of all marine microplastic debris to be in the form of microfibres (Galgani et al., 2015; Cesa et al., 2017; Barrows et al., 2017; Woods et al., 2018). As opposed to other morphotypes, fibres are thought to be particularly extensive in the marine environment, with a large proportion coming from human clothing, ropes, and fishing gear (Andrady, 2011; Cesa et al., 2017).

Clothing remains a significant source of microplastic pollution, as many items are made from synthetic materials such as nylon and polyester. Due to their miniscule size, most washing machines and dryers do not have inbuilt filters that can capture microfibres, so these escape into the wastewater drains and eventually are discharged into the sea. Browne et al. (2011) reported that one single polyester fibre shirt can release 1900 fibres during a single wash, so this value adds up quickly. As evidenced by the microfibres found within $M$.

galloprovincialis tissues during this study, along with ingested microfibres reported in other species including - but not limited to - other invertebrates such as Carcinus maenas crabs (Watts et al., 2015), fish larvae (Steer et al., 2017), and shorebirds (Lourenço et al., 2017), it is clear that this morphotype is bioavailable to marine organisms, consequently entering the marine food web. While scientific research and the public's understanding of microplastic pollution has grown extensively in recent years, most of this awareness has focused upon other morphotypes such as beads and fragments from larger debris, as evidenced by popular campaigns from environmental organisations including Greenpeace (Greenpeace New Zealand, 2020) and Plastic Oceans (Plastic Oceans International, 2020). Consequently, there now appears to be a gap between what microplastic researchers are finding within the environment and what the public is cognisant of, with regards to the sources of plastic and mitigation solutions.

\section{Limitations of Research}

Due to the breadth of information collated within this study, the main limitations of this thesis arose from both time and resource logistical constraints. For the two data chapters (Chapters $2 \& 3$ ), time and resource limitations resulted in the sample analyses being conducted through visual microscopic analysis, but without the opportunity for confirmatory spectroscopy. Typically, many studies identify microplastics first through microscopic analysis, then confirmation of synthetic particles with Raman or Fourier transform infrared (FTIR) spectroscopy, which can further characterise the specific polymers of the plastic particles, beyond the simple morphotype. Furthermore, laboratory analysis utilised adapted methods 
from previous papers, including Dehaut et al. (2016), Zhao et al. (2016), and Miller et al. (2017). Methodologies such as which separation technique to use, the most effective chemical for degradation of a mussel's soft tissue, best filtration size for microplastic separation, and the type of net most suited to carrying out surface water plankton tows all differed drastically throughout the current available literature, thus making comparisons between my thesis and other examples within literature difficult.

The time and resource constraints also meant that the ability to undertake replication of mussel, beach sediment, and surface water surveys within Wellington Harbour was limited, with the plankton tows only able to give a baseline indication of the abundance of microplastics contained within surface waters once every three months. Mussel and beach sampling was more robust, with multiple samples taken from each site during each collection, however the time it took to thoroughly process each sample meant I was unable to examine a larger sample size within this study. Larger sample sizes would provide a clearer and broader perspective of the overall microplastic pollution load within this coastal environment.

Environmental drivers are a significant factor when it comes to microplastic abundance and distribution, variables such as wind strength, vertical mixing, and seasonal changes in ocean currents (Eriksen et al., 2014) are expected to result in a significant change in marine microplastic load throughout the seasons. Data from chapter 3 sees a peak in microplastic abundance towards the beginning of the year, in the summer and early autumnal months. Investigations into the environmental variables at play within Wellington Harbour would be expected to provide inference into the reasons behind any possible temporal change. Chapter 2 illustrated the temporal change that often occurs in surface water microplastic loads from year to year, which was an aspect unable to be examined in Chapter 3, as a long-term study was not feasible in the scope of this study. Temporal and spatial microplastic research appears to be a recent development in the field, with a handful of studies examining a range of different scales, whether that be investigating the fine-scale daily changes within a small area (Imhof et al., 2017), as well as broader seasonal changes across a coastline (Baechler et $a l ., 2020)$ and monthly variation in beach sediments across the span of a year, on three different islands (Herrera et al., 2018). The consideration of changes throughout time and space are considered necessary for the development of an overall understanding of microplastic occurrence, as well as future predictions. 
Studies investigating annual changes in marine plastic pollution are rare to come by, as they require a significant logistical commitment. Two previous research papers which have carried out such a study are Isobe et al. (2019) and Ostle et al. (2019). The study by Ostle et al. (2019) examined the occurrence of plastics throughout the North Atlantic, over a 60-year period (1957 - 2016). This study also utilised a CPR for its sub-surface water sampling, and reported a clear temporal increase in both microplastics and macroplastics. On the other hand, Isobe et al. (2019) used data from Neuston net transects collected between Japan and Antarctica in 2016 to infer previous and future estimates of microplastic abundance and distribution using a numerical model. Both studies are extremely different in their approaches, however the reported results provide strong support for a long-term increase in marine plastic pollution, along with the potential for even greater microplastic loads to be seen throughout the world's oceans in the coming years.

Contamination from outside sources poses a significant risk to microplastic studies, particularly as fibres and fragments circulate in the air and are easily removed from clothing. Many studies cite contamination as a means for error in results, including Li et al. (2019), stating that contamination control is an integral detail that must be taken into account when designing an experiment or conducting a field survey. Recent studies have reported that microplastics can travel through the atmosphere, including both urban (Wright et al., 2020) and remote (Allen et al., 2019) locations. Estimations using air mass trajectory suggest that microplastics of multiple morphotypes can cover a distance of over $95 \mathrm{~km}$ before they settle in the terrestrial or marine environment, thus illustrating their potential to be a major source of transport for plastic pollution (Allen et al., 2019). Contamination risk throughout this thesis is low, as preventative measures were made by using a limited amount of plastic laboratory equipment, not wearing synthetic clothing during collection or analysis, and covering samples to prevent contamination from the air. In saying that, the samples for Chapter 2 were collected by a third party, the crew of San Aotea II, before being initially processed by NIWA. However, steps to prevent contamination within these samples were taken, including comprehensive training of a dedicated crew member to the deployment and retrieval of the CPR, as well as training in how to appropriately label and preserve the silks (Robinson et al., 2014). Regardless, a small level of contamination is likely to have resulted in a minimal amount of measurement error. 


\section{Conclusions and Suggestions for Further Research}

This thesis has contributed to the global pool of information on temporal and spatial trends of microplastic loads within the marine environment. With consideration to the Southern Hemisphere, little research currently exists to confirm whether the abundance and distribution of microplastics are comparable to what has been reported in the Northern Hemisphere. The differing responses to temporal and spatial sampling, and the highly dynamic nature of microplastic load in Wellington Harbour and the Southern Ocean demonstrates how integral it is to consider time and space when focussing management efforts. These results also support the consensus that no matter where studies are carried out throughout the globe, marine biota is still at risk of ingesting these foreign particles. Ideally, additional research would establish multi-year studies that further demonstrate the spatial and temporal changes that occur in various regions around New Zealand, along with a continuation of surface water collections between New Zealand and the Ross Sea with microplastics abundance confirmed through the use of FTIR or Raman spectroscopy. Ideally, such research would combine field studies with laboratory experiments, to determine the vulnerability of species in New Zealand and Antarctica to the deleterious effects of synthetic particles. These kinds of investigations would account for some of the areas that could not be examined in detail within this study. Additionally, this research would add valuable information that contributes to the development of management and mitigation advice in order to eventually reduce the negative effects that plastic pollution wreaks upon the local, national, and global marine environment. 


\section{References}

Absher, T.M., Ferreira, S.L., Kern, Y., Ferreira Jr., A.L., Christo, S.W. \& Ando, R.A. (2019). Incidence and identification of microfibers in ocean waters in Admiralty Bay, Antarctica. Environmental Science and Pollution Research, 26, 292-298.

Agamuthu, P., Mehran, S.B., Norkhairah, A. \& Norkhairiyah, A. (2019). Marine debris: A review of impacts and global initiatives. Waste Management \& Research, 37, 987-1002.

Allen, S., Allen, D., Phoenix, V.R., Le Roux, G., Jiménez, P.D., Simonneau, A., Binet, S. \& Galop, D. (2019). Atmospheric transport and deposition of microplastics in a remote mountain catchment. Nature Geoscience, 12, 339-344.

Andrady, A.L. (2011). Microplastics in the marine environment. Marine Pollution Bulletin, 62, 1596-1605.

Andrady, A.L. (2017). The plastic in microplastics: A review. Marine Pollution Bulletin, 119, $12-22$.

Avery-Gomm, S., Borrelle, S.B. \& Provencher, J.F. (2018). Linking plastic ingestion research with marine wildlife conservation. Science of the Total Environment, 637-638, 14921495.

Avio, C.G., Gorbi, S. \& Regoli, F. (2017). Plastics and microplastics in the oceans: From emerging pollutants to emerged threat. Marine Environmental Research, 128, 2-11.

Baechler, B.R., Granek, E.F., Hunter, M.V. \& Conn, K.E. (2020). Microplastic concentrations in two Oregon bivalve species: Spatial, temporal, and species variability. Limnology and Oceanography Letters, 5, 54-65.

Bakir, A., Rowland, S.J. \& Thompson, R.C. (2012). Competitive sorption of persistent organic pollutants onto microplastics in the marine environment. Marine Pollution Bulletin, 64, 2782-2789.

Barnes, D.K.A., Galgani, F., Thompson, R.C. \& Barlaz, M. (2009). Accumulation and fragmentation of plastic debris in global environments. Philosophical Transactions of the Royal Society B. 364, 1985-1998.

Barrows, A.P.W., Neumann, C.A., Berger, M.L. \& Shaw, S.D (2017). Grab vs. neuston tow net: A microplastic sampling performance comparison and possible advances in the field. Analytical Methods, 9, 1446-1453.

Battacharya, P., Turner, J.P. \& Ke, P.C. (2010). Physical adsorption of charged plastic nanoparticles affects algal photosynthesis. The Journal of Physical Chemistry C, 114, 1655616561.

Bergmann, M. \& Klages, M. (2012). Increase of litter at the Arctic deep-sea observatory HAUSGARTEN. Marine Pollution Bulletin, 64, 2734-2741.

Bergmann, M., Tekman, M.B. \& Gutow, L. (2017). Sea change for plastic pollution. Nature, 544, 297. 
Bernard, K.S. \& Steinberg, D.K. (2013). Krill biomass and aggregation structure in relation to tidal cycle in a penguin foraging region off the Western Antarctic Peninsula. ICES Journal of Marine Science, 70, 834-849.

Bessa, F., Ratcliffe, N., Otero, V., Sobral, P. \& Marques, J.C. (2019). Microplastics in gentoo penguins from the Antarctic region. Scientific Reports (Nature Publisher Group), 9, 1-7.

Besseling, E., Wegner, A., Foekema, E.M., Van Den Heuvel-Greve, M.J. \& Koelmans, A.A. (2013). Effects of microplastic on fitness and PCB bioaccumulation by the Lugworm Arenicola marina (L.). Environmental Science \& Technology, 47, 593-600.

Beyer, J., Green, N.W., Brooks, S., Allan, I.J., Ruus, A., Gomes, T., Brate, I.L.N. \& Schoyen, M. (2017). Blue mussels (Mytilus edulis spp.) as sentinel organisms in coastal pollution monitoring: A review. Marine Environmental Research, 130, 338-365.

Booth, J.D. (1975). Seasonal and tidal variation in the hydrology of Wellington Harbour. New Zealand Journal of Freshwater Research, 9, 333-354.

Brate, I.L.N., Hurley, R., Iverson, K., Beyer, J., Thomas, K.V., Steindal, C.C., Green, N.W., Olsen, M. \& Lusher, A. (2018). Mytilus spp. as sentinels for monitoring microplastic pollution in Norweigan coastal waters: A qualitative and quantitative study. Environmental Pollution, 243, 383-393.

Bridson, J.H., Patel, M., Lewis, A., Gaw, S. \& Parker, K. (2020). Microplastic contamination in Auckland (New Zealand) beach sediments. Marine Pollution Bulletin, 151, 110867.

Browne, M.A., Crump, P., Niven, S.J., Teuten, E., Tonkin, A., Galloway, T. \& Thompson, R. (2011). Accumulation of microplastic on shorelines worldwide: Sources and sinks.

Environmental Science \& Technology, 45, 9175-9178.

Browne, M.A., Dissanayake, A., Galloway, T.S., Lowe, D.M. \& Thompson, R.C. (2008). Ingested microscopic plastic translocates to the circulatory system of the mussel, Mytilus edulis (L.). Environmental Science and Technology, 42, 5026-5031.

Buchanan, J.B. (1971). Pollution by synthetic fibres. Marine Pollution Bulletin, 2, 23.

Capolupo, M., Franzellitti, S., Valbonesi, P., Lanzas, C.S. \& Fabbri, E. (2018). Uptake and transcriptional effects of polystyrene microplastics in larval stages of the Mediterranean mussel Mytilus galloprovincialis. Environmental Pollution, 241, 1038-1047.

Carpenter, E.J. \& Smith, K.L. (1972). Plastics on the Sargasso Sea surface. Science, 175, 1240-1241.

Carpenter, E.J., Anderson, S.J., Harvey, G.R., Miklas, H.P. \& Peck, B.B. (1972). Polystyrene spherules in coastal waters. Science, 175, 749-750.

Carter, L. (1977). Sand transport, Wellington Harbour entrance, New Zealand. New Zealand Journal of Geology and Geophysics, 20, 335-351.

Cesa, F.S., Turra, A. \& Baruque-Ramos, J. (2017). Synthetic fibers as microplastics in the marine environment: A review from textile perspective with a focus on domestic washings. Science of the Total Environment, 598, 1116-1129. 
Chae, Y. \& An, Y.-J. (2018). Current research trends on plastic pollution and ecological impacts on the soil ecosystem: A review. Environmental Pollution, 240, 387-395.

Chae, Y. \& An, Y.-J. (2020). Effects of food presence on microplastic ingestion and egestion in Mytilus galloprovincialis. Chemosphere, 240, 124855.

Cincinelli, A., Scopetani, C., Chelazzi, D., Lombardini, E., Martellini, T., Katsoyiannis, A., Fossi, M.C. \& Corsolini, S. (2017). Microplastic in the surface waters of the Ross Sea (Antarctica): Occurrence, distribution and characterization by FTIR. Chemosphere, 175, 391400 .

Claessons, M., De Meester, S., Van Landuyt, I., De Clerck, K. \& Janssen, C.R. (2011). Occurrence and distribution of microplastics in marine sediments along the Belgian coast. Marine Pollution Bulletin, 62, 2199-2204.

Claessons, M., Van Cauwenberghe, L., Vandegehuchte, M.B .\& Janssen, C.R. (2013). New techniques for the detection of microplastics in sediments and field collected organisms. Marine Pollution Bulletin, 70, 227-233.

Clunies-Ross, P.J., Smith, G.P.S., Gordon, K.C. \& Gaw, S. (2016). Synthetic shorelines in New Zealand? Quantification and characterisation of microplastic pollution on Canterbury's coastlines. New Zealand Journal of Marine and Freshwater Research, 50, 317-325

Cole, M., Lindeque, P., Halsband, C. \& Galloway, T. (2011). Microplastics as contaminants in the marine environment: A review. Marine Pollution Bulletin, 62, 25882597

Cole, M., Lindeque, P.K., Fileman, E.S., Halsband, C., Goodhead, R., Moger, J. \& Galloway, T.S. (2013). Microplastic ingestion by zooplankton. Environmental Science \& Technology, 47, 6646-6655.

Collignon, A., Hecq, J.H., Galgani, F., Voisin, P., Collard, F. \& Goffart, A. (2012). Neustonic microplastic and zooplankton in the North Western Mediterranean Sea. Marine Pollution Bulletin, 64, 861-864.

Colton, J.B., Knapp, F.D. \& Burns, B.R. (1974) Plastic particles in surface waters of the Northwestern Atlantic. Science, 185, 491-497.

Costa, M.F., Silva-Cavalcanti, J.S., Barbosa, C.C., Portugal, J.L. \& Barletta, M. (2011). Plastics buried in the inter-tidal plain of a tropical estuarine ecosystem. Journal of Coastal Research, SI, 339-343.

Cózar, A., Echevarria, F., Gonzalez-Gordillo, J.I., Irigoien, X., Ubeda, B., Hernandez-Leon, S., Palma, A.T., Navarro, S., Garcia-de-Lomas, J., Ruiz, A., Fernandez-de-Puellos, M.L. \& Duarte, C.M. (2014). Plastic debris in the open ocean. Proceedings of the National Academy of Sciences of the United States of America, 111, 10239-10244.

Critchell, K. \& Hoogenboom, M.O. (2018). Effects of microplastic exposure on the body condition and behaviour of planktivorous reef fish (Acanthochromis polyacanthus). PLoS ONE, 13, e0193308.

Dauvergne, P. (2018). Why is the global governance of plastic failing the oceans? Global Environmental Change, 51, 22-31. 
Dawson, A.L., Kawaguchi, S., King, C.K., Townsend, K.A., King, R., Huston, W.M. \& Bengtson Nash, S.M. (2018). Turning microplastics into nanoplastics through digestive fragmentation by Antarctic krill. Nature Communications, 9, 1-8.

Dehaut, A., Cassone, A.L., Frere, L., Hermabessiere, L., Himber, C., Rinnert, E., Riviere, G., Lambert, C., Soudant, P., Huvet, A., Duflos, G. \& Paul-Pont, I. (2016). Microplastics in seafood: benchmark protocol for their extraction and characterization. Environmental Pollution, 215, 223-233.

Derraik, J.G.B. (2002). The pollution of the marine environment by plastic debris: A review. Marine Pollution Bulletin, 44, 842-852.

De Sá, L.C., Luís, L.G. \& Guilhermino, L. (2015). Effects of microplastics on juveniles of the common goby (Pomatoschistus microps): Confusion with prey, reduction of the predatory performance and efficiency, and possible influence of developmental conditions.

Environmental Pollution, 196, 359-362.

Desforges, J.-P.W., Galbraith, M., Dangerfield, N. \& Ross, P.S. (2014). Widespread distribution of microplastics in subsurface seawater in the NE Pacific Ocean. Marine Pollution Bulletin, 79, 94-99.

Dikareva, N. \& Simon, K. (2019). Microplastic pollution in streams spanning an urbanisation gradient. Environmental Pollution, 250, 292-299.

Engler, R.E. (2012). The complex interaction between marine debris and toxic chemicals in the ocean. Environmental Science \& Technology, 46, 12302-12315.

Eriksen, M., Lebreton, L.C.M., Carson, H.S., Thiel, M., Moore, C.M., Borerro, J.C., Galgani, F., Ryan, P.G. \& Reisser, J. (2014). Plastic Pollution in the world's oceans: More than 5 trillion plastic pieces weighing over 250,000 tons afloat at sea. PLOS ONE, 9, e1111913.

Eriksen, M., Maximenko, N., Thiel, M., Cummins, A., Lattin, G., Wilson, S., Hafner, J., Zellers, A. \& Rifman, S. (2013). Plastic pollution in the South Pacific subtropical gyre. Marine Pollution Bulletin, 68, 71-76.

Fazey, F.M.C. \& Ryan, P.G. (2016). Debris size and buoyancy influence the dispersal distance of stranded litter. Marine Pollution Bulletin, 110, 371-377.

Fendall, L.S. \& Sewell, M.A. (2009). Contributing to marine pollution by washing your face: microplastics in facial cleansers. Marine Pollution Bulletin, 58, 1225-1228.

Fowler, C.W. (1987). Marine debris and northern fur seals: A case study. Marine Pollution Bulletin, 18, 326-335.

Fry, D.M., Fefer, S.I. \& Sileo, L. (1987). Ingestion of plastic debris by Laysan albatrosses and wedge-tailed shearwaters in the Hawaiian Islands. Marine Pollution Bulletin, 18, 339343.

Galgani, F., Hanke, G. \& Maes, T. (2015). Global distribution, composition, and abundance of marine litter. In: Bergmann, M., Gutow, L. \& Klages, M (Eds.), Marine Anthropogenic Litter. Springer International Publishing, pp. 29-56 (chapter 2). 
Gall, S.C. \& Thompson, R.C. (2015). The impact of debris on marine life. Marine Pollution Bulletin, 92, 170-179.

Galloway, T.S. \& Lewis, C.N. (2016). Marine microplastics spell big problems for future generations. Proceedings of the National Academy of Sciences of the United States of America, 113, 2331-2333.

Gardner, J.P.A. (2002). Effects of seston variability on the clearance rate and absorption efficiency of the mussels Aulacomya maoriana, Mytilus galloprovincialis, and Perna canaliculus from New Zealand. Journal of Experimental Marine Biology and Ecology, 268, 83-101.

Geilfus, N.X., Munson, K.M., Sousa, J., Germanov, Y., Bhugaloo, S., Babb, D. \& Wang, F. (2019). Distribution and impacts of microplastic incorporation within sea ice. Marine Pollution Bulletin, 145, 463-473.

Goldberg, E.D. (1997). Plasticizing the seafloor: An overview. Environmental Technology, 18, 195-201.

Gomiero, A., Strafella, P., Øysæd, K.B. \& Fabi, G. (2019). First occurrence and composition assessment of microplastics in native mussels collected from coastal and offshore areas of the northern and central Adriatic Sea. Environmental Science and Pollution Research, 26, 2440724416.

Gonçalves, C., Martins, M., Sobral, P., Costa, P.M. \& Costa, M.H. (2019). An assessment of the ability to ingest and excrete microplastics by filter-feeders: A case study with the Mediterranean mussel. Environmental Pollution, 245, 600-606.

Graham, R.M., Boer, A.M., Heywood, K.J., Chapman, M.R. \& Stevens, D.P. (2012). Southern Ocean fronts: Controlled by wind or topography? Journal of Geophysical Research: Oceans, 117.

Green, D.S., Kregting, L., Boots, B., Blockley, D.J., Brickle, P., da Costa, M. \& Crowley, Q. (2018). A comparison of sampling methods for seawater microplastics and a first report of the microplastic litter in coastal waters of Ascension and Falkland Islands. Marine Pollution Bulletin, 137, 695-701.

Greenpeace New Zealand. (2020). Protect the Oceans. Retrieved from https://www.greenpeace.org/new-zealand/act/protect-the-oceans/.

Gregory, M.R. (1977). Plastic pellets on New Zealand beaches. Marine Pollution Bulletin, 8, 82-84.

Gregory, M.R. (1978). Accumulation and distribution of virgin plastic granules on New Zealand beaches. Journal of Marine and Freshwater Research, 12, 399-414.

Gregory, M.R. (1996). Plastic 'scrubbers' in hand cleansers: a further (and minor) source for marine pollution identified. Marine Pollution Bulletin, 32, 867-871.

Gregory, M.R. (2009). Environmental implications of plastic debris in marine settings entanglement, ingestion, smothering, hangers-on, hitch-hiking, and alien invasions.

Philosophical Transactions of the Royal Society B, 364, 2013-2025. 
Hall, N.M., Berry, K.L.E., Rintoul, L. \& Hoogenboom, M.O. (2015). Microplastic ingestion by scleractinian corals. Marine Biology, 162, 725-732.

Harper, P.C. \& Fowler, J.A. (1987). Plastic pellets in New Zealand storm-killed prions (Pachyptila spp.) 1958-1977. Notornis 2 34, 65-70.

Hart, D.E. \& Bryan, K.R. (2008). New Zealand coastal system boundaries, connections and management. New Zealand Geographer, 64, 129-143.

Hartmann, N.B., Hüffer, T., Thompson, R.C., Hassellöv, M., Verschoor, A., Daugaard, A.E., Rist, S., Karlsson, T., Brennholt, N., Cole, M., Herrling, M.P., Hess, M.C., Ivleva, N.P., Lusher, A.L. \& Wagner, M. (2019). Are we speaking the same language? Recommendations for a definition and categorization framework for plastic debris. Environmental Science \& Technology, 53, 1039-1047.

Hays, H. \& Cormons, G. (1974). Plastic particles found in tern pellets, on coastal beaches and at factory sites. Marine Pollution Bulletin, 5, 44-46.

Heath, R.A. (1977). Circulation and hydrology of Wellington Harbour. New Zealand Oceanographic survey, $\mathbf{1 2}, 8$.

Henderson, J.R. (2001). A pre- and post-MARPOL Annex V summary of Hawaiian monk seal entanglements and marine debris accumulation in the Northwestern Hawaiian Islands, 1982-1988. Marine Pollution Bulletin, 42, 584-589.

Hermabessiere, L., Dehaut, A., Paul-Pont, I., Lacroix, C., Jezequel, R., Soudant, P. \& Duflos, G. (2017). Occurrence and effects of plastic additives on marine environments and organisms: A review. Chemosphere, 182, 781-793.

Hermabessiere, L. Paul-Pont, I., Cassone, A.-L. Himber, C., Reveveur, J., Jezequel, R., El Rakwe, M., Rinnert, E., Rivière, G., Lambert, C., Huvet, A., Dehaut, A., Duflos, G. \& Soudant, P. (2019). Microplastic contamination and pollutant levels in mussels and cockles collected along the channel coasts. Environmental Pollution, 250, 807-819.

Herrera, A., Asensio, M., Martinez, I., Santana, A., Packard, T. \& Gómez, M. (2018). Microplastic and tar pollution on three Canary Islands beaches: An annual study. Marine Pollution Bulletin, 129, 494-502.

Hidalgo-Ruz, V., Gutow, L., Thompson, R.C. \& Thiel, M. (2012). Microplastics in the marine environment: A review of the methods used for identification and quantification. Environmental Science \& Technology, 46, 3060-3075.

Hughes, K.A. (2010). How committed are we to monitoring human impacts in Antarctica? Environmental Research Letters, 5, 041001.

Imhof, H.K., Sigl, R., Brauer, E., Feyl, S., Giesemann, P., Klink, S., Leupolz, K., Löder, M.G.J., Löschel, L.A., Missun, J., Muszynski, S., Ramsperger, A.F.R.M., Schrank, I., Speck, S., Steibl, S., Trotter, B., Winter, I. \& Laforsch, C. (2017). Spatial and temporal variation of macro-, meso- and microplastic abundance on a remote coral island of the Maldives, Indian Ocean. Marine Pollution Bulletin, 116, 340-347. 
Isobe, A., Uchiyama-Matsumoto, K., Uchida, K. \& Tokai, T. (2017). Microplastics in the Southern Ocean. Marine Pollution Bulletin, 114, 623-626.

Isobe, A., Iwasaki, S., Uchida, K. \& Tokai, T. (2019). Abundance of non-conservative microplastics in the upper ocean from 1957 to 2066. Nature Communications, 10, 417.

Ivar do Sul, J.A. \& Costa, M.F. (2014). The present and future of microplastic pollution in the marine environment. Environmental Pollution, 185, 352-364.

Jacobson, M.A. (1947). An impeded herring gull. The Auk, 64, 619.

Jambeck, J.R., Geyer, R., Wilcox, C., Siegler, T.R., Perryman, M., Andrady, A., Narayan, R. \& Law, K.L. (2015). Plastic waste inputs from land into the ocean. Science, 347, 768-771.

Kanhai, L.D.K., Officer, R., Lyashevska, O., Thompson, R.C. \& O’Connor, I. (2017). Microplastic abundance, distribution and composition along a latitudinal gradient in the Atlantic Ocean. Marine Pollution Bulletin, 115, 307-314.

Karami, A., Golieskardi, A., Choo, C.K., Romano, N., Ho, Y.B. \& Salamatinia, B. (2017). A high-performance protocol for extraction of microplastics in fish. Science of the Total Environment, 578, 485-494.

Kartar, S., Milne, R.A. \& Sainsbury, M. (1973). Polystyrene waste in the Severn Estuary. Marine Pollution Bulletin, 4, 144.

Kelly, A., Lannuzel, D., Rodemann, T., Meiners, K.M. \& Auman, H.J. (2020). Microplastic contamination in east Antarctic sea ice. Marine Pollution Bulletin, 154, 111130.

Kelly, B.C., Ikonomou, M.G., Blair, J.D., Morin, A.E., Gobas, F.A.P.C. \& Kelly, B.C. (Correspondence author). (2007). Food web-specific biomagnification of persistent organic pollutants. Science, 317, 236-239.

Kim, Y.S. \& Orsi, A.H. (2014). On the variability of Antarctic Circumpolar Current fronts inferred from 1992-2011 altimetry*. Journal of Physical Oceanography, 44, 3054-3071.

Kinjo, A., Mizukawa, K., Takada, H. \& Inoue, K. (2019). Size-dependent elimination of ingested microplastics in the Mediterranean mussel Mytilus galloprovincialis. Marine Pollution Bulletin, 149, 110512.

Koelmans, A.A., Gouin, T., Thompson, R., Wallace, N. \& Arthur, C. (2014). Plastics in the marine environment. Environmental Toxicology and Chemistry, 33, 5-10.

Kolandhasamy, P., Su, L., Li, J., Qu, X., Jabeen, K. \& Shi, H. (2018). Adherence of microplastics to soft tissue of mussels: A novel way to uptake microplastics beyond ingestion. Science of the Total Environment, 610-611, 635-640.

Kröger, K., Gardner, J.P.A., Rowden, A.A. \& Wear, R.G. (2006). Long-term effects of a toxic algal bloom on subtidal soft-sediment macroinvertebrate communities in Wellington Harbour, New Zealand. Estuarine, Coastal and Shelf Science, 67, 589-604.

Kukulka, T. Proskurowski, G., Moret-Ferguson, S., Meyer, D.W. \& Law, K.L. (2012). The effect of wind mixing on the vertical distribution of buoyant plastic debris. Geophysical Research Letters, 39, 1-6. 
Lacerda, A.L.d.F., Rodrigues, L.d.S., Van Sebille, E., Rodrigues, F.L., Ribeiro, L., Secchi, E.R., Kessler, F. \& Proietti, M.C. (2019). Plastics in sea surface waters around the Antarctic Peninsula. Scientific Reports (Nature Publisher Group), 92, 3977.

Law, K.L. (2017). Plastics in the marine environment. Annual Review of Marine Science, 9, 205-229.

Laws, R.M. (1977). Seals and whales of the Southern Ocean. Philosophical Transactions of the Royal Society of London. Series B, Biological Sciences (1934-1990), 279, 81-96.

Lebreton, L.C.-M. \& Borrero, J.C. (2013). Modeling the transport and accumulations floating debris generated by the 11 March 2011 Tohoku Tsunami. Marine Pollution Bulletin, 66, 5358 .

Lee, K.W., Shim, W.J., Kwon, O.Y. \& Kang, J.H. (2013). Size-dependent effects of micro polystyrene particles in the marine copepod Tigriopus japonicus. Environmental Science \& Technology, 47, 11278-11283.

Li, J.N., Lusher, A.L., Rotchell, J.M., Deudero, S., Turra, A., Brate, I.L.N., Sun, C.J., Hossain, M.S., Li, Q.P., Kolandhasamy, P. \& Shi, H.H. (2019). Using mussel as a global bioindicator of coastal microplastic pollution. Environmental Pollution, 244, 522-533.

Li, J., Qu, X., Su, L., Zhang, W., Yang, D., Kolanhasamy, P., Li, D. \& Shi, H. (2016). Microplastics in mussels along the coastal waters of China. Environmental Pollution, 214, 177-184., 146-155.

Lima, A.R., Costa, M.F. \& Barletta, M. (2014). Distribution patterns of microplastics within the plankton of a tropical estuary. Environmental Research, 132

Löder, M.G.J. \& Gerdts, G. (2015). Methodology used for the detection and identification of microplastics - a critical appraisal. Marine Anthropogenic Litter, 201-227.

Lourenço, P.M., Serra-Gonçalves, C., Ferreira, J.L., Catry, T., Granadeiro, J.P. (2017). Plastic and other microfibers in sediments, macroinvertebrates and shorebirds from three intertidal wetlands of southern Europe and west Africa. Environmental Pollution, 231, 123-133.

Lusher, A. (2015). Microplastics in the marine environment: Distribution, interactions and effects. In: M. Bergmann, L. Gutow \& M. Klages (Eds.), Marine Anthropogenic Litter, pp 245-307. Springer, Cham.

Lusher, A.L. \& Wagner, M. (2019). Are we speaking the same language? Recommendations for a definition and categorization framework for plastic debris. Environmental Science \& Technology, 53, 1039-1047.

Maes, T., Van der Meulen, M.D., Devriese, L.I., Leslie, H.A., Huvet, A., Frère, L., Robbens, J. \& Vethaak, A.D. (2017). Microplastics baseline surveys at the water surface and in sediments of the North-East Atlantic. Frontiers in Marine Science, 4.

Marshall, G.J., Stott, P.A., Turner, J., Connolley, W.M., King, J.C. \& Lachlan-Cope, T.A. (2004). Causes of exceptional atmospheric circulation changes in the southern hemisphere.

Geophysical Research Letters, 31, L14205. 
Martinson, D.G. (2012). Antarctic circumpolar current's role in the Antarctic ice system: An overview. Palaeogeography, Palaeoclimatology, Palaeocology, 335-336, 71-74.

Mattlin, R.H. \& Cawthorn, M.W. (1986). Marine debris - an international problem. New Zealand Environment, 51, 3-6.

Miller, M.E., Kroon, F.J. \& Motti, C.A. (2017). Recovering microplastics from marine samples: A review of current practices. Marine Pollution Bulletin, 123, 6-18.

Ministry for the Environment (2017). Monthly El Niño Southern Oscillation Index, 19862016. Retrieved from https://data.mfe.govt.nz/table/89381-monthly-el-nino-southernoscillation-index-19862016/.

Moore, C.J. (2008). Synthetic polymers in the marine environment: A rapidly increasing, long-term threat. Environmental Research, 108, 131-139.

Moore, C.J., Moore, S.L., Leecaster, M.K. \& Weisberg, S.B. (2001). A comparison of plastic and plankton in the North Pacific Central Gyre. Marine Pollution Bulletin, 42, 1297-1300.

Moore, J.K., Abbot, M.R. \& Richman, J.G. (1999). Location and dynamics of the Antarctic Polar Front from satellite sea surface temperature data. Journal of Geophysical Research, 104, 3059-3073.

Mora-Teddy, A.K. \& Matthaei, C.D. (2020). Microplastic pollution in urban streams across New Zealand: Concentrations, composition and implications. New Zealand Journal of Marine and Freshwater Research, 54, 233-250.

Morishige, C., Donohue, M.J., Flint, E., Swenson, C. \& Woolaway, C. (2007). Factors affecting marine debris deposition at French Frigate Shoals, Northwestern Hawaiian Islands Marine National Monument, 1990-2006. Marine Pollution Bulletin, 54, 1162-1169.

Morris A.W. \& Hamilton, E.I. (1974). Polystyrene spherules in the Bristol Channel. Marine Pollution Bulletin, 5, 26-27.

Munari, C., Infantini, V., Scoponi, M., Rastelli, E., Corinalidesi, C. \& Mistri, M. (2017). Microplastics in the sediments of Terra Nova Bay (Ross Sea, Antarctica). Marine Pollution Bulletin, 122, 161-165.

Napper, I.E., Bakir, A., Rowland, S.J. \& Thompson, R.C. (2015). Characterisation, quantity and sorptive properties of microplastics extracted from cosmetics. Marine Pollution Bulletin, 99, 178-185.

Nel, H.A. \& Froneman, P.W. (2015). A quantitative analysis of microplastic pollution along the south-eastern coastline of South Africa. Marine Pollution Bulletin, 101, 274-279.

Nicholson, S.-A., Lévy, M., Llort, J., Swart, S. \& Monteiro, P.M.S. (2016). Investigation into the impact of storms on sustaining summer primary productivity in the Sub-Antarctic Ocean. Geophysical Research Letters, 43, 9192-9199.

Obbard, R.W., Sadri, S., Wong, Y.Q., Khitun, A.A., Baker, I. \& Thompson, R.C. (2014).

Global warming releases microplastic legacy frozen in Arctic sea ice. Earth's Future, 2, 315320. 
Obbard, R. (2018). Microplastics in polar regions: The role of long range transport. Current Opinion in Environmental Science \& Health, 1, 24-29.

Oehlmann, J., Schulte-Oehlmann, U., Kloas, W., Jagnytsch, O., Lutz, I. \& Kusk, K.O. (2009). A critical analysis of the biological impacts of plasticizers on wildlife. Philosophical Transactions of the Royal Society B: Biological Sciences, 364, 2047-2062.

Oigman-Pszczol, S.S. \& Creed, J.C. (2007). Quantification and classification of marine litter on beaches along Armação dos Búzios, Rio de Janeiro, Brazil. Journal of Coastal Research, 23, 421-428.

Orsi, A.H., Whitworth III, T., Nowlin Jr., W.D. (1995). On the meridional extent and fronts of the Antarctic Circumpolar Current. Deep Sea Research Part 1: Oceanographic Research Papers, 42, 641-673.

Ostle, C., Thompson, R.C., Broughton, D., Gregory, L., Wootton, M. \& Johns, D. (2019). The rise in ocean plastics evidenced from a 60-year time series. Nature Communications, $\mathbf{1 0}$, $1-6$.

Plastic Oceans International. (2020). Who We Are. Retrieved from https://plasticoceans.org/who-we-are/.

PlasticsEurope. (2019). Plastics - the facts 2019: An analysis of European plastics production, demand, and waste data. Retrieved from https://www.plasticseurope.org/en/resources/market-data.

Peeken, I., Primpke, S., Beyer,B., Gütermann, Katlein, C., Krumpen, T., Bergmann, M., Hehemann, L. \& Gerdts, G. (2018). Arctic sea ice is an important temporal sink and means of transport for microplastic. Nature Communications, 9, 1-12.

Price, H.J., Boyd, K.R. \& Boyd, C.M. (1988). Omnivorous feeding behaviour of the Antarctic Krill Euphausia superba. Marine Biology, 97, 67-77.

Qu, X., Su, L., Li, H., Liang, M. \& Shi, H. (2018). Assessing the relationship between the abundance and properties of microplastics in water and in mussels. Science of the Total Environment, 621, 679-686.

R-Core-Team. (2016). R: A language and Environment for Statistical Computing. R Foundation for Statistical Computing, Vienna, Austria. Retrieved from https://www.Rproject.org/.

Reed, S., Clark, M., Thompson, R. \& Hughes, K.A. (2018). Microplastics in marine sediments near Rothera Research Station, Antarctica. Marine Pollution Bulletin, 133, 460463.

Reisser, J., Shaw, J., Wilcox, C., Hardesty, B.D., Proietti, M., Thums, M. \& Pattiaratchi, C. (2013). Marine Plastic Pollution in waters around Australia: Characteristics, concentrations, and pathways. PLoS ONE, 8, e80466.

Ribic, C.A., Sheavly, S.B. \& Klavitter, J. (2012). Baseline for beached marine debris on Sand Island, Midway Atoll. Marine Pollution Bulletin, 64, 1726-1729. 
Rintoul, S.R. (2018). The global influence of localised dynamics in the Southern Ocean. Nature, 558, 209-218.

Rintoul, S.R., Hughes, C.W., Olbers, D., Siedler, G. (editor), Church, J. (editor) \& Gould, J. (editor). (2001). The Antarctic Circumpolar Current System. International Geophysics Series, Ocean Circulation and climate; observing and modelling the global ocean, 77, 271-302.

Rios, L.M., Moore, C. \& Jones, P.R. (2007). Persistent organic pollutants carried by synthetic polymers in the ocean environment. Marine Pollution Bulletin, 54, 1230-1237.

Rivera-Hernández, J.R., Fernández, B., Santos-Echeandia, J., Garrido, S., Morante, M., Santos, P. \& Albentosa, M. (2019). Biodynamics of mercury in mussel tissues as a function of exposure pathway: Natural vs. microplastic routes. Science of the Total Environment, 674, 412-423.

Robinson, K.V., Pinkerton, M.H., Hall, J.A. \& Hosie, G.W. (2014). Continuous Plankton Recorder sampling between New Zealand and the Ross Sea, 2006-2013. Ministry for Primary Industries, Wellington, New Zealand.

Rochman, C.M., Browne, M.A., Underwood, A.J., Van Freneker, J.A., Thompson, R.C. \& Amaral-Zettler, L.A. (2016). The ecological impacts of marine debris: Unraveling the demonstrated evidence from what is perceived. Ecology, 97, 302-312.

Rodhouse, P.G. \& White, M.G. (1995). Cephalopods occupy the ecological niche of epipelagic fish in the Antarctic Polar Frontal Zone. Biological Bulletin, 189, 77-80.

RStudio. Team. (2020). RStudio: Integrated Development for R. RStudio, Inc, Boston, MA. Retrieved from https://www.rstudio.com/.

Ryan, P.G. (1988). The characteristics and distribution of plastic particles at the sea surface off the Southwestern Cape province, South Africa. Marine Environmental Research, 25, 249273.

Ryan, P.G. \& Moloney, C.L. (1993). Marine litter keeps increasing. Nature, 361, 23.

Scott, N., Porter, A., Santillo, D., Simpson, H., Lloyd-Williams, S. \& Lewis, C. (2019). Particle characteristics of microplastics contaminating the mussel Mytilus edulis and their surrounding environments. Marine Pollution Bulletin, 146, 125-133.

Setälä, O., Magnusson, K., Lehtiniemi, M. \& Norén, F. (2016). Distribution and abundance of surface water microlitter in the Baltic Sea: A compariswon of two sampling methods. Marine Pollution Bulletin, 110, 177-183.

Sfriso, A.A., Tomio, Y., Rosso, B., Gambaro, A., Sfriso, A., Corami, F., Rastelli, E., Corinaldesi, C., Mistri, M. \& Munari, C. (2020). Microplastic accumulation in benthic invertebrates in Terra Nova Bay (Ross Sea, Antarctica). Environmental International, 137, 105587.

Shah, A.A., Hasan, F., Hameed, A. \& Ahmed, S. (2008). Biological degradation of plastics: A comprehensive review. Biotechnology Advances, 26, 246-265.

Shah, R.M. (2013). Mitigating the impact of human activities in Antarctica for better quality of life. Procedia - Social and Behavioural Sciences, 101, 284-291. 
Solokov, S. \& Rintoul, S.R. (2009). Circumpolar structure and distribution of the Antarctic Circumpolar Current fronts: 1. Mean circumpolar paths. Journal of Geophysical Research: Oceans, 114.

Sparks, C. (2020). Microplastics in mussels along the coast of Cape Town, South Africa. Bulletin of Environmental Contamination and Toxicology, 104, 423-431.

Steer, M., Cole, M., Thompson, R.C. \& Lindeque, P.K. (2017). Microplastic ingestion in fish larvae in the western English Channel. Environmental Pollution, 226, 250-259.

Stössel, A., Notz, D., Haumann, F.A., Haak, H., Jungclaus, J. \& Mikolajewicz, U. (2015). Controlling high-latitude Southern Ocean convection in climate models. Ocean Modelling, 86, 58-75.

Suaria, G., Perold, V., Lee, J., Lebouard, F., Aliani, S. \& Ryan, P. (2020). Floating macroand microplastics around the Southern Ocean: Results from the Antarctic Circumnavigation Expedition. Environment International, 136, 105494.

Sussarellu, R., Suquet, M., Thomas, Y., Lambert, C., Fabioux, C., Pernet, M.E.J., Le Goic, N., Quillien, V., Mingant, C., Epelboin, Y., Corpoteau, C., Guyomarch, J., Robbens, J., PaulPont, I., Soudant, P. \& Huvet, A. (2016). Oyster reproduction is affected by exposure to polystyrene microplastics. Proceedings of the National Academy of Sciences of the United States of America, 113, 2430-2435.

Tanaka, K. \& Takada, H. (2016). Microplastic fragments and microbeads in digestive tracts of planktivorous fish from urban coastal waters. Scientific Reports, 6, 34351.

Tekman, M.B., Gutow, L., Macario, A., Haas, A., Walter, A. \& Bergmann, M. (2019). The amount and distribution of litter and microplastic. Alfred-Wegener-Institut HelmholtzZentrum für Polar- und Meersesforschung, AWI-LITTERBASE. Retrieved from https://litterbase.awi.de/litter_detail.

Tetu, S.G., Sarker, I., Schrameyer, V., Pickford, R., Elbourne, L.D.H., Moore, L.R. \& Paulsen, I.T. (2019). Plastic leachates impair growth and oxygen production in Prochlorococcus, the ocean's most abundant photosynthetic bacteria. Communications Biology, 2, 184.

Thompson, R.C., Olsen, Y., Mitchell, R.P., Davis, A., Rowland, S.J., John, A.W.G., McGonigle, D. \& Russel, A.E. (2004). Lost at sea: Where is all the plastic? Science, 304, 838.

Thompson, R.C., Swan, S.H., Moore, C.J. \& vom Saal, F.S. (2009). Our plastic age. Philosophical Transactions of the Royal Society B: Biological Sciences, 364, 1973-1976.

Turner, J. (2004). The El Niño-Southern Oscillation and Antarctica. International Journal of Climatology, 24, 1-31.

Tynan, C.T. (1998). Ecological importance of the Southern Boundary of the Antarctic Circumpolar Current. Nature, 392, 708-710. 
Van Cauwenberghe, L., Claessens, M., Vandegehuchte, M.B. \& Janssen, C.R. (2015). Microplastics are taken up by mussels (Mytilus edulis) and lugworms (Arenicola marina) living in natural habitats. Environmental Pollution, 199, 10-17.

Van Cauwenberghe, L. \& Janssen, C.R. (2014). Microplastics in bivalves cultured for human consumption. Environmental Pollution, 193, 65-70.

Van Cauwenberghe, L., Vanreusel, A., Mees, J. \& Janssen, C.R. (2013). Microplastic pollution in deep-sea sediments. Environmental Pollution, 182, 495-499.

Van der Linden, W.J.M. (1967). A textural analysis of Wellington Harbour sediments. New Zealand Journal of Marine and Freshwater Research, 1, 26-37.

Vandermeersch, G., Van Cauwenberghe, L., Janssen, C.R., Marques, A., Granby, K., Fait, G., Kotterman, M.J.J., Diogène, J., Bekaert, K., Robbens, J. \& Devriese, L. (2015). A critical view on microplastic quantification in aquatic organisms. Environmental Research, 143, 4655.

Van Franeker, J.A. \& Bell, P.J. (1988). Plastic ingestion by petrels breeding in Antarctica. Marine Pollution Bulletin, 19, 672-674.

Van Franeker, J.A., Blaize, C., Danielson, J., Fairclough, K., Gollan, J., Guse, N., Hansen, P.L. Heubeck, M. Jensen, J.-K., Le Guillou, G., Olsen, B., Olsen, K.-O., Pederson, J., Stienen, E.W.M. \& Turner, D.M. (2011). Monitoring plastic ingestion by the northern fulmar Fulmarus glacialis in the North Sea. Environmental Pollution, 159, 2609-2615.

Van Sebille, E., England, M.H. \& Froyland, G. (2012). Origin, dynamics and evolution of ocean garbage patches from observed surface drifters. Environmental Research Letters, 7, 044040 .

Van Sebille, E., Wilcox, C., Lebreton, L., Maximenko, N., Hardesty, B.D., Van Franeker, J.A., Erikson, M., Siegal, D., Galgani, F. \& Law, K.L. (2015). A global inventory of small floating plastic debris. Environmental Research Letters, 10, 124006.

Vikas, M. \& Dwarakish, G.S. (2015). Coastal pollution: A review. Aquatic Procedia, 4, 381388.

Wagner, J., Wang, Z.-M., Ghosal, S., Rochman, C., Gassel, M. \& Wall, S. (2017). Novel method for the extraction and identification of microplastics in ocean trawl and fish gut matrices. Analytical Methods, 9, 1479-1490.

Waller, C.L., Griffiths, H.J., Waluda, C.M., Thorpe, S.E., Loaiza, I., Moreno, B., Pacherres, C.O. \& Hughes, K.A. (2017). Microplastics in the Antarctic marine system: An emerging area of research. Science of the Total Environment, 598, 220-227.

Watts, A.J.R., Urbina, M.A., Corr, S., Lewis, C., Galloway, T.S., Watts, A.J.R. (Correspondence author). (2015). Ingestion of plastic microfibers by the crab Carcinus maenas and its effect on food consumption and energy balance. Environmental Science and Technology, 49, 14597-14604.

Webb, S., Ruffell, H., Marsden, I., Pantos, O. \& Gaw, S. (2019). Microplastics in the New Zealand green lipped mussel Perna Canaliculus. Marine Pollution Bulletin, 149, 110641. 
Welhouse, L.J., Lazzara, M.A., Keller, L.M., Tripoli, G.J. \& Hitchman, M.H. (2016). Composite analysis of the effects of ENSO events on Antarctica. Journal of Climate, 29, 1797-1808.

Woodall, L.C., Sanchez-Vidal, A., Canals, M., Paterson, G.I.J., Coppock, R., Sleight, V., Calafat, A., Rogers, A.D., Narayanaswamy, B.E. \& Thompson, R.C. (2014). The deep sea is a major sink for microplastic debris. Royal Society Open Science, 1, 140317.

Woods, M.N., Stack, M.E., Fields, D.M., Shaw, S.D. \& Matrai, P.A. (2018). Microplastic fiber uptake, ingestion, and egestion rates in the blue mussel (Mytilus edulis). Marine Pollution Bulletin, 137, 638-645.

Worm, B., Lotze, H.K., Jubinville, I., Wilcox, C. \& Jambeck, J. (2017). Plastic as a persistent marine pollutant. Annual Review of Environment and Resources, 42, 1-26.

Wright, S.L., Rowe, D., Thompson, R.C. \& Galloway, T.S. (2013). Microplastic ingestion decreases energy reserves in marine worms. Current Biology, 23, R1031-R1033.

Wright, S.L., Ulke, J., Font, A., Chan, K.L.A. \& Kelly, F.J. (2020). Atmospheric microplastic deposition in an urban environment and an evaluation of transport. Environment

International, 136, 105411.

Xanthos, D. \& Walker, T.R. (2017). International policies to reduce plastic marine pollution from single-use plastics (plastic bags and microbeads): A review. Marine Pollution Bulletin, 118, 17-26.

Ye, S. \& Andrady, A.L. (1991). Fouling of floating plastic debris under Biscayne Bay exposure conditions. Marine Pollution Bulletin, 22, 608-613.

Young, A.M. \& Elliott, J.A. (2016). Characterization of microplastic and mesoplastic debris in sediments from Kamilo Beach and Kahuku Beach, Hawai'i. Marine Pollution Bulletin, 113, 477-482.

Yuan, X. (2004). ENSO-related impacts on Antarctic sea ice: A synthesis of phenomenon and mechanisms. Antarctic Science, 16, 415-425.

Zhao, S., Zhu, L. \& Li, D. (2016). Microscopic anthropogenic litter in terrestrial birds from Shanghai, China: Not only plastics but also natural fibers. Science of the Total Environment, 550, 1110-1115.

Zitko, V. \& Hanlon, M. (1991). Another source of pollution by plastics: skin cleansers with plastic scrubbers. Marine Pollution Bulletin, 22, 41-42. 


\section{Appendix}

Table A2.1: Collective number of tows undertaken, samples collected, and distance towed (nmi) throughout each annual CPR survey from the FV San Aotea II.

\begin{tabular}{|l|r|r|r|}
\hline Year & Tows & \# samples & Distance towed (nmi) \\
\hline $2008 / 09$ & 7 & 461 & 2310 \\
\hline $2009 / 10$ & 6 & 468 & 2336 \\
\hline $2010 / 11$ & 8 & 541 & 2703 \\
\hline $2011 / 12$ & 5 & 404 & 2017 \\
\hline $2012 / 13$ & 8 & 504 & 2513 \\
\hline $2013 / 14$ & 9 & 449 & 2244 \\
\hline $2014 / 15$ & 8 & 454 & 2270 \\
\hline $2015 / 16$ & 7 & 465 & 2325 \\
\hline $2016 / 17$ & 6 & 438 & 2136 \\
\hline $2017 / 18$ & 7 & 487 & 2432 \\
\hline & 71 & 4,671 & 23,286 \\
\hline
\end{tabular}

